Florida International University FIU Digital Commons

3-20-2015

\title{
Regulation of Bone Marrow Stem Cells through Oscillatory Shear Stresses - A Heart Valve Tissue Engineering Perspective
}

Sasmita Rath

Florida International University, srath002@fiu.edu

DOI: $10.25148 /$ etd.FI15050204

Follow this and additional works at: https://digitalcommons.fiu.edu/etd

Part of the Biomedical Engineering and Bioengineering Commons

\section{Recommended Citation}

Rath, Sasmita, "Regulation of Bone Marrow Stem Cells through Oscillatory Shear Stresses - A Heart Valve Tissue Engineering Perspective" (2015). FIU Electronic Theses and Dissertations. 1824.

https://digitalcommons.fiu.edu/etd/1824 


\section{FLORIDA INTERNATIONAL UNIVERSITY \\ Miami, Florida}

\section{REGULATION OF BONE MARROW STEM CELLS THROUGH OSCILLATORY SHEAR STRESSES - A HEART VALVE TISSUE ENGINEERING PERSPECTIVE}

A dissertation submitted in partial fulfillment of the requirements for the degree of DOCTOR OF PHILOSOPHY

in

BIOMEDICAL ENGINEERING

by

Sasmita Rath 
To: Dean Amir Mirmiran

College of Engineering

This dissertation, written by Sasmita Rath, and entitled Regulation of Bone Marrow Stem Cells through Oscillatory Shear Stresses - A Heart Valve Tissue Engineering Perspective, having been approved in respect to style and intellectual content, is referred to you for judgment.

We have read this dissertation and recommend that it be approved.

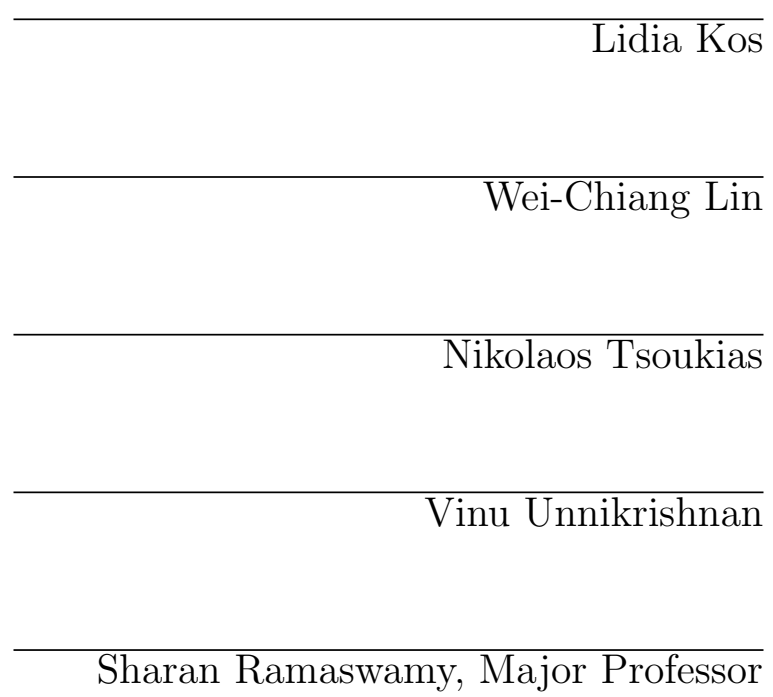

Date of Defense: March 20, 2015

The dissertation of Sasmita Rath is approved.

\begin{tabular}{r} 
Dean Amir Mirmiran \\
College of Engineering \\
\hline Dean Lakshmi N. Reddi \\
University Graduate School
\end{tabular}

Florida International University, 2015 
(C) Copyright 2015 by Sasmita Rath All rights reserved. 


\section{DEDICATION}

To my parents. 


\section{ACKNOWLEDGMENTS}

First and foremost, I would like to convey my deepest gratitude to my advisor and mentor Dr. Sharan Ramaswamy for his guidance, support and encouragement throughout my research and in every step, from the beginning to complete my final dissertation, coaching me in the writing of manuscripts, and presenting seminars. His open-minded approach towards research and willingness to provide exposure to students always inspired me to be an independent researcher. His technical and editorial advice was essential for the completion of this work. He taught me about the importance of quality in my work, and through his support for travel to conferences, provided me with invaluable insights into the workings of academic research and the broader world outside. I would like to express my sincere appreciation to Dr. Nikolaos Tsoukias to grant access to use the equipment in his laboratory. I have operated an Olympus inverted fluorescent microscope and Applied Biosystems step one q-RTPCR device in order to collect immunofluorescence and gene expression data. I would like to express my sincere acknowledgement to Dr. Wei-Chiang Lin for his help and support as my committee member as well as academic advisor during my study. His insightful comments and scientific discussions helped me improve and strengthen this dissertation. I would like to express my sincere gratitude to Dr. Lidia Kos and Dr. Unnikrisnan for their valuable comments on my dissertation chapters. I would like to thank all my teachers during my PhD coursework at FIU.

On a personal note, I extend my appreciation to Dr. James Byrne, who was always there to help with laboratory requirements. His expertise and willingness to help solve equipment-related issues made it possible to overcome some difficult machine related problems. I would like to thank Mr. Richard-Todd Zicarelli, Coordinator for Engineering Manufacturing Center of Mechanical and Materials Engineering at FIU for his prompt help during my research. He provided his expertise in cutting 
and fixing some of machine parts that were critical for equipment set ups. I would like to thank all current and previous group members of TEMIM lab with whom I have overlapped my laboratory work; their understanding and time management to use the shared facilities was one of the key factors to complete my experimental work on schedule; without their support this work would not have been possible. I would like to extend my special thanks to past alumni Ana Villegas, Makensley Lordeus and current undergraduate student Danique Stewart for their generous help at the time of need. I thank my lab students I would like to thank Dr. Erasmo Perera from Biology department, FIU for his help and support providing equipment help for biological sample preparation. Many of the very expensive experiments described in this dissertation, as well as my graduate tuition and living support, could not have been possible without the support of funding sources. I sincerely thank Biomedical engineering department, FIU for their continuous financial support, I would also like to thank University Graduate School, FIU for awarding me Dissertation Year Fellowship that supported my dissertation research during summer and fall semesters 2104. I extend my sincere appreciation to Claudia Estrada, for her help and support during my study, whether my class registration or my conference travel reimbursements. The journey from my home town to the USA, leaving my family and my friends behind, was one of my greatest challenges, and I couldnt have achieved any of this without the constant support of my parents. I would also like to extend my sincere gratitude to my mother-in law and father- in law for their incredible support. Finally, I would like to conclude with an expression of gratitude to my best friend and husband, Shishir who has accompanied and encouraged me through many ups and downs of my lifes journey. . 


\author{
ABSTRACT OF THE DISSERTATION \\ REGULATION OF BONE MARROW STEM CELLS THROUGH \\ OSCILLATORY SHEAR STRESSES - A HEART VALVE TISSUE \\ ENGINEERING PERSPECTIVE \\ by \\ Sasmita Rath \\ Florida International University, 2015 \\ Miami, Florida \\ Professor Sharan Ramaswamy, Major Professor
}

Heart valve disease occurs in adults as well as in pediatric population due to age-related changes, rheumatic fever, infection or congenital condition. Current treatment options are limited to mechanical heart valve (MHV) or bio-prosthetic heart valve $(\mathrm{BHV})$ replacements. Lifelong anti-coagulant medication in case of $\mathrm{MHV}$ and calcification, durability in case of BHV are major setbacks for both treatments. Lack of somatic growth of these implants require multiple surgical interventions in case of pediatric patients. Advent of stem cell research and regenerative therapy propose an alternative and potential tissue engineered heart valves (TEHV) treatment approach to treat this life threatening condition. TEHV has the potential to promote tissue growth by replacing and regenerating a functional native valve. Hemodynamics plays a crucial role in heart valve tissue formation and sustained performance. The focus of this study is to understand the role of physiological shear stress and flexure effects on de novo HV tissue formation as well as resulting gene and protein expression. A bioreactor system was used to generate physiological shear stress and cyclic flexure. Human bone marrow mesenchymal stem cell derived tissue constructs were exposed to native valve-like physiological conditioning. Responses of these tissue constructs to the valve-relevant stress states along 
with gene and protein expression were investigated after 22 days of tissue culture. We conclude that the combination of steady flow and cyclic flexure helps support engineered tissue formation as previously observed, by the co-existence of both OSS and appreciable shear stress magnitudes, and potentially augment valvular gene and protein expression when both parameters are in the physiological range. 


\section{TABLE OF CONTENTS}

CHAPTER

PAGE

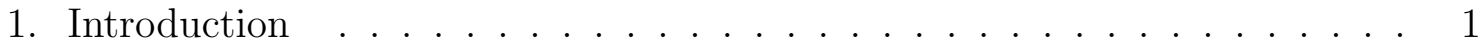

1.1 Problem Statement . . . . . . . . . . . . . . . . . . . . . . . . . . 1

1.2 Hypothesis . . . . . . . . . . . . . . . . . . . . . . . 2

1.3 Specific Aims . . . . . . . . . . . . . . . . . . . . 3

1.3 .1 Specific Aim $1 \ldots \ldots \ldots \ldots \ldots$

1.3 .2 Specific Aim $2 \ldots \ldots \ldots \ldots \ldots$

$1.3 .3 \quad$ Specific Aim $3 \ldots \ldots \ldots \ldots \ldots$

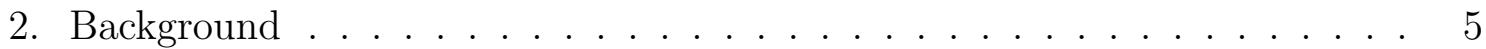

2.1 Introduction . . . . . . . . . . . . . . . . . . 5

2.2 Anatomy of the Human Heart . . . . . . . . . . . . . . . . 5

2.3 Heart valves and valve diseases $\ldots \ldots \ldots . \ldots . \ldots . \ldots$

2.4 Clinically available treatments . . . . . . . . . . . . . . . . . . 11

2.5 Limitations of MHV and BHV . . . . . . . . . . . . . . . . . 14

2.5.1 Tissue Engineered Heart valve . . . . . . . . . . . . . . . . . . 15

2.6 TEHV Definition . . . . . . . . . . . . . . . . . . . . . 20

2.7 Heart valve development, maturation, adaptation, and repair: key information for TEHV . . . . . . . . . . . . . . . . . . . 21

2.8 Heart Valve structural properties . . . . . . . . . . . . . . . . . 23

2.9 Tissue Engineering Heart Valve Methodology: . . . . . . . . . . . . . . 25

2.10 Scaffold . . . . . . . . . . . . . . . . . . . . 26

2.11 Cell sources . . . . . . . . . . . . . . . . . . . . . . . . 30

2.12 In vivo and clinical approach . . . . . . . . . . . . . . . . . 30

2.13 Challenges of in vivoHV engineering approaches . . . . . . . . . . . . . 31

2.14 In vitro approaches(Bioreactors, an engineered device) . . . . . . . . . . 32

2.15 Challenges of in vitro HV engineering approaches . . . . . . . . . . . . 33

2.16 Summary of the review articles . . . . . . . . . . . . . 34

2.17 Challenges of TEHV . . . . . . . . . . . . . . . . . 35

3. Marrow stem cell differentiation for valvulogenesis via oscillatory flow and nicotine agonists: unusual suspects . . . . . . . . . . . . 36

3.1 Introduction . . . . . . . . . . . . . . . . . . 36

3.2 Materials and Methods . . . . . . . . . . . . . . . . . . . . . . 39

$3.2 .1 \quad$ BMMSC Culture . . . . . . . . . . . . . . . . . . . . . . . . . . . . . . . 39

3.2 .2 Immunofluorescence Staining . . . . . . . . . . . . . . . . . . 43

3.3 Results . . . . . . . . . . . . . . . . . . . . . . . . . . 45

$3.3 .1 \quad$ F-actin staining . . . . . . . . . . . . . . . . . . 46

3.4 Discussion . . . . . . . . . . . . . . . . . . . . . . 52 
4. Physiologically-relevant flexure and flow induces valvulogenesis in stem cellseeded scaffolds . . . . . . . . . . . . . . . . . . . . . . . 59

4.1 Introduction . . . . . . . . . . . . . . . . . . . . . . . . 59

4.2 Methods . . . . . . . . . . . . . . . . . . . . . 62

4.2 .1 BMSCs Culture and eExpansion . . . . . . . . . . . . . . 62

4.2 .2 Tissue Engineering Experiments . . . . . . . . . . . . . . . . . . . . 64

4.2 .3 Collagen Assay . . . . . . . . . . . . . . . . . . . . . . 66

4.2.4 Quantitative real time polymerase chain reaction . . . . . . . . . 66

4.3 Immunostaining . . . . . . . . . . . . . . . . . . . . . 67

4.3 .1 Computational Fluid Dynamics (CFD) . . . . . . . . . . . 70

4.3 .2 Statistical Analysis _ . . . . . . . . . . . . . . . . . . 71

4.4 Results . . . . . . . . . . . . . . . . . . . . . 71

4.4 Collagen Production . . . . . . . . . . . . . . . . . . 71

4.4 .2 Gene expression . . . . . . . . . . . . . . . . . . . . . . . . . . 72

4.5 Discussion . . . . . . . . . . . . . . . . . . . . . . . . . 82

5. Conclusion,Limitation and Future study . . . . . . . . . . . . . . . . . 89

5.1 Conclusion . . . . . . . . . . . . . . . . . . . . . . . . . . . . . . . . . . . . . . 89

5.2 Limitations . . . . . . . . . . . . . . . . . . . . . . . . . 92

5.3 Future Study . . . . . . . . . . . . . . . . . . . . . . . . . . . 95

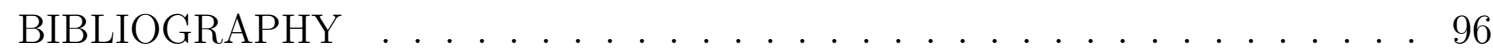

Vita . . . . . . . . . . . . . . . . . . . . . 112 


\section{LIST OF TABLES}

TABLE

PAGE

2.1 A comparison of cardiac cycles with valve opening and closing events . . 8

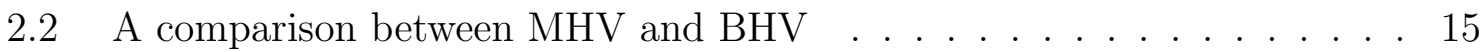

2.3 Required design objectives and characteristics of replacement valves. . . 17

2.4 Proposed Pathway for TEHV . . . . . . . . . . . . . . 26

2.5 PGA:PLLA (synthetic scaffold) used for Heart Valve Tissue regeneration

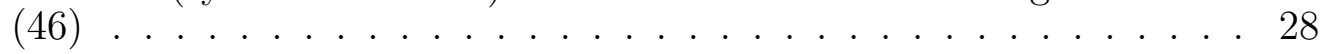

2.6 Synthetic scaffold used for Heart Valve Tissue regeneration (46) by trade name ...................... . . 29

2.7 Cell sources and properties table included in supplemental section(46, 47) 30

2.8 Current generation Bioreactors based on mechanical stimulation for

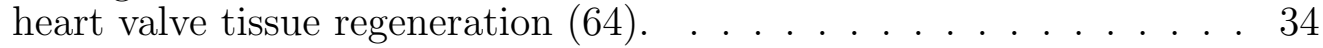

2.9 Summary of Literature Review-table included in supplemental section. . 35

3.1 Number,Orientation and Length of actin filaments in control, OSS and nicotine groups. . . . . . . . . . . . . . . . 50

4.1 Primer sequences utilized for QRT-PCR analyses in this study . . . . . 68 


\section{LIST OF FIGURES}

FIGURE

PAGE

2.1 Anatomy of human heart with four valves and blood flow directions . . 6

2.2 Schematic diagram of heart as a blood pumping organ to and from lungs 7

2.3 Top view cross section of heart with four heart valve . . . . . . . . . 9

2.4 A pictorial representation of diseased and normal heart valves; a) mitral regurgitation, b) aortic stenosis, c) atresia, d) normal porcine heart valve (Photograph taken in TEMIM lab) . . . . . . . . . . . . 1

2.5 Schematics of different types of prosthetic mechanical valves: Caged ball, tilting disc,single leaflet, bi-leaflet mechanical valve; Left column displays valves in open state and right column displays in close

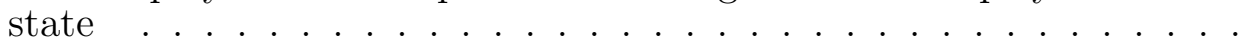

2.6 A schematic representation of bioprosthetic heart valve: left column displays valve in open state and right column displays in close state (11) . Actual images corresponding to the schematics are shown as: (A) a porcine bioprosthetic valve xenograft, (B) bovine pericardial valve, and (C) human aortic valve allograft, also called a homograft.

3.1 a)Ramping protocol involving a six day step-wise increment in steady shear stress to permit BMMSC acclimatization to the channel flow environment; b) Continuous pulsatile wave form adapted from a physiological flow waveform which was used to impart OSS to the BMMSCs for 48 hours. c) Longitudinal optical microscopy of adhered cells to the bottom surface of the microfluidic channel over an eight day timeframe. The BMMSCs appeared to have adhered well after gradual augmentation of steady shear stress followed by OSS conditions were prescribed . . . . . . . . . . . . . .

3.2 Immunofluorescence staining for F-actin (red) of BMMSCs cultured under No Stress (NS) (column1) and OSS (column2) condition for eight days in the microchannels. A distinct stretching pattern of F-actin filaments was observed after exposure to OSS compared to NS coun-

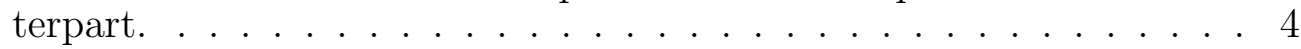

3.3 Immunofluorescence staining for F-actin (red) in BMMSCs cultured without Nicotine (column1) and with Nicotine $10^{-6} \mathrm{M}$, column 2 ) in a 24 well plate for 10 days. No visible stretching pattern in F-actin was observed in either of these groups. However, an increase in the number of actin filaments was clearly visible in the Nicotine treated group in comparison to its corresponding control, i.e., untreated group. 47

3.4 Immunofluorescence images of BMMSCs cultured under NS (column1) and OSS (column2) in the microchannels for eight days. An absence is preferential cell membrane distribution in vinculin was observed in both the OSS and corresponding control groups . . . . . . . . 48 
3.5 Immunofluorescence images of BMMSCs cultured without Nicotine (column1) and with Nicotine $\left(10^{-6} \mathrm{M}\right.$, column 2$)$ for 10 days. An absence is preferential cell membrane distribution in vinculin was observed in both the untreated and Nicotine-treated groups. . . . . . . . . .

3.6 a) Immunofluorescence staining for CD31 expression by BMMSCs under NS (column1) and OSS (column2) conditions after 8 days of culture within the microfluidic channel environment. b) Quantification of positive staining (green; from images in part a)) for CD31 signalintensity in NS and OSS groups; Samples exposed to OSS expressed a significantly higher level of positive CD31 $(\mathrm{p}<0.05)$ in comparison to the control group. . . . . . . . . . . . . . .

3.7 Immunofluorescence staining for CD31 expression by BMMSCs under Nicotine-untreated (column1) and Nicotine-treated (column2, $10^{-6}$ M) conditions after 10 days of culture within 24-well plates. b) Quantification of positive staining (green; from images in part a)) for CD31 signal-intensity in Nicotine-untreated and Nicotine-treated groups; Samples exposed to low dosage of Nicotine $\left(10^{-6} \mathrm{M}\right)$ expressed a significantly higher level of positive CD31 $(\mathrm{p}<0.05)$ in comparison to the untreated, control group. . . . . . . . . . . . . .

4.1 a) Schematic diagram of the custom built U-shaped bioreactor connected to a linear actuator which guides the rods that threads through samples, permitting them to bend and straighten. b) Inset: shows three samples inside the conditioning chamber that can be moved one end (ring) and is fixed on the other (pin). In the current study, the actuator was set to a $1 \mathrm{~Hz}$ frequency to permit cyclic flexure while the pump operated at a steady flow rate of $850 \mathrm{ml} / \mathrm{min}$. . . . . . . . .

4.2 Collagen content in specimens derived from each group investigated. The Flex-Flow group produced significantly $(\mathrm{p}<0.05)$ higher collagen compared to all other groups . . . . . . . . . . . .

4.3 Gene expression of BMSC-derived engineered valvular tissues. The four groups investigated were: Static Controls, Flow $(850 \mathrm{ml} / \mathrm{min})$, Flex $(1 \mathrm{~Hz}$ ) and Flex-Flow (Simultaneous application of $850 \mathrm{ml} / \mathrm{min}$ flow rate and $1 \mathrm{~Hz}$ frequency for cyclic bending of specimens). A flow rate of $850 \mathrm{ml} / \mathrm{min}$ for cell culture media circulating through the bioreactor conditioning chambers permitted physiologically-relevant 4 fluidinduced mean shear stresses of 2.91 dyne $/ \mathrm{cm}^{2}$ and 4.73 dynes $/ \mathrm{cm}^{2}$ on the inner and outer specimen walls respectively. . . . . . . . . . . 73

4.4 Immunofluorescence staining of porcine heart valve shows non-specific binding. Only secondary antibody, no primary antibody, PBS was used as blocking buffer. 
4.5 Immunofluorescence staining of $\alpha$-SMA protein on both surface layers ( $\sim 90 \mathrm{~m}$ thickness on each side), middle core (interstitial tissue) regions ( $\sim 400 \mathrm{~m}$ thickness) of the valve; 1st row: Static Controls; 2nd row: Flex; 3rd row: Flow; 4th row: Flex-Flow conditioning; 5th row: porcine heart valve as Positive control. Among the experimental groups, $\alpha$-SMA-expressing cells were found to be predominant within the interstitial region (middle layer) of the engineered tissues in solely the Flex-Flow group(continue to next page) . . . . . . . .

4.6 Immunofluorescence staining of $\alpha$-SMA protein on both surface layers ( $\sim 90 \mu \mathrm{m}$ thickness on each side), middle core (interstitial tissue) regions ( $\sim 400 \mu \mathrm{mm}$ thickness) of the valve; 1st row: Static Controls; 2nd row: Flex; 3rd row: Flow; 4th row: Flex-Flow conditioning; 5th row: porcine heart valve as Positive control. Among the experimental groups, $\alpha$-SMA-expressing cells were found to be predominant within the interstitial region (middle layer) of the engineered tissues in solely the Flex-Flow group(continued from previous page) . . . . .

$4.7 \alpha$-SMA expression in static control, flex only, flow only, flex-flow and PHV (+ve control) in three different layers, such as: top, mid core and bottom of the tissue sample. . . . . . . . . . . . . . 77

4.8 Immunofluorescence staining of CD31, an EC marker, on both surface layers $(\sim 90 \mathrm{~mm}$ thickness on each side $)$, middle core sections $(\sim 400$ $\mathrm{mm}$ thickness) of the valve tissue; 1st row: Static Controls; 2nd row: Flex; 3rd row: Flow; 4th row: Flex-Flow conditioning; 5th row: porcine heart valve as Positive control. Among the experimental groups, CD31-expressing cells were visible within the superficial layers (top and bottom layers) of the engineered tissues, in solely the flex-flow group.(continue to next page) . . . . . . . . . . . . .

4.9 Immunofluorescence staining of CD31, an EC marker, on both surface layers $(\sim 90 \mathrm{~mm}$ thickness on each side), middle core sections $(\sim 400$ $\mathrm{mm}$ thickness) of the valve tissue; 1st row: Static Controls; 2nd row: Flex; 3rd row: Flow; 4th row: Flex-Flow conditioning; 5th row: porcine heart valve as Positive control. Among the experimental groups, CD31-expressing cells were visible within the superficial layers (top and bottom layers) of the engineered tissues, in solely the flex-flow group.(continued from previous page) . . . . . . . . . . .

4.10 CD31 expression in static control, flex only, flow only, flex-flow and PHV (+ve control) in three different layers, such as: top, mid core and bottom of the tissue sample. . . . . . . . . . . . . . 80

4.11 Fluid-induced, time-averaged shear stresses over one cycle on specimen inner and outer walls for the following four cases: i) Static Controls, ii) Flow, iii) Flexure iv) Flex-Flow states. In comparing the two dynamic cases (iii) versus (iv), the flex-flow state displayed much higher shear stress values. . . . . . . . . . . . . 
4.12 OSI-scaled shear stress magnitude (OSI- $\tau$ ) on the inner and outer specimen surface for the dynamic Flex and Flex-Flow cases. . . . . . . . 81

5.1 A one way analysis of variance (one way ANOVA) test showing significant difference in the collagen production . . . . . . . . . . . 93

5.2 Result of Anova analysis . . . . . . . . . . . . . . . . . . . . . . . 94

5.3 Analysis of variance . . . . . . . . . . . . . . . . . . . 94 


\section{CHAPTER 1}

\section{Introduction}

\subsection{Problem Statement}

Children born with critical congenital heart valve disease require surgical intervention as it is usually a life threatening condition.Statistical reports show that 8 out of 1000 live births in USA alone [1],present with anomalies of the heart, and commonly the valve is one of the organs affected. More than five million Americans are diagnosed with heart valve disease each year [2]. Approximately 90,000 valve substitutes are now implanted in USA and 280,000 worldwide each year; half of which are mechanical heart valves (MHV) and half are bioprosthetic heart valves $(\mathrm{BHV})[1],[3],[4]$.

While mechanical and tissue valves offer a promising option, their inability to permit somatic growth after implantation remains a major drawback. In case of MHV, patients require life-long anticoagulant for survival [5]; some patients, however, do not tolerate the noise these valves may make after implant. Alternatively, BHV do not require anticoagulants; but durability, calcification and immunological rejections are the major setbacks [6]. Regardless of the two valve prosthetics are suitable for pediatric patients because of their inability to grow with the patient. As a result, multiple surgical interventions are required to maintain the patients growing need. Therefore, for pediatric patients, treatment of critical congenital heart valve diseases still remains a major challenge and needs to be addressed uniquely from standard care and treatment of acquired heart valve diseases in adults.

Tissue-engineered heart valves (TEHVs) have the potential to remodel and regenerate with the patient [7], [8]. This fairly new approach is appealing because of its potential to allow somatic growth along with continuous adaptation to surround- 
ing physiological conditions in vivo, thereby enabling a replacement that can last for a lifetime. Pioneering work by Sutherlands group has thus far demonstrated the potential of bone marrow derived stem cells (BMSCs), including extracellular matrix organization and heterogeneous cellularity of TEHVs similar to native valves [9].Recent studies indicate that the promotion of engineered heart valve tissues by BMSCs can be regulated by receiving signaling cues from oscillatory shear stress (OSS) with a simultaneous presence of certain level of physiologically relevant stress associated with it [2007, Sacks et al; 2010, Ramaswamy et al]. Pioneering studies by Englmayr group has demonstrated that combine cyclic flexure and laminar flow synergistically promotes collagen production, a critical ECM protein for heart valve (HV) tissues in vitro [10]. However, these studies did not explain direct mechanical factors responsible for collagen production. Primarily, two types of cells are found in heart valves i) endothelial cells (ECs) and ii) interstitial cells (ICs) which exhibit expression of the -SMA marker. The ECs cover both sides of the valve surfaces; whereas, ICs populate the body of the valve cusp and represent a heterogeneous population of cells consisting of family of fibroblast like cells, myofibroblast like cells and smooth muscle cells (SMCs) [11].A focus of this study is to investigate the potential of human BMSCs to support the heart valve cell phenotype, specifically by demonstrating concomitant differentiation to ECs and -SMA expressing cells, both relevant to heart valves, after exposure to physiologically relevant shear stresses.

\subsection{Hypothesis}

In vitro cyclic flexure and steady flow condition, in combination, regulate human bone marrow mesenchymal stem cells to differentiate into heart valve phenotypes because of heightened oscillatory shear stress application on growing tissue 
samples. In addition, physiological range of cyclic flexure and steady flow parameters may provide additional benefits owing to recapitulation of healthy native valve hemodynamic conditions.

\subsection{Specific Aims}

\subsubsection{Specific Aim 1}

Apply oscillatory shear stress (OSS) on a two dimensional (2D) bone marrow mesenchymal stem cell (BMSCs) mono-layer to observe the changes in cell entities, such as f-actin and vinculin. F-actin is a cytoskeletal protein, vinculin is a focal adhesion protein and both are known to respond to shear stresses. After a duration of 8 days OSS application, cells were evaluated for endothelial cell expression by immunofluorescence technique to detect CD31 which is a marker for EC and expressed on EC surface. The objective of this investigation was to demonstrate that OSS can promote BMSCs differentiation to endothelial cells (EC).

\subsubsection{Specific Aim 2}

Apply heart valve relevant mechanical conditions such as steady flow and cyclic flexure to three dimensional (3D) BMSC-seeded polymer scaffolds to study the effects of mechanical regulation on engineered tissue growth when stresses are applied in the physiological ranges. 


\subsubsection{Specific Aim 3}

Apply heart valve relevant shear stress conditions as in specific aim 2 to $3 \mathrm{D}$ BMSC-seeded scaffolds to investigate gene expression responses and cellular distribution in engineered tissues. 


\section{CHAPTER 2}

\section{Background}

\section{$2.1 \quad$ Introduction}

This chapter provides a comprehensive review of existing engineering technology pertaining to tissue engineered heart valves. A rational approach to heart valve tissue engineering depends on a thorough understanding of the complexity of biologically relevant functional elements and their coordinated interactions. Functionality of the human heart including four valves and the causes of their failures should be understood. Currently available treatment options such as mechanical heart valve, bioprosthesis heart valve as well as advantages and disadvantages of these treatments are mentioned. The need of tissue engineering heart valve, current status, progress and challenges are discussed in depth.

\subsection{Anatomy of the Human Heart}

Human heart, being the size of an adult fist, is an important organ and is responsible for pumping blood throughout the body. It beats approximately 100,000 times a day, pumping an average of 2,000 gallons of blood through a network of 60,000 miles of vessels in our body [12], [13], [14]. It is composed of four major chambers and four valves.

The chambers are called:

i)Right Atrium

ii)Right ventricle

iii)Left atrium

iv)Left ventricle 


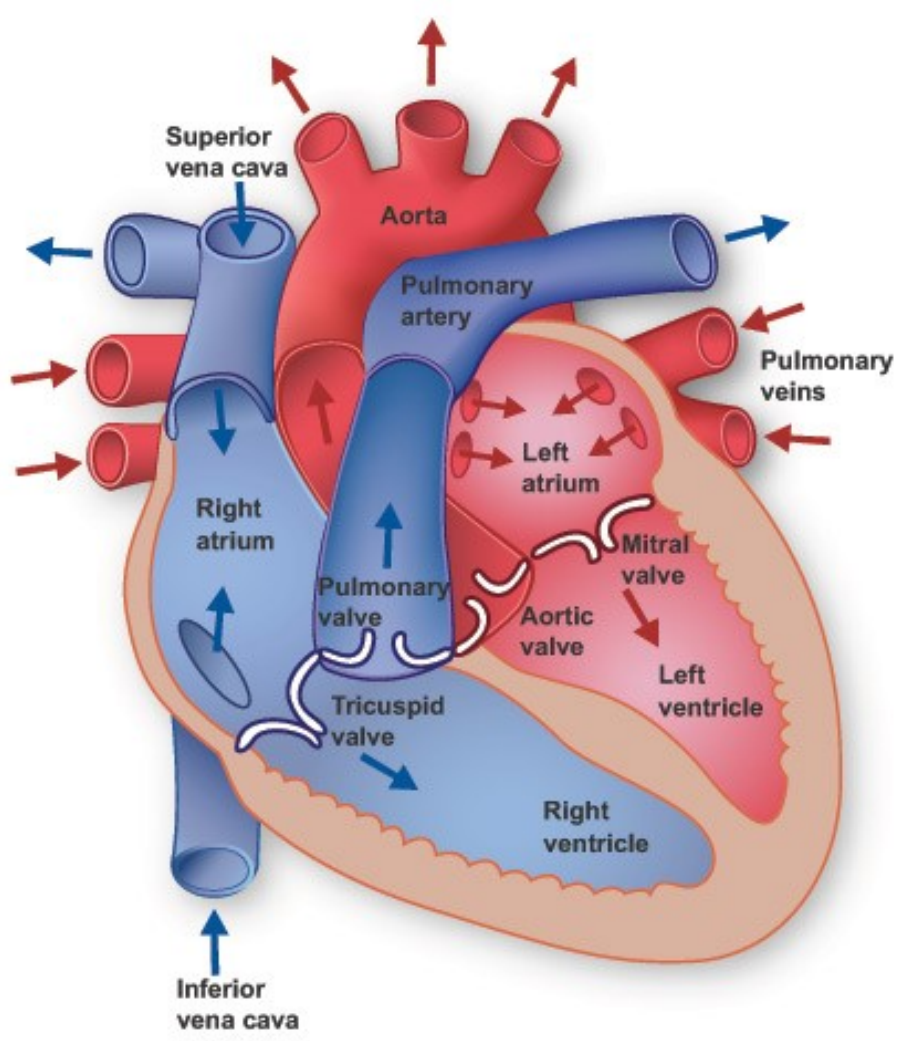

Figure 2.1: Anatomy of human heart with four valves and blood flow directions

Atria are the upper compartments whereas ventricles are lower compartments. These compartments play an important role in regulating blood flow during systole and diastole.

The cardiac muscle, known as myocardium, contracts and relaxes in each cardiac cycle. Atria are the upper chambers and function mainly to collect blood, whereas ventricles are lower chambers responsible for pumping blood. Right atrium collects deoxygenated blood from various parts of our body via superior and inferior vena cava; right ventricle pumps this blood to lungs; left atrium receives oxygenated blood from lungs; left ventricle pumps this blood to various part of our body, initially passing through the aorta. The set of four valves of the heart control 
the unidirectional blood flow. The atrioventricular or AV valves allow only blood to flow from atria to ventricles. The semilunar valves, the pulmonary and aortic valve only allow blood to flow from ventricles to out of the heart through the great arteries [12] (Figure 2.1).

Deoxygenated blood from body

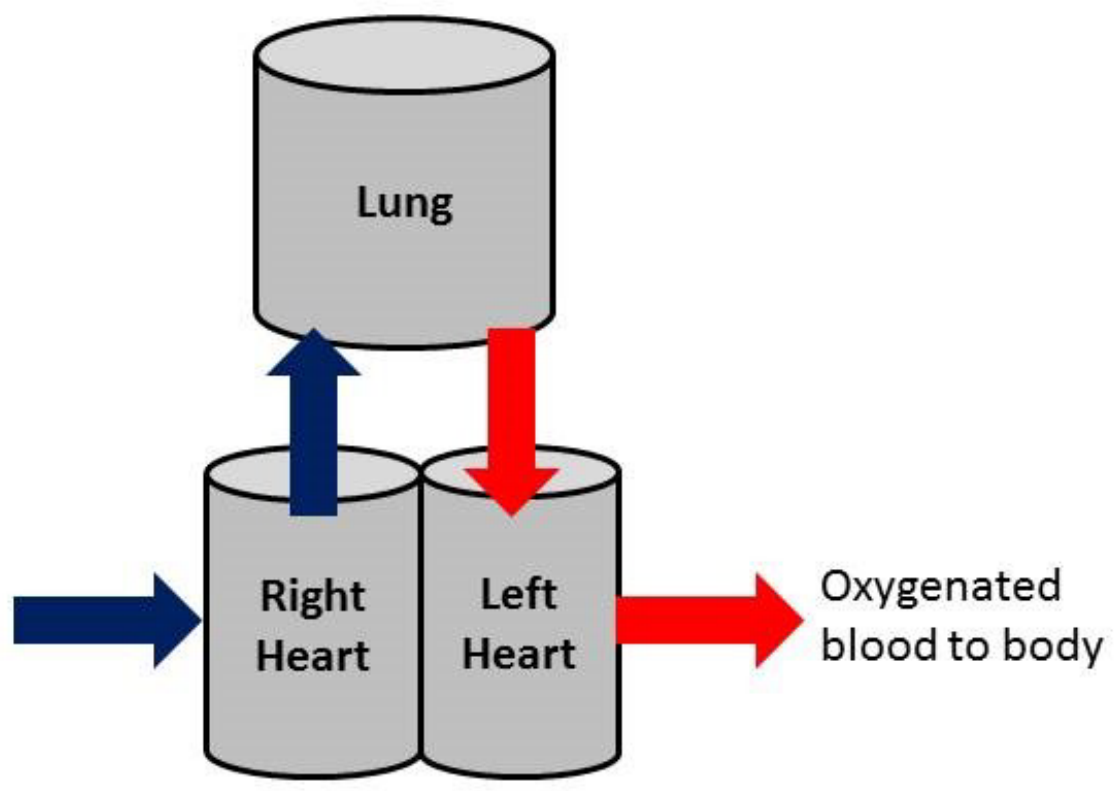

Figure 2.2: Schematic diagram of heart as a blood pumping organ to and from lungs

As shown above (Figure 2.2), a simplified representation of the heart shows the directionality of the blood flow. The input can be described as a flow of deoxygenated blood from the body to right part of the heart, then pumped out to the lungs and collected in the left part of the heart; finally the output is the oxygenated blood pumped out to the body. Four heart valves, located inside the heart, play an important role maintaining unidirectional blood flow during the cardiac cycles. 
Table 2.1: A comparison of cardiac cycles with valve opening and closing events

\begin{tabular}{|l|l|}
\hline \multicolumn{1}{|c|}{$\begin{array}{c}\text { Systole } \\
\text { (Semilunar valves open and close) }\end{array}$} & \begin{tabular}{l}
\multicolumn{1}{c|}{ Diastole } \\
(Atrioventricular valves open and close)
\end{tabular} \\
\hline $\begin{array}{l}\text { a)Contraction in cardiac muscle in the } \\
\text { ventricles is called systole }\end{array}$ & $\begin{array}{l}\text { a) Relaxation in cardiac muscle in the } \\
\text { ventricles is called diastole }\end{array}$ \\
\hline $\begin{array}{l}\text { b)Both the ventricles contract simul- } \\
\text { taneously and force blood from these } \\
\text { chambers into the arteries to flow blood } \\
\text { out of heart }\end{array}$ & $\begin{array}{l}\text { ously and make space to accept blood } \\
\text { from the atria }\end{array}$ \\
\hline $\begin{array}{l}\text { c)Left ventricle empties blood into the } \\
\text { aorta whereas the right ventricle into } \\
\text { the pulmonary artery }\end{array}$ & $\begin{array}{l}\text { c)Left atrium empties oxygenated blood } \\
\text { into left ventricle whereas right atrium } \\
\text { empties deoxygenated blood into right } \\
\text { ventricle }\end{array}$ \\
\hline $\begin{array}{l}\text { d)Increased pressure due to the con- } \\
\text { traction of the ventricles is called sys- } \\
\text { tolic pressure }\end{array}$ & $\begin{array}{l}\text { d) Decreased pressure due to the relax- } \\
\text { ation of the ventricles is called diastolic } \\
\text { pressure }\end{array}$ \\
\hline
\end{tabular}

\subsection{Heart valves and valve diseases}

The schematic diagram in figure 2.3 illustrates a top view of the four valves of the heart and their orientation within a heart. Heart valves open and close approximately 40 million times a year and $3 \times 10^{9}$ times over an average lifetime [15]. These valves have tissue flaps, called leaflets, which open and close with each heartbeat. The leaflets facilitate blood flow in the correct direction through the chambers and to rest of the body.

i) Tricuspid Valve

ii) Pulmonary valve

iii) Mitral Valve

iv) Aortic valve

Aortic, tricuspid and pulmonary valves have three leaflets whereas mitral valve has two leaflets. While the synchronized opening and closing of valves play an important role in controlling blood inflow and outflow in heart chambers; disease can occur in any single or a combination of the four valves. Birth defects, age-related changes, 
infections due to rheumatic fever, or other health conditions can hinder optimal valve function leading to life threatening conditions. Tricuspid valve closes off the upper right atrium that holds blood coming in from the body and opens to allow blood to flow from the top right atrium to right ventricle.

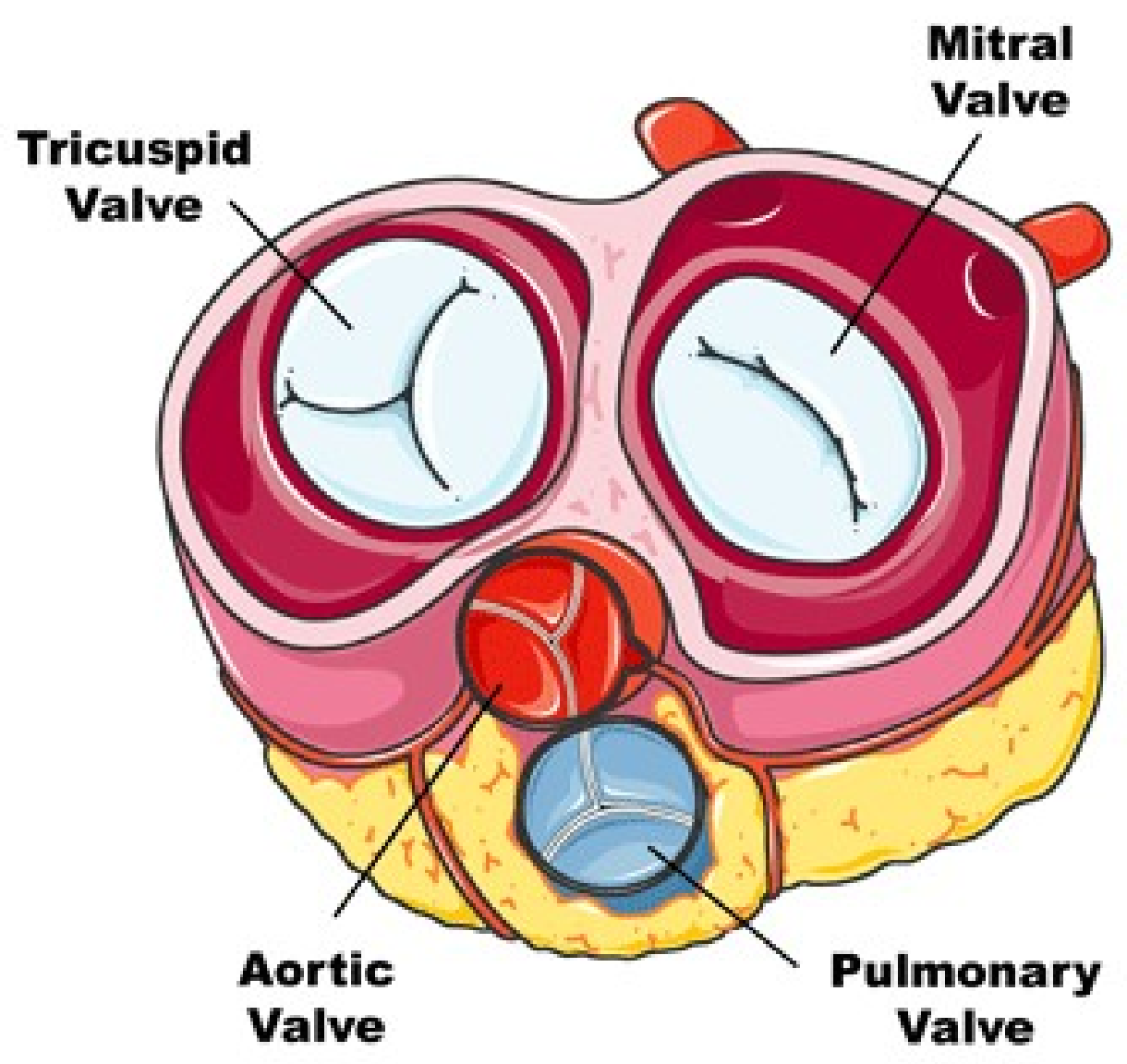

Figure 2.3: Top view cross section of heart with four heart valve

The tricuspid valve also prevents the back flow of blood from the ventricle to the atrium when blood is pumped out of the ventricle to pulmonary artery. The pulmonary valve closes off the lower right ventricle and opens to allow blood to be pumped from the heart to lungs through the pulmonary artery, where it receives 
oxygen. This valve is prone to pulmonary valve stenosis and regurgitation. The mitral valve closes off the upper left atrium collecting the oxygen-rich blood coming from lungs and opens to allow blood to pass from upper left side to lower left atrium eventually venting to the left ventricle. Degeneration of this can lead to mitral valve prolapse, regurgitation or stenosis. Aortic valve closes off the lower left ventricle that holds the oxygen-rich blood before it is pumped out to the body and opens to allow blood to leave the heart from the left ventricle to the aorta and back into the body. Degeneration of this can lead to aortic regurgitation or aortic stenosis. Broadly, there are three basic types of HV Disease:

i) Regurgitation

ii) Stenosis

iii) Atresia

Regurgitation or backflow occurs if a valve doesnt close tightly, leaking blood back into the chambers rather than flowing forward through heart or into an artery. Stenosis occurs if the flaps of a valve fuse together causing narrowing of valve opening. As a result, not enough blood flows through the valve. Some valves can have both regurgitation and stenosis problems. Atresia occurs when a valve is absent and hence lacks an opening for blood to pass through.

Heart valve disease that develops before birth is called congenital heart valve disease and often involves improper formation of pulmonary, mitral or aortic valves. These valves may not have enough tissue flaps, wrong size, shape, or may lack an opening through which blood can flow properly. Acquired heart valve disease usually involves aortic or mitral valves. Although the valves are normal at first problems may develop over time. Both congenital and acquired heart valve disease 
can cause stenosis or backflow. This can make the heart work harder and affect its ability to pump blood in a long run. If left untreated in critical cases, heart failure may result.
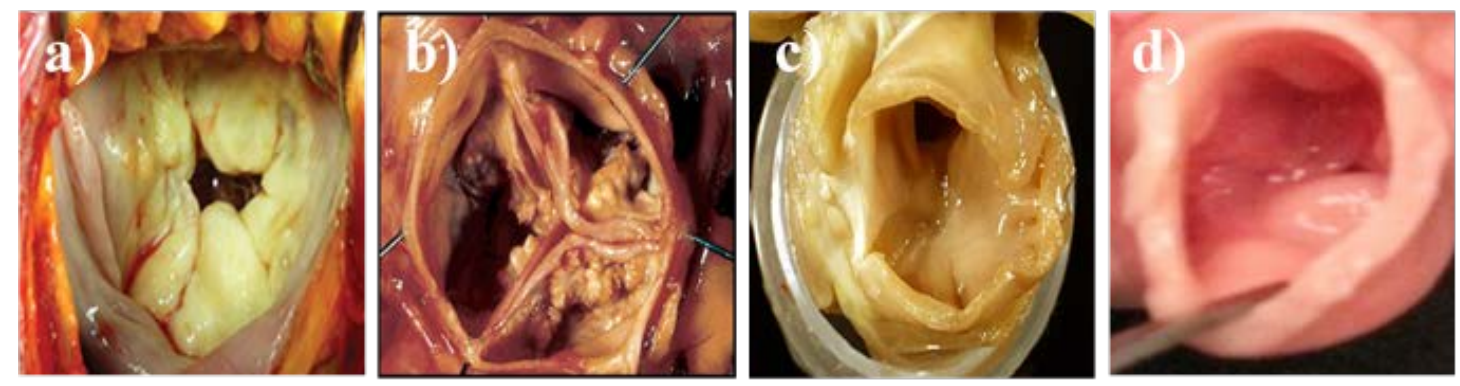

Figure 2.4: A pictorial representation of diseased and normal heart valves; a) mitral regurgitation, b) aortic stenosis, c) atresia , d) normal porcine heart valve (Photograph taken in TEMIM lab)

\subsection{Clinically available treatments}

Primarily there are two types of valve replacement procedures available in clinic.

i) Mechanical Heart Valve (MHV)

ii) Bioprosthetic heart Valve (BHV)

MHV prosthetics are designed to replicate the function of a natural valve. Available MHV include a) caged ball, b) tilting disc, c) single leaflet d) bi-leaflet mechanical valve types, which are shown in Figure 2.5. This conventional valve technology is very mature with well described performance criteria. With improvements in surgical techniques and technologies, mortality during first surgery have been reduced to $1 \%$. However, a need for reoperation involves high risks with mortality as high as 20\%. MHV are more durable, however patients need a lifelong anticoagulant medication to avoid thrombosis [16]. 
BHV are derived either from human or animals. For example, allograft or homograft are derived from human cadavers, whose heart has healthy valves. The homograft is stored frozen and implanted without any other chemical preparation and often without any tissue type matching. In some cases diseased aortic valve is replaced with the persons own pulmonary valve (i.e. autograft) and a pulmonary allograft (valve taken from a cadaver is then replaced with the patients own pulmonary valve; known as Ross Procedure). Xenografts are the implants derived from bovine or porcine percutaneous tissue. Both the porcine and bovine valves are treated with glutaraldehyde before implantation. There are generally three types of bioprosthetic valves available commercially: a) porcine xenograft valves, b) bovine pericardial valves, and c) allograft or homograft valves (Figure 2.6). BHV used in HV replacement generally offer functional properties such as hemodynamics, resistance to thrombosis that are more similar to those of native valves. Currently available BHV include stented porcine bioprosthetic, stented pericardial bioprosthetic, stent less porcine bioprosthetic, percutaneous bio- prosthetic expanded over a balloon and self-expandable percutaneous bioprosthetic [3]. For example, durability of the Edwards pericardial valve, perceived by many to be the most durable bioprosthesis, is close to 20 years [17], [18]. This life span is equivalent to the aortic valve homograft which, because of its excellent longevity, is considered by many to be highly useful for conventional valve replacement in adults [16], [19]. 


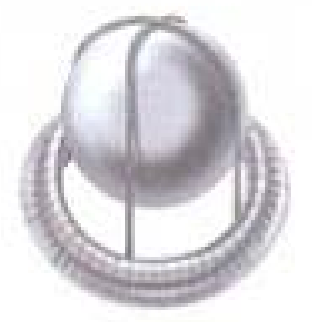

Caged

ball

valve

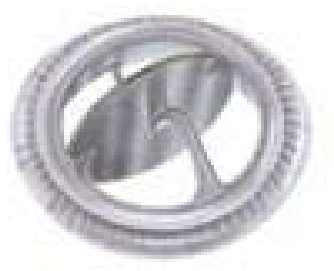

\section{Tilting \\ disc \\ valve}
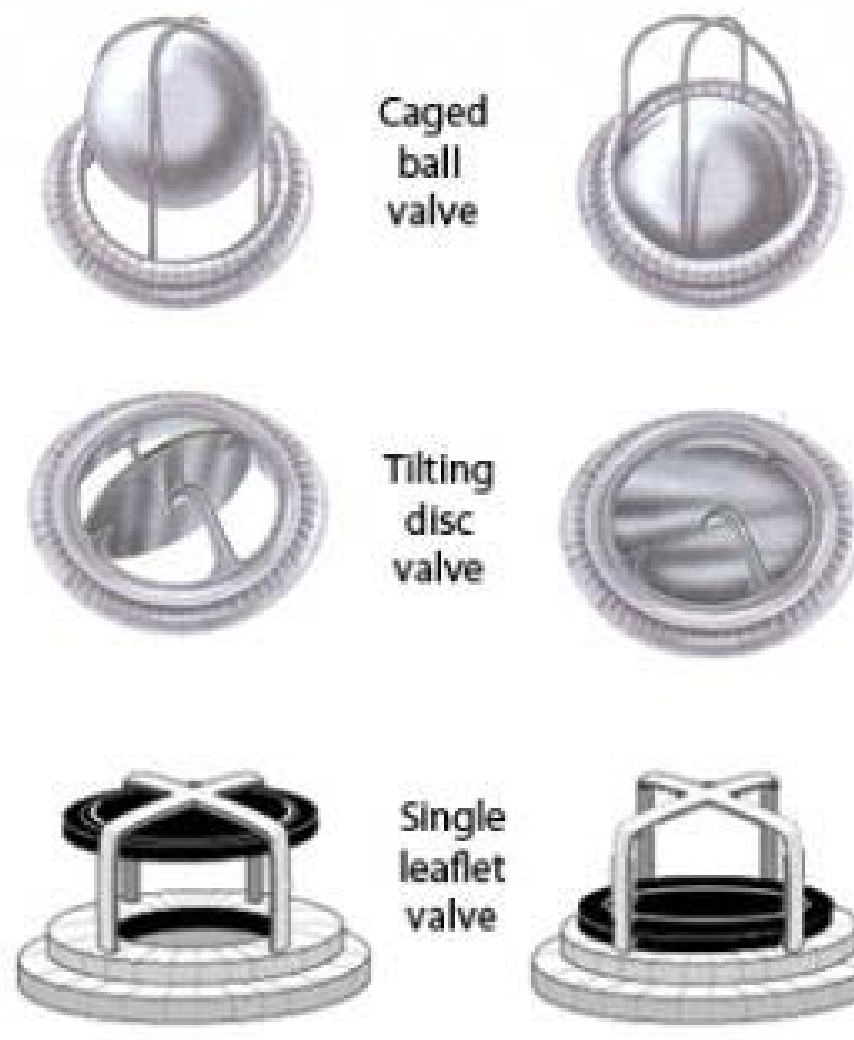

Single
leaflet
valve
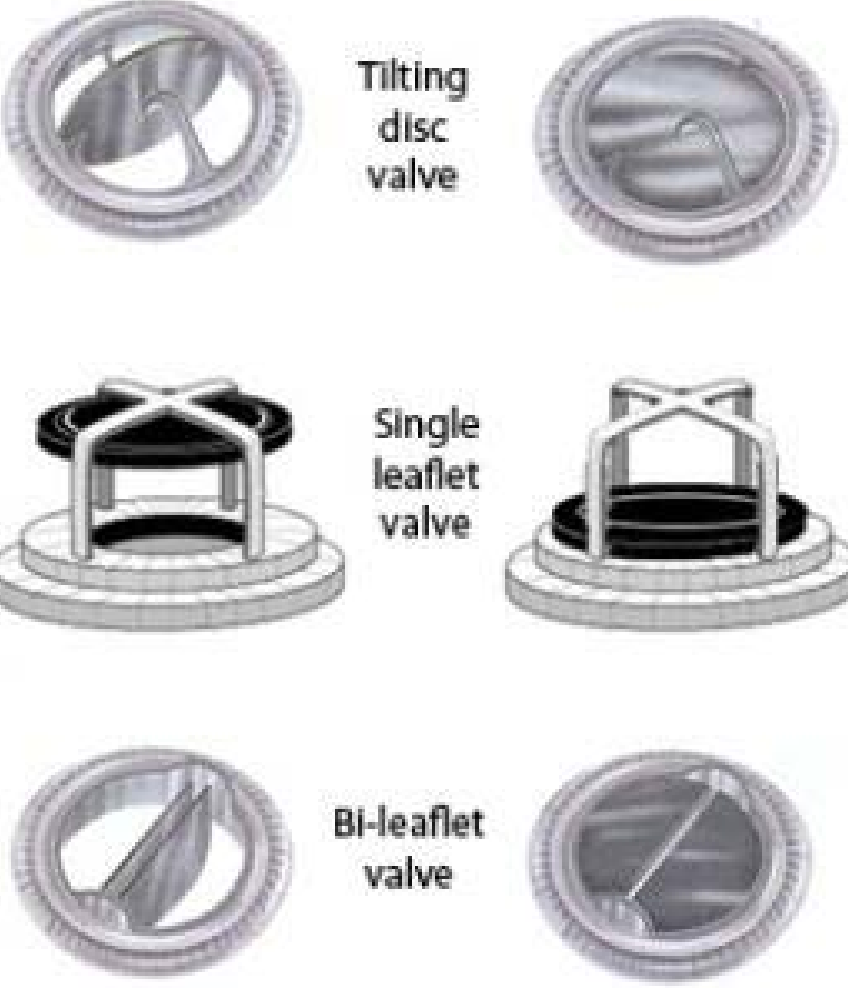

\section{Bi-leaflet valve}

Figure 2.5: Schematics of different types of prosthetic mechanical valves: Caged ball, tilting disc,single leaflet, bi-leaflet mechanical valve; Left column displays valves in open state and right column displays in close state 


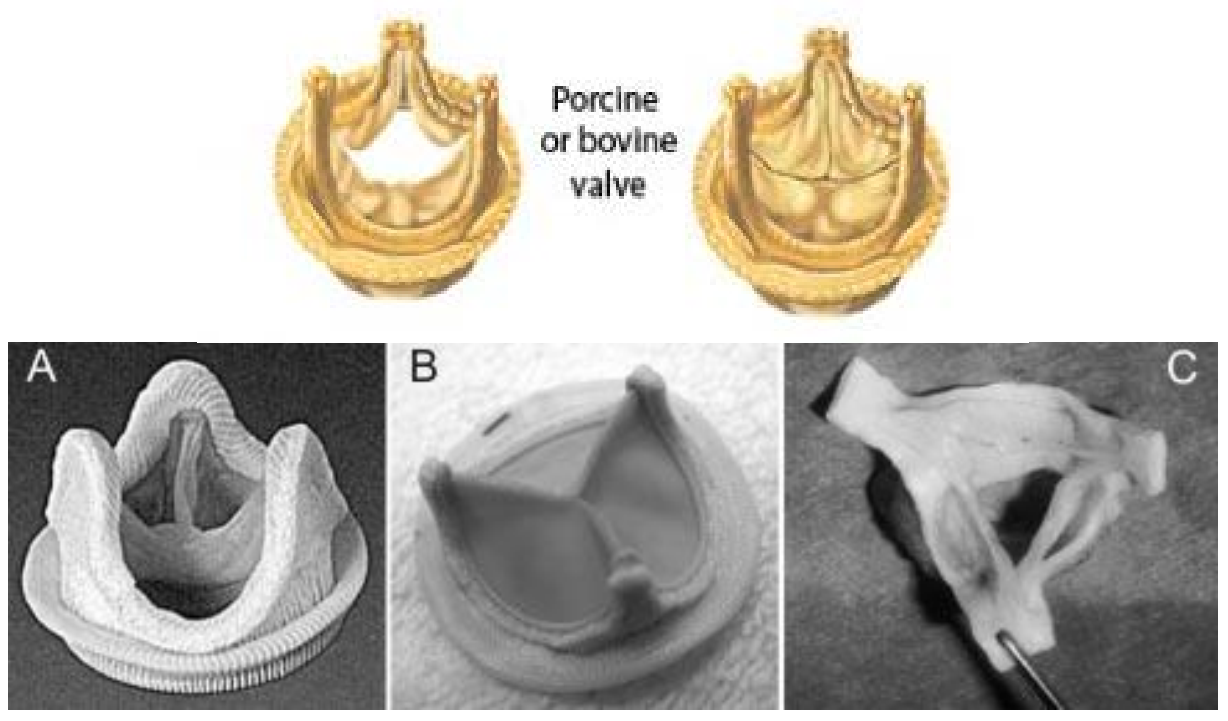

Figure 2.6: A schematic representation of bioprosthetic heart valve: left column displays valve in open state and right column displays in close state (11) . Actual images corresponding to the schematics are shown as: (A) a porcine bioprosthetic valve xenograft, (B) bovine pericardial valve, and (C) human aortic valve allograft, also called a homograft.

\subsection{Limitations of MHV and BHV}

Patients with mechanical heart valve prostheses may experience valve thrombosis and subsequent systemic embolism, for which they are treated with oral anticoagulant therapy [5].Embolism occurs due to lodging of a blood clot in bloodstream, creating a blockage that may affect a part of the body at a distant location such as brain. Endocarditis, the inflammation of the inner layer of the heart involving the heart valves is another cause of failure of MHV. In addition, anticoagulant-related hemorrhage may occur, requiring periodic dose of anticoagulants to prevent thromboembolism [20]. Complications of prosthetic valves include primary valve failure that may occur abruptly from tearing or breakage of components or from a thrombus suddenly impinging on leaflet mobility. In summary, MHV can trigger life threat- 
Table 2.2: A comparison between MHV and BHV

\begin{tabular}{|c|c|}
\hline MHV & BHV \\
\hline $\begin{array}{l}\text { - Thrombogenic, Patients need lifelong } \\
\text { anticoagulant medication after implan- } \\
\text { tation } \\
\text { - Systemic embolism } \\
\text { - Durable (20- } 30 \text { years) } \\
\text { - Valve hemodynamics compromised } \\
\text { - Calcification Resistance } \\
\text { - No immunological problem } \\
\text { - Commercially available } \\
\text { - Size does not cause much of a problem } \\
\text { - No stenosis hematogenous } \\
\text { - Contamination or hread occurs more }\end{array}$ & $\begin{array}{l}\text { - Less thromboembolism than MHV } \\
\text { - Diminished durable ( } 5 \text { years) } \\
\text { - Supports native valve Hemodynamics } \\
\text { - Prone to calcification } \\
\text {-Immunological Rejection } \\
\text { - Lack of availability of Homo- } \\
\text { graft/Allograft } \\
\text { - Need for multiple surgical procedures } \\
\text { for pediatric patients } \\
\text {-Stenosis is more common } \\
\text { - Ring abscess, purulent pericarditis, } \\
\text { and myocardial abscesses are much less } \\
\text { frequent in BHV endocarditis }\end{array}$ \\
\hline
\end{tabular}

ing complications such as prosthetic valve endocarditis, prosthetic valve thrombosis, thromboembolism, and mechanical hemolytic anemia. BHV failure usually starts with calcifications and structural deterioration [21]. Degradation without calcification has also been observed in non-chemical treated cryopreserved allografts [22]. MHV replacement has been available for more than six decades and BHV replacement has been available for more than four decades. However, these valves are unable to grow, repair, or remodel and can be susceptible to infection. These characteristics have significantly limited their adaptability, durability and longevity for treatment of critical congenital valve diseases in pediatric patients [23].

\subsubsection{Tissue Engineered Heart valve}

TEHV, in theory, would be a viable option for children with congenital heart condition. Every year 87,000 children born in the United States and more than 
275,000 children worldwide need heart valve replacement surgery [24]. Among these children with critical valvular disease, MHV does not provide the best option due to its requirement of anticoagulant. Other available option in form of BHV are prone to rapid calcification [22]. Also, the approach such as oversized valves that demands multiple surgeries in pediatric patient fails to deliver a prolonged solution as these valves and its conduits are vulnerable to stenosis. Lack of adaptability to pediatric patients hemodynamic environment is an intrinsic limitation of existing mechanical and biological prostheses, necessitating the requirement of multiple invasive procedures. Mechanical valves are the prosthesis of choice for children heart valve diseases. These valves prevents somatic growth and the regimen of appropriate anticoagulation medication is controversial for pediatric population. Studies reported that morbidity and mortality is significant in mechanical valve replacement in pediatric patients [25].On the other hand TEHV has tremendous potential in satisfying the criteria of a substitute heart valve, including its ability to address the issue of somatic growth [26]. In order to be a substitute to existing prosthetic options, tissue engineered heart valve (TEHV) must satisfy some stringent criteria such as its adaptability to patients hemodynamic environment to function adequately through a normal human life time. This requires the valve to be made of non-thrombogenic living tissue. It must possess remodel in a healthy manner and provide the intrinsic function of facilitating uni-directional blood flow. It should be designed to support rapid and complete closure without creating any obstruction to blood flow. Finally, it should facilitate somatic growth of the patient [15]. 
Table 2.3: Required design objectives and characteristics of replacement valves.

\begin{tabular}{|c|c|c|}
\hline Feature to optimize & Conventional methods & Tissue engineered \\
\hline Closure of leaflets & $\begin{array}{l}\text { Resistance to throm- } \\
\text { bosis }\end{array}$ & Rapid and complete \\
\hline Fluidic function & Good & $\begin{array}{l}\text { Potentially identical to native } \\
\text { valve in terms of effective ori- } \\
\text { fice area and pulmonary and } \\
\text { systemic pressure and flow lev- } \\
\text { els }\end{array}$ \\
\hline Size of orifice area & $\begin{array}{l}\text { Less than that of nat- } \\
\text { ural valves }\end{array}$ & Better \\
\hline Mechanical properties & Stable & Stable \\
\hline Surgical insertion & Easy and permanent & Easy and permanent \\
\hline $\begin{array}{l}\text { Surgical considera- } \\
\text { tions }\end{array}$ & $\begin{array}{l}\text { Sterility, design, and } \\
\text { implantation proce- } \\
\text { dures well established }\end{array}$ & $\begin{array}{l}\text { Sterility,Practical consider- } \\
\text { ations in cell sourcing, Im- } \\
\text { plantation Suturing/physical } \\
\text { handling }\end{array}$ \\
\hline Risk of thrombosis & $\begin{array}{l}\text { Yes, especially me- } \\
\text { chanical valves, which } \\
\text { require anticoag- } \\
\text { ulation, causing } \\
\text { vulnerability to hem- } \\
\text { orrhage }\end{array}$ & $\begin{array}{l}\text { No; endothelial surface to in- } \\
\text { hibit thrombogenesis }\end{array}$ \\
\hline
\end{tabular}


Table 2.3-continued from previous page

\begin{tabular}{|c|c|c|}
\hline Feature to optimize & Conventional methods & Tissue engineered \\
\hline $\begin{array}{l}\text { Risk of structural dys- } \\
\text { function }\end{array}$ & $\begin{array}{l}\text { Degradation of syn- } \\
\text { thetic materials rare } \\
\text { with mechanical } \\
\text { valves, resistant to } \\
\text { degradation and } \\
\text { calcification Tissue } \\
\text { degradation and cal- } \\
\text { cification of leaflets } \\
\text { with bioprosthetic } \\
\text { valves }\end{array}$ & $\begin{array}{l}\text { Resistant to degradation and } \\
\text { calcification }\end{array}$ \\
\hline Risk of Infection & Ever present & Resistant to infection \\
\hline Viability & None & $\begin{array}{l}\text { Yes, able to repair injury, re- } \\
\text { model, and potentially grow } \\
\text { with patient }\end{array}$ \\
\hline Cellular function & None & $\begin{array}{l}\text { Physiological VIC and VEC } \\
\text { function }\end{array}$ \\
\hline
\end{tabular}

Continued on next page 
Table 2.3-continued from previous page

\begin{tabular}{|c|c|c|}
\hline Feature to optimize & Conventional methods & Tissue engineered \\
\hline Tissue function & $\begin{array}{l}\text { Durable and stable, } \\
\text { chemically inert, non- } \\
\text { hemolytic }\end{array}$ & $\begin{array}{l}\text { Durable and stable Functional } \\
\text { anatomic characteristics: col- } \\
\text { lagen, elastin, GAG distri- } \\
\text { bution and structure Func- } \\
\text { tional mechanical characteris- } \\
\text { tics: anisotropy, high tensile } \\
\text { strength, low effective flexural } \\
\text { rigidity, Remodel according to } \\
\text { need Somatic growth }\end{array}$ \\
\hline $\begin{array}{l}\text { In vivo monitoring re- } \\
\text { quirements }\end{array}$ & $\begin{array}{l}\text { Standard hemody- } \\
\text { namic functionDegen- } \\
\text { eration/regurgitation }\end{array}$ & $\begin{array}{l}\text { Hemodynamic conditions over } \\
\text { initial and long-term remod- } \\
\text { eling periods Cellular physio- } \\
\text { logical and phenotype, mass } \\
\text { and content levels Changes in } \\
\text { tissue components and mass } \\
\text { changes Structure and me- } \\
\text { chanical properties Differences } \\
\text { between neonate, juvenile, and } \\
\text { adult }\end{array}$ \\
\hline
\end{tabular}

Continued on next page 
Table 2.3-continued from previous page

\begin{tabular}{|l|l|l|}
\hline Feature to optimize & Conventional methods & Tissue engineered \\
\hline Geometry & $\begin{array}{l}\text { Set by design (me- } \\
\text { chanical/pericardial } \\
\text { bioprosthetic) or tis- } \\
\text { sue source (porcine } \\
\text { bioprosthetic) }\end{array}$ & \\
\hline
\end{tabular}

\subsection{TEHV Definition}

Originating in 1960s as tissue culture technique to populate skin cells and as a skin graft method in 1970s, tissue engineering have matured into a field of its own with contribution from scientific as well as clinical results. Being formally recognized in 1987, tissue engineering has experienced significant progress in past two decades [16]. The application of scientific principles to the design, construction, modification, growth and maintenance of living tissue is among one of several definitions of tissue engineering as this area encompasses interdisciplinary research. However, an alternative and more complex definition is also available in a report presented by NIH, the Food and Drug Administration (FDA), and other government agencies in World Technology Panel Report [27], which states that the application of principles and methods of engineering and life sciences to obtain a fundamental understanding of structure-function relationships in novel and pathological mammalian tissues and the development of biological substitutes to restore, maintain or improve tissue function [16]. According to Vesely, tissue engineering relevant to heart valves is defined as the manipulation of biological molecules and cells for the purpose of creating new valvular structures capable of metabolic activity. Mendelson proposed 
a successful tissue engineered valve and its components must not only accommodate those deformations but also have ongoing strength, flexibility, and durability, beginning at the instant of implantation and continuing indefinitely thereafter, possibly despite an evolving tissue architecture. Therefore, an engineered tissue valve should have the fundamental biophysical and biochemical similarities of a native heart valve. The next section describes the details of the native valve properties as a reference.

\subsection{Heart valve development, maturation, adaptation, and repair: key information for TEHV}

Developmental Biology provides a thorough understanding of biology, physiology, and pathophysiology of heart valves, which is critical for tissue regeneration. This knowledge may be informative and provide opportunity to recapitulate critical components for valve engineering. During embryological development, the three germ layers ectoderm, endoderm, and mesoderm give rise to cells that differentiate to form the bodys tissues and complex organs. The heart develops primarily from the embryonic layer called mesoderm [28]. A complex signaling pathways initiate

the conversion of mesodermal cells to cardiac lineages. Cardiac myocytes become organized and form linear heart tubes that eventually becomes loops, and with development of septa heart achieve its multi-chambered configuration. During cardiac development endothelial cells lining the inside surface undergo an epithelial to mesenchymal trans-differentiation and form called cardiac jelly to become precursors of mature valve interstitial cells (VICs) [29]. It is well accepted that epithelial mesenchymal transitions depends on cell-cell and cell-matrix interactions. Many different signaling pathways, growth and transcriptional factors (including vascular 
endothelial growth factor [VEGF], nuclear factor in activated T cells [NFATc1], and Notch) regulate the process of heart valve formation [30]. Studies have reported that maturation and evolution of human semilunar valves in fetuses, neonates, children, and adults are different. Adult valves are fully matured and organized compared to fetal valves. Immature activated cells in fetal valves are capable of dynamic adaptation to structures. Initially HV architecture, collagen content, and organization of ECM are immature compared with that of adult valves [31]. VIC express characteristics of myofibroblast-like phenotype, express $\alpha$-SMA, MMP-13, and SMemb, and continuously remodel the ECM during fetal HV development. The cells transition to a quiescent state in the normal valve after birth, which suggests a progressive adaptation to the profound hemodynamic environment. The cell density progressively decreases (by nearly 90\%) throughout life [30]. For targeted treatment of heart valve disease, it is critical to understand the role of valve endothelial cell and VICs in valvular wound healing, adaptation, and remodeling. This information is important in selecting the type of cells that should be used for engineering a valve. Normal and pathological cardiac valves respond to environmental conditions, such as mechanical loading, by cell activation and matrix remodeling. Studies have shown that VIC return to their normal quiescent fibroblast phenotype after undergoing remodeling and repair in an in vivo implant [32], [33], [34]. These findings suggest that a tissue engineered valve can gain guided differentiation, adaptation, remodeling and regeneration after implant, however the suitable cell type, scaffold type, chemical and mechanical conditioning should be clearly identified [30]. 


\subsection{Heart Valve structural properties}

Heart valve is a unique type of tissue comprised of extracellular matrix, cells with negligible presence of blood vessels and nerves. The valve ECM is made up of structural components such as, collagen, elastin, glycosaminoglycans (GAGs) and valve interstitial cells (VICs), endothelial cells (EC). Each component contributes to the unique properties of valve; for example: collagen provides strength and stiffness to maintain coaptation during diastole, when cusp has maximal area; Elastin extends in diastole, contracts in systole to minimize cusp area; GAGs accommodate shear of cuspal layers, cushions shock during valve cycle; VICs synthesize ECM; EC maintain non-thrombogenic blood-tissue interface and regulate immune and inflammatory reactions [35]. Microscopically, the aortic valve is composed of three distinct layers: (1) the ventricularis closest to the inflow surface, rich in elastin, (2) the fibrosa closest to the outflow surface, primarily composed of densely packed collagen, and (3) the centrally located spongiosa, largely composed of glycosoaminoglycans (GAGs). Together, collagen, elastin, and GAGs comprise the valvular ECM [30]. In vivo, heart valve leaflets experience a dynamic and complex mechanical stress state during every cardiac cycle: sheer stress due to blood flow (open valve), flexure (opening and closing), and tension (closed valve) [36]. It is becoming more scientifically proven and acceptable that valvular endothelial cells (VEC) are responsible for non-thrombogenic blood-tissue interface and regulate immune as well as inflammatory reactions. EC isolated from vascular and valvular sources display differences in gene expression and other properties, which is a major indication of endothelial cell heterogeneity [37]. Heart valve endothelial cells are different from those in the aorta [38], [39]; for example, in response to mechanical stress, porcine aortic valve endothelial cells align perpendicular to flow whereas endothelial cells from the 
aorta align parallel to flow and their gene expression is different from that of aortic endothelial cells exposed to the same mechanical environment. These differences suggest a unique phenotype of VEC not mimicked by vascular cells and could have implications for cardiovascular cell biology and cell-source considerations for tissueengineered heart valves. Moreover, different transcriptional profiles are expressed by the endothelium on the aortic side versus ventricular side of normal adult pig aortic valves [40]. On the other hand, VIC is the most numerous valvular cell type and responsible for ECM synthesis and secretes ECM degrading enzymes, metalloproteinase (MMPs), and their inhibitors (TIMPs). These biochemical combinations mediate matrix re- modeling [31], [41]. Besides all the mentioned properties, additionally, VIC include a dynamic population of resident cells of diverse and dynamic phenotypes such as fibroblast like cells to myofibroblast-like cells; it is believed that their phenotype is regulated by biochemical as well as biomechanical conditions. Tissue samples from adult heart valves in situ reveals that VIC shows a dormant state and ex- hibits a fibroblast-like phenotype, characteristic of intermediate filaments and is detected by the presence of a cell marker called vimentin and a very low levels of $\alpha$-SMA. In fact, less than $5 \%$ of normal adult VIC express $\alpha$-SMA and in quiescent state, which is a characteristic genetic marker of myofibroblast-like function. Myofibroblasts are a version of activated fibroblasts responsible for ECM synthesis, which in turn facilitate tissue remodeling. Interestingly, previous in vitro studies in which isolated cells were cultured from heart valves, demonstrates $56 \%$ to $78 \%$ of cells with $\alpha$-SMA marker [37] [41]. This suggests that removal of cells from the environment of the intact valve or their manipulation stimulates VIC [30].

It is hypothesized and scientifically becoming more significant that biomechanical and biochemical factors play an important and potentially synergistic role in determining the local homeostatic environment of the aortic VIC. As demon- 
strated in in vitro studies, application of mechanical stimulation such as tension and addition of cytokine stimulation such as TGF-1 were found to synergistically alter the contractile and biosynthetic proteins of aortic VICs to a greater extent than each factor alone [36]. The need for mechanical stimulation and/or cytokines and potentially other soluble factors for the maintenance of appropriate cellular biosynthetic activity are proposed as the key ingredients for valve tissue engineering efforts. In the present research, the focus is on biomechanical regulations of bone marrow derived mesenchymal stem cells which support the valvular phenotype.

\subsection{Tissue Engineering Heart Valve Methodology:}

Researchers have suggested tissue-engineered heart valves to be the ultimate solution for treating valvular heart disease. An ideal TEHV would be able to respond to growth and physiological forces in the same way that the native valve does, whereas existing valve implants only replace a diseased or defective native valve. These valves are either derived from metal, polymers or fixed tissues which are unable to adopt the biological processes. However, a tissue engineered valve would be a living organ. Two main approaches have been attempted over the past 10 to 15 years;

\section{Regeneration}

\section{Repopulation}

Regeneration is the process in which a resorbable matrix or scaffold, either acellular or seeded in vitro with cells (e.g. stem cells) is implanted in situ. It is expected that the implant will remodel over a period of time and eventually yield a functional valve composed of native cells and de novo tissues. In this approach it is believed that the patients cells will migrate to the scaffold and secrete extracellular matrix. Whereas, 
Table 2.4: Proposed Pathway for TEHV

\begin{tabular}{|l|l|l|}
\hline $\begin{array}{l}\text { Basic requirements } \\
\text { and Involved Steps }\end{array}$ & $\begin{array}{l}\text { Pathway In vitro } \\
\text { (Conventional } \\
\text { Paradigm) }\end{array}$ & $\begin{array}{l}\text { Pathway In vivo } \\
\text { (Modified Paradigm) }\end{array}$ \\
\hline Required Elements & Exogenous Cell Scaffold & $\begin{array}{l}\text { Circulating Precursor } \\
\text { cells (Endothelial and } \\
\text { Mesenchymal) Scaffold }\end{array}$ \\
\hline $\begin{array}{l}\text { In vitro Phase (Con- } \\
\text { struct) }\end{array}$ & $\begin{array}{l}\text { In vitro maturation in a } \\
\text { bioreactor }\end{array}$ & \begin{tabular}{l} 
Not Required \\
\hline In vivo Phase
\end{tabular} \\
$\begin{array}{l}\text { Engineered tissue and } \\
\text { derivatives of seeded cells } \\
\text { and/or new cells in vivo } \\
\text { remodeling }\end{array}$ & $\begin{array}{l}\text { Engineered tissue and } \\
\text { derivatives of seeded cells } \\
\text { and/or new cells in vivo } \\
\text { remodeling }\end{array}$ \\
\hline
\end{tabular}

in repopulation a whole porcine or bovine acellular aortic valve is implanted in situ.

In this case the implanted tissue mostly remain intact which provides a mechanically sound connective tissue matrix foundation for tissue building over the time. In this case the cells of the patients are also expected to migrate and hence repopulate the acellular matrix. It is hypothesized that this model can create living tissue which has the complex microstructure necessary for proper function and durability of the valve [16].The subtle differences between regenerate and repopulate strategies thus have to do with:

i) In vitro seeding of cells

ii)Use of a synthetic scaffold versus a decellularized bio-scaffold

\subsection{Scaffold}

Both chemical and mechanical factors can regulate cell biosynthesis ECM production [42], [43], [44], [45], [46]. Native tissues experience multi-scale modes of deformation which trigger biochemical stimuli which determine physiologic responses. To activate viable tissue regeneration and reproduction in tissue engineering ap- 
proaches, recapitulation of mechanical properties of complex multi-scale native tissue architectures, the cascade biological phenomena, and some level of detail of mechanical deformation (in case of heart valves) are critical. It is a huge challenge to replicate a substrate that possess all biological, chemical and mechanical properties of native tissues; however an optimum condition substrate or scaffold should be identified for tissue engineering purposes. To mimic native tissue structure and organization, it is first necessary to develop techniques to produce scaffolds in a controlled manner with characteristic lengths on a scale comparable to those observed in nature. For example, mechanical regulation of cell function can be regulated with geometrically modulated elastomeric substrates [47]. Scaffold designing requires desired chemical, physical, and mechanical characteristics in a controlled and reproducible manner. Physical characteristics such as, surface texture play an important role in promoting cell attachment. A highly porous microstructure is required to allow tissue ingrowth, and an interconnected porous network is required to allow adequate nutrient transport and cytokine activity. Above all scaffold should maintain desired mechanical properties. Currently available long continuous fiber structures with a fiber diameter of native ECM collagen fibers in the range of $50 \mathrm{~nm}$ to $1000 \mathrm{~nm}$ approximate the local cellular environment adequately. An organized formation of fiber structures make them appropriate for load handling such as these encountered during cyclic tensile or bending states. Xenograft or homograft are animal or human derived valve tissues respectively. In this type of materials chemical procedures are performed to decellularized the ECM with a minimal damage to the tissue structure. Homografts are limited by availability. With the benefits of native tissue like regeneration and growth after implantation, xenografts possess the risk of zoonoses (i.e. diseases can communicate from animals to human). Synthetic biodegradable polymers polymers such as: polyglycolic acid (PGA), polylactic acid 
Table 2.5: PGA:PLLA (synthetic scaffold) used for Heart Valve Tissue regeneration (46)

\begin{tabular}{|c|c|c|}
\hline Year, Reference & Material/Polymer & Outcome. \\
\hline 1996, Shinoka et al. & $\begin{array}{l}\text { Polyglycolic acid fiber } \\
\text { matrix Biodegradable }\end{array}$ & In vivo Lamb Model \\
\hline 2005, Sutherland et al. & $\begin{array}{ll}\text { Polyglycolic } & \text { acid } \\
\text { and polylactic } & \text { acid } \\
\text { Biodegradable } & \end{array}$ & In vivo, Sheep model \\
\hline 2006, Engelmayr et al. & $\begin{array}{ll}\text { Polyglycolic } & \text { acid } \\
\text { and polylactic } & \text { acid } \\
\text { Biodegradable } & \end{array}$ & In vitro FSF bioreactor \\
\hline 2010, Ramaswamy et al. & $\begin{array}{ll}\text { Polyglycolic } & \text { acid } \\
\text { and polylactic } & \text { acid } \\
\text { Biodegradable } & \end{array}$ & In vitro $\mathrm{CFF}$ bioreactor \\
\hline
\end{tabular}

(PLA), poly-4-hydroxybutyrate (P4HB) and polycaprolactone (PCL) are currently used in laboratory investigations as scaffold substitutes.

This section includes a brief discussion on the mechanical behavior of the synthetic scaffold for tissue regeneration. Many different approaches have been adopted to design scaffolds for heart valve tissue engineering; for example fabrication of synthetic and native tissue derived procedures [48], [49], [50]. These scaffolds can be classified into polymeric scaffolds, native ECM scaffolds and collagen or fibrin gel scaffolds. Although there has been good progress in all these approaches, the synthetic, polymeric scaffolds have to date received the most attention [15]. 
Table 2.6: Synthetic scaffold used for Heart Valve Tissue regeneration (46) by trade name

\begin{tabular}{|c|c|c|}
\hline $\begin{array}{l}\text { Year, Trade Name, In } \\
\text { vivo or In vitro }\end{array}$ & Material/Polymer & Outcome \\
\hline $\begin{array}{l}\text { 1967, Biomer, Elasthan, } \\
\text { Bovine }\end{array}$ & Polyether urethanes & $\begin{array}{l}\text { 1. Better hydrolytic sta- } \\
\text { bility. } 2 . \quad \text { Oxidative } \\
\text { degradation of the soft } \\
\text { segment. } 3 \text {. Environ- } \\
\text { mental stress cracking }\end{array}$ \\
\hline 1980, Thoralon, Rat & $\begin{array}{l}\text { Silicone in backbone of } \\
\text { polyether urethane }\end{array}$ & $\begin{array}{l}\text { 1. Siloxane end groups: } \\
\text { (a) Give protection to the } \\
\text { polyether soft segment } \\
\text { (b) Provide low strength }\end{array}$ \\
\hline $\begin{array}{l}\text { 1990, ChronoFlex, Bion- } \\
\text { ate, In vitro and in rabbit }\end{array}$ & Polycarbonate urethane & $\begin{array}{l}\text { 1. More stable than PEU } \\
\text { 2. Crack resistant } 3 . \\
\text { Susceptible to hydrolysis }\end{array}$ \\
\hline $\begin{array}{l}\text { 1991, PurSil, Carbosil, } \\
\text { Rabbit }\end{array}$ & $\begin{array}{l}\text { Silicone end groups and } \\
\text { midblocks with polyether } \\
\text { or polycarbonate ure- } \\
\text { thane }\end{array}$ & $\begin{array}{l}\text { 1. Increased resistance to } \\
\text { oxidation }\end{array}$ \\
\hline $\begin{array}{l}\text { 1996, ElastEon, In vitro } \\
\text { and in sheep model }\end{array}$ & $\begin{array}{l}\text { Silicone midblocks and } \\
\text { polyether urethanes }\end{array}$ & 1. Good biostability \\
\hline $\begin{array}{l}\text { 1997, ChronoFlex C, In } \\
\text { vitro }\end{array}$ & $\begin{array}{l}\text { Silicone midblocks and } \\
\text { polycarbonate urethanes }\end{array}$ & $\begin{array}{l}\text { 1. High strength } 2 . \\
\text { Hydrolytically and prote- } \\
\text { olytically stable }\end{array}$ \\
\hline 2005, Seifalian, In vitro & $\begin{array}{l}\text { Polyhedral oligomeric } \\
\text { silsesquioxane integrated } \\
\text { poly(carbonate urea) } \\
\text { urethane }\end{array}$ & $\begin{array}{l}\text { 1. High strength, elastic- } \\
\text { ity at high levels of stress } \\
\text { 2. Resistance to degrada- } \\
\text { tion } 3 \text {. Reduced calcifica- } \\
\text { tion } 4 \text {. Reduced platelet } \\
\text { Adhesion }\end{array}$ \\
\hline
\end{tabular}




\subsection{Cell sources}

Different types of cells have been used for experimental purposes in vivo as well as in vitro. Table below is a description of cells with their advantage and disadvantage of their usage. Ample cell availability can sometimes be a limitation. However, advanced biological techniques and cell culture, proliferation protocols are solving these obstacles. Progress has been made over the past few decades to identify a suitable cell source, scaffold material and guided signaling cues.

Table 2.7: Cell sources and properties table included in supplemental section(46, 47)

\subsection{In vivo and clinical approach}

This approach can be perceived as being more attractive because in this procedure there is no need for in vitro tissue culture and this can simplify the replacement procedure to a great extent. This approach relies on natural regenerative potential of the body. A nonthrombogenic, nonimmunogenic functional scaffold capable of host cell repopulation and remodeling is the key to this approach. Native ECM scaffold (decellularized xenografts, homografts) implants have shown exciting tissue regeneration in juvenile sheep and dog models [51], [52]; however it is not clear if it can be translated to human counterparts. Some investigation are promising in adult patients, but immunogenic response and graft failure are reported in children patients [53].Results are dependent on the techniques of decellularization and use of chemicals on the treated matrix. Recent reports have suggested deoxycholic acidtreated porcine xenografts provide endothelial coverage of pulmonary valve intimal

surface after 10 months in humans [54]. Even though early sign of tissue regeneration occurs both in homografts and xenografts, but when compared to conventional 
cryopreserved homografts, no clear benefits in functionality were observed at one year follow up. Use of synthetic scaffold at the implant site has several advantages over native scaffolds. These materials can be modulated for chemical and mechanical properties. Cellularization and tissue regeneration has been found in animal models [55], [56], [57], [58], [59], [60].Different approaches such as scaffold surface conditioning with bio molecules to enhance cell attachment, combining autologous cells with scaffold or use of a peritoneal cavity as a bioreactor have also proposed and currently under study [61].However, these approaches are not yet verified whether they render the correct cell phenotypes in neo valve tissue. In a single human patient clinical study Dohmen et al. reported excellent in vivo repopulation of valve tissue after implant. In this study a Ross procedure was performed in a 63 year adult male patient and a healthy recovery was observed. However this study along with other study agrees that glutaraldehyde preserved heart valves degenerate more rapidly in young patients than older patients. An increased calcium turn over in case of young patients limit these approach for long term viability as an implant [62].

\subsection{Challenges of in vivoHV engineering approaches}

In vivorepopulation and regeneration mentioned earlier represents a quick, inexpensive and on-demand approach; however translation of this approach to a clinical application faces several challenges. It is well accepted that after implantation native decellularized or synthetic scaffolds achieve cellularity due to presence of circulating endothelial progenitor cells present in blood or originating from bone marrow, neovascularization and adjacent tissue. However, according to previous studies most animal models may be inappropriate for studying these phenomenon and may not be clinically relevant [63], [64]. Use of decellularized xenografts in 
human studies presents controversial results. The main challenge is to unlock the guided pathways of repopulation in vivo and to obtain valve relevant cells for appropriate functionalities.

\subsection{In vitro approaches(Bioreactors, an engineered device)}

In vitro tissue engineering combine the biomechanical and biochemical conditions in an In vitro tissue culture phase. Scaffold materials and cell sources are basic building blocks for tissue formation in these environments. Bioreactor is an engineered device often used in tissue engineering laboratories to culture, grow or monitor tissues regeneration. These devices are designed to maintain a sterile environment that is necessary to culture biological samples. A suitable environment is achieved and maintained that ideally should reproduces the physiological environment (including biochemical and mechanical functions) specific to the tissue that is to be regenerated. Bioreactors can also be used during maturation of the regenerating tissue for studying and understanding the biological factors influencing tissue regeneration. There are commercially available bioreactors used in laboratories; however, requirements for new culture environments and mechanical conditioning demands improved designs. Scientists and Engineers are making a conscious efforts to improve and better match the native biological surroundings in order to understand the fundamentals of tissue regeneration. Bioreactors have been designed and used for the mechanical conditioning of tissue engineered cardiovascular constructs; for example: vascular grafts [65], [66], myocardial patches [67], and heart valves [68], [69]. These instruments typically rely on fluid flow in the form of media supplements to generate a physiological or nonphysiological biomechanical environment. Use of these devices have been demonstrated to promote extracellular matrix 
elements resulting in improved tissue mechanical strength [65], [66], [69]. Increased cellular function within these tissue engineered constructs also reported [66]). This research being presented here is interested in studying the effects of dynamic mechanical stimulation on the development of TEHVs. Previous studies have used cyclic flexure stretch, and flow (FSF) bioreactors to exhibit both independent and coupled stimulatory effects [70], [71], [72], [73] on tissue regeneration.Organ level conditioning of tri-leaflet heart valves have been reported for augmentation of collagen content compared to previous studies [74].It has been well accepted that even simple deformation modes can have a profound effect on forming heart valve tissues.

\subsection{Challenges of in vitro $\mathrm{HV}$ engineering approaches}

Bioreactors possess vast implications for the development of functional tissue regeneration; however small sample capacity, anatomical sample geometry, and coupled mechanical stimuli are some of the limitations of current generation bioreactors. For robust and statistically significant results, it is important to regenerate ample number of samples. Therefore, most bioreactor studies are limited by statistical significance. Very few customized bioreactors have been designed and used in laboratory environments for precise study of the individual or combine effects of mechanical stimulation on engineered valve tissues. Ease of handling starting from tissue culture, assembly of equipment in sterile condition for long term studies are some critical challenges for this study. Sample analysis at multiple time points, and accommodation of simple sample geometries amenable to subsequent mechanical

testing are limited and need to be improved [15]. Mol et al. suggests the lack of knowledge for generating elastin network in valve tissues which should be addressed. It is well accepted that elastin is a critical component in $\mathrm{HV}$ and yet no bioreactor 
Table 2.8: Current generation Bioreactors based on mechanical stimulation for heart valve tissue regeneration (64).

\begin{tabular}{|c|c|c|}
\hline Authors, Year & Type of Bioreactor & Parameters studied \\
\hline $\begin{array}{l}\text { Hoerstrup et al., } 2000 \\
(56)\end{array}$ & $\begin{array}{l}\text { Dynamical stress in- } \\
\text { duced by flow }\end{array}$ & $\begin{array}{l}\text { Effects of pulsed flow vs } \\
\text { steady flow }\end{array}$ \\
\hline Dumont et al., 2002 (65) & $\begin{array}{l}\text { Dynamical stress in- } \\
\text { duced by flow and } \\
\text { resistance }\end{array}$ & $\begin{array}{l}\text { Prototype of a compact } \\
\text { pulsatile flow system }\end{array}$ \\
\hline $\begin{array}{l}\text { Engelmayr et al., } 2003 \\
(61)\end{array}$ & $\begin{array}{l}\text { Combine cyclic flexure } \\
\text { and steady flow }\end{array}$ & $\begin{array}{l}\text { Effects of cyclic flexure } \\
\text { and flow on valve tissue } \\
\text { regeneration }\end{array}$ \\
\hline Mol et al., 2003 (66) & Increasing cyclic strain & Effects of cyclic strain \\
\hline $\begin{array}{l}\text { Schenke-Layland et al., } \\
2003(67)\end{array}$ & $\begin{array}{l}\text { Dynamical stress in- } \\
\text { duced by flow }\end{array}$ & $\begin{array}{l}\text { Repopulation potential } \\
\text { of decellularized valves }\end{array}$ \\
\hline $\begin{array}{l}\text { Ramaswamy et al., } 2010 \\
(63)\end{array}$ & Organ level conditioning & $\begin{array}{l}\text { Pulmonary artery pres- } \\
\text { sure conditions }\end{array}$ \\
\hline
\end{tabular}

in vitro system exist that can produce elastin in a laboratory environment [61]. Finally, implantation of TEHV procedures either by invasive open heart surgeries or minimally noninvasive approach is not known yet. If a minimally invasive approach has to be adopted, then valve crimping and deployment should be evaluated.

\subsection{Summary of the review articles}

A PubMed search on heart valve tissue engineering reveals more than 1000 citations since 1995, more than 30 of which are review articles. Tissue engineering of heart valves is considered one of the few technologies in the field of tissue engineering that has tremendous potential for creating tissues analogous to a native human heart valve, with long sustainability. In spite of being in early stages of development, with advanced biotechnology and improved biomaterials in conjunction with optimization of mechanical conditioning, TEHVs have the potential to revolutionize treatment of critical valve diseases [75]. 
Table 2.9: Summary of Literature Review-table included in supplemental section.

\subsection{Challenges of TEHV}

Advancement in medical procedures have enabled modern civilization to triumph over many life-threatening diseases. The complications considered deadly a few decades ago can be cured and life can be saved. However, in case of critical heart valve diseases, survival is still not assured. On one hand, TEHV has tremendous potential, on the other hand the concept is still in infancy. Efforts are in progress, but the complex nature of heart valve structure, maintenance and functionality require more scientific as well as engineering insights. The key bioengineering challenge is to determine how biological, structural, and mechanical factors affect cellularity and ECM formation; mechanical stimulation plays a vital role in individual tissue organization and a synchronized stimulation is responsible for in vivo functionality. These factors are fundamental to any approach toward developing a clinically viable tissue engineered heart valve (TEHV). In current approaches scaffold material, design, functional viability, biocompatibility and material responses to the hemodynamic environment are critical. Understanding of cell and sub-cellular events, signal generation and interpretation are key factors in stem cell based heart valve tissue engineering. Overall, such approaches need to be structured to address these fundamental issues for laying the basis for TEHVs that can be designed and subsequently for long-term clinical functionality [15]. 


\section{CHAPTER 3}

\section{Marrow stem cell differentiation for valvulogenesis via oscillatory flow and nicotine agonists: unusual suspects}

\subsection{Introduction}

Fluid-induced oscillatory shear stress (OSS) and Nicotine are known antagonists in cardiovascular disease. However, from a regenerative medicine standpoint, we hypothesized that these parameters may support the cell differentiation of bone marrow mesenchymal stem cells (BMSCs) for engineering heart valves. Thus in this study, OSS and Nicotine $\left(10^{-6} \mathrm{M}\right)$ were applied individually to BMSCs in monolayer culture. In both cases, a significantly higher expression of CD31 was detected compared to corresponding controls $(\mathrm{p}<0.05)$. We interpret that both OSS and Nicotine independently support mesenchymal to endothelial transformation. However, the underlying mechanism for this transformation in terms of the cell cytoskeletal structure was entirely different between the two stimulants. In the case of OSS, F-actin filaments exhibited a stretching response and formed a preferential alignment with each other. However, in the Nicotine-treated group, there was clearly an increase in the number of actin filaments present which led to the maximum expression of CD31 in comparison to the OSS and control groups. From our findings, we speculate that while Nicotine may stimulate an increase in the differentiation of BMSCs to endothelial cells, OSS may play a greater role in cellular distribution, and the eventual creation of a tissue engineered heart valves (TEHV) endothelium.

Since 1960s, treatment of diseased heart valves (HV) has achieved tremendous success in improving the survival results for adults as well as pediatric patients [76], [77], [78] , [79].Surgery enables replacement of mechanical heart valves (MHV)

and bioprosthetic heart valves (BHV) to treat severe HV anomalies [1], [80], [81]. 
MHVs exhibit robust durability; however life-long anticoagulant intake is required to minimize the risk of thrombus [5].On the other hand, premature structural breakdown as well as calcification is the major limitation for BHVs [3], [82]. Owing to somatic growth pediatric patients suffering from severe heart valve disease in particular often require complex, multistep, valve replacement surgical procedures. A tissue engineering approach may potentially overcome current treatment limitations for the pediatric patient requiring valve replacement and may also serve as a permanent treatment strategy [23], [51].Conceptually, (TEHV) can be constructed by combining a polymeric matrix scaffold seeded with stem cells which can differentiate into heart valve cell types, i.e., depicting a valve interstitial cell phenotype within the tissues and a surface, valvular endothelium. For this reason, research efforts have focused on establishing suitable biomaterials and potential cell sources that can yield optimized TEHV properties for implantation. On one hand, human embryonic stem cells (hESC) possess the potential to differentiate into the three germ layers, including gut epithelium (endoderm); cartilage, bone, smooth muscle, and striated muscle (mesoderm) as well as neural epithelium, embryonic ganglia, and stratified squamous epithelium (ectoderm) [83]. However due to ethical constraints and limitations in supply, hESCs are not a practical cell source. On the other hand, human induced pluripotent stem cells (iPSC) also possess the ability to differentiate into the three germ layers in vitro; however the slow kinetics and low efficiency of reprogramming methods to generate human iPSC as well as a real risk of teratoma formation [84]impose major limitations on their utility [85]

Adult stem cells have generated significant interest in both the clinical and basic scientific community due to their immune modulatory characteristics and their ability to transdifferentiate into different cell types [86]. Very frequently, mesenchymal stem cells (MSCs) can be extracted from several sources such as adi- 
pose tissue, peripheral blood, skeletal muscle, umbilical cord blood, placenta and bone marrow [87] . In heart valve tissue engineering, bone marrow derived mesenchymal stem cells (BMMSCs) have been extensively investigated [88], [89] . A few key studies are summarized here: BMMSC-based tri-leaflet TEHVs were previously developed in a bioreactor in vitro and demonstrated morphological and mechanical properties similar to human native heart valves [90].Meanwhile, Sutherland et al successively demonstrated that tissue engineered heart valves (TEHV) can be created from ovine BMMSCs and function satisfactorily in vivo for four months [9]. The valves exhibited extensive tissue remodeling in that timeframe and eventually resembled native heart valve histological features, with recapitulation of the through-thickness valvular layers. Mechanically, heart valves experience cyclic flexure, tensile and fluid-induced shear stresses during their lifetime [91] . The disruption of hydrodynamic forces was shown to produce dramatic cardiac defects in zebra fish, including failure of valve formation, an absence of heart looping and the formation of a third chamber [92] . Moreover, shear flow has been reported to promote endothelial cell (EC) differentiation of MSCs [93], [94] and cardiac differentiation of embryonic stem cells [95]. In addition, bioreactor-based mechanical pre-conditioning of engineered heart valve constructs have been shown to be critical in promoting robust tissue formation from BMMSCs, which is likely to be important in augmenting the construct properties prior to implantation [74]. However the extent to which BMMSCs can support heterogeneous valvular cell differentiation, in particular, growth of a valve endothelium is still not conclusive. In line with these observations, the focus of this study was to evaluate the effects of one mechanical and one biochemical stimulant on BMMSCs differentiation towards the heart valve lineage. For the mechanical factor, oscillatory shear stress (OSS), which is innately present during native valve dynamics, was applied to BMMSCs growing in 2D mono- 
layer culture. OSS has previously been hypothesized to be an important mechanical metric for heart valves [96] , [97] . For the biochemical factor we hypothesized that a small concentration of Nicotine $\left(10^{-6} \mathrm{M}\right)$ which has previously served to promote vasculognesis may potentially promote a valvular endothelium for BMMSC-derived tissue engineered heart valves [98], [99], [100], [101], [102], [103] . Ironically, both

OSS and Nicotin are known antagonists in cardiovascular disease; yet we postulated that these unusual suspects would have a beneficial effect in promoting mesenchymal to endothelial transformation, which in turn would support the formation of an engineered valve endothelium.

\subsection{Materials and Methods}

\subsubsection{BMMSC Culture}

Human BMMSCs were purchased (Fisher Scientific, Pittsburgh, PA, passage 1) and cultured in T75 cell culture flasks until $\sim 95 \%$ confluence. MSC culture medium with supplemental growth factors (Thermo Scientific HyClone AdvanceSTEM Mesenchymal Stem Cell Expansion Kit) was used to culture expands the BMMSCs for seven days.

\section{BMMSCs in Low Dosage Nicotine Supplement}

BMMSCs were cultured in a 24 well plate with Dulbeccos Modified Eagle Medium (DMEM), 10 percentage Fetal Bovine Serum (FBS) and 1percentage penicillin and streptomycin (Fisher Scientific) for 10 days. Twelve wells were treated with $10^{-6} \mathrm{M}$ Nicotine whereas another twelve wells were cultured without Nicotine. Media was changed every four days for all 24-wells. Immunostaining was performed 
on four of the wells for each group to visualize F-actin, Vinculin, and CD31 under florescent microscope.

\section{BMMSCs under OSS environments}

A microfluidic channel (Bioflux200 system; Fluxion Biosciences, San Francisco, CA) was used to permit OSS conditioning of BMMSC monolayer culture. The manufacturers protocol (www.fluxionbio.com) was followed in order to permit adhesion of BMMSCs inside the channel. A 48 well, low shear (0-20 dyne $/ \mathrm{cm}^{2}$ plate with a channel $350 \mathrm{um}$ wide, $4.8 \mathrm{~mm}$ long was used to culture the cells in no stress (NS) and OSS environments ( $\mathrm{n}=12$ wells/group). Regular basal medium DMEM, 10percentage FBS, 1percentage penicillin/streptomycin (Fisher Scientific) was used to culture BMMSCs for 8 days. Continuous medium flow was regulated from input well to output well by a pneumatic pump controller. Cells were exposed to steady flow for six days which included a ramp up protocol (Fig.3.1a) followed by OSS conditions for an additional 48 hours that was induced by a physiological shear stress waveform (Fig.3.1b) [104]. This ramping process was necessary to improve cell attachment to the bottom wall of the microfluidics channel prior to OSS conditioning. Confirmation of robust BMMSC attachment was observed after eight days of shear stress exposure (Fig.3.1c), i.e., six days of increasing steady shear stress followed by two days of OSS.

\section{Computational Model of OSS in Microfluidic channel}

To quantify the magnitude of oscillatory conditions the cells were exposed to, a computational fluid dynamic (CFD) analysis of the media flow past the microfluidic channel in which the cells were attached to was performed. In brief, the fluid domain of the rectangular channel was drawn and discretized (Ansys commercial 
software, Ansys Inc, Canonsburg, PA). The CFD set-up included the physical properties of the cell culture media with a density $=1.01 \mathrm{~g} / \mathrm{cm}^{3}$ and a dynamic viscosity of $1.27 \mathrm{cp}$ as previously reported [105]. At the inlet a physiologically valid velocity waveform was imposed. The outlet was set to zero relative pressure and all walls were set to non-slip conditions. A convergence criteria of $1 \times 10^{-6}$ was used for both momentum and continuity equations. Simulations were run in a Hewlett Packard work station with an intel(R) Xeon(R) CPU, x5550@ 2.67GHz (2processors) with 16.0 GB installed memory and 64-bit Windows 7 operating system. Independence tests were performed on the mesh, time step and periodicity for steady and pulsatile simulations accordingly. A 5\% error acceptance criterion in comparison with highly resolved simulations (spatially, temporally, and three cycles) for the wall shear stress variable was used in the selection of the finalized mesh, time step and periodicity parameters which were: i) mesh: structured type -10, 916, 96 nodes and 10,080,00 quadrilateral elements, time step: 2 ms and periodicity: 2nd cycle. Finally to quantify the oscillatory environment, the oscillatory shear index (OSI) was calculated based on the previously reported definition by $\mathrm{He}$ and $\mathrm{Ku}$ [106], wherein an OSI = 0 represents complete uni-directional flow whereas an OSI $=0.5$ represents fully oscillatory flow. The OSI calculation on the microfluidic channel surface to which the cells were adhered to revealed a very uniform and a maximum level of oscillations, with an OSI $\sim 0.5$ everywhere on the channel surface. 
a)

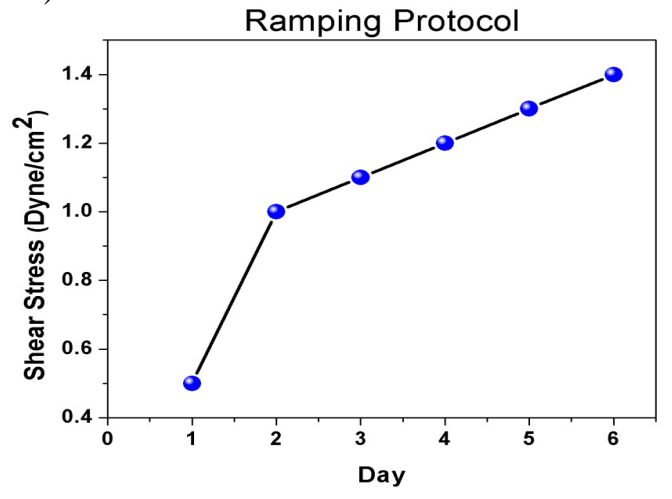

b)

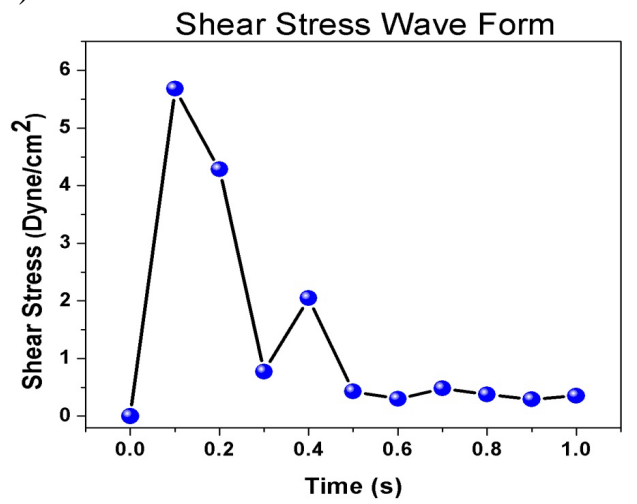

c)

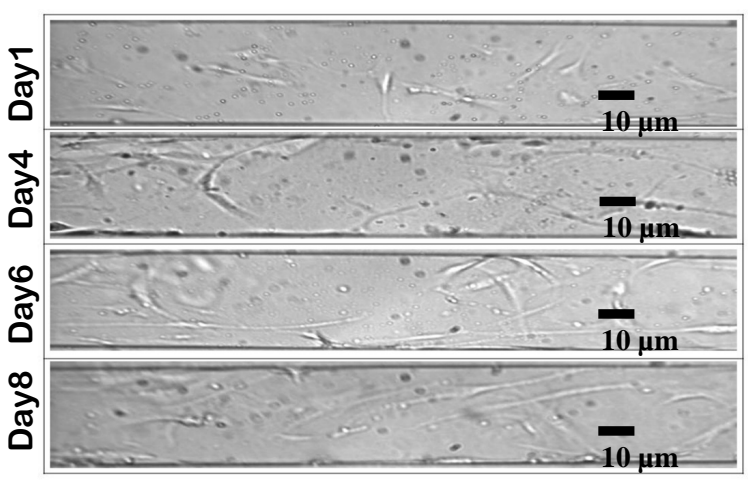

Figure 3.1: a)Ramping protocol involving a six day step-wise increment in steady shear stress to permit BMMSC acclimatization to the channel flow environment; b) Continuous pulsatile wave form adapted from a physiological flow waveform which was used to impart OSS to the BMMSCs for 48 hours. c) Longitudinal optical microscopy of adhered cells to the bottom surface of the microfluidic channel over an eight day timeframe. The BMMSCs appeared to have adhered well after gradual augmentation of steady shear stress followed by OSS conditions were prescribed 


\subsubsection{Immunofluorescence Staining}

Immunostaining of F-actin, vinculin, and CD31 were performed on the samples exposed to Nicotine after ten days. The staining was also repeated to BMMSCs exposed to an increasing steady shear stress for six days followed by two days of high OSS conditions (OSI $\sim 0.5)$. The following staining procedure was prescribed: BMMSCs were washed twice with pre-warmed, phosphate-buffered saline (PBS, Thermo Scientific* HyClone* Dulbecco's Phosphate Buffered Saline, pH 7.4) and fixed with $4 \%$ paraformaldehyde for $15-20$ minutes at $4^{\circ} \mathrm{C}$. After fixation cells were washed three times for 5-10 minutes each with PBS. Then $0.1 \%$ Triton X-100 was applied to enhance immunostain permeability to the cells for 3 to 5 minutes followed by washing three times for 5-10 minutes with PBS. Blocking of nonspecific epitopes was performed by adding 1percentage goat serum in PBS for 2030 minutes.

\section{F-actin}

Nicotine and non-Nicotine samples $(n=4)$ were treated with Cyto Painter Factin Staining Kit Red Fluorescence conjugated Phalloidin (Abcam) next day. Samples were incubated for $30-60$ minutes at $4^{\circ} \mathrm{C}$. Cells were rinsed gently with PBS 2 to 3 times to remove excess dye. PBS was added to the wells to avoid drying during imaging under the microscope. A similar processing protocol was performed for the microfluidic OSS samples except that a steady shear stress of $1 \mathrm{dyne} / \mathrm{cm}^{2}$ was applied to add and remove the reagents at each step.

\section{Vinculin}

Cells were incubated with dilute primary antibody (mouse monoclonal anti vinculin, Thermo Scientific) to a working concentration in blocking solution overnight at $4^{\circ} \mathrm{C}$. Next, the cells were washed three times for 5-10 minutes each with PBS. 
Dilute Flurophore-conjugated isotype specific secondary polyclonal antibody (Goat anti-Mouse IgG (H+L), DyLight 488) (Fisher Scientific) was added and incubated for 30-60 minutes at $4^{\circ} \mathrm{C}$. Cells were rinsed gently with PBS 2 to 3 times to remove excess dye and PBS was added to avoid drying of cells during imaging.

\section{CD31}

For CD31 cell surface marker detection, the permeability step was omitted; instead, cells were directly incubated with dilute primary antibody (mouse monoclonal anti CD31, Abcam) to a working concentration in blocking solution overnight at $4^{\circ} \mathrm{C}$. Cells were washed three times for 5-10 minutes each with PBS. Dilute flurophoreconjugated isotype specific secondary polyclonal antibody (Goat anti-Mouse IgG $(\mathrm{H}+\mathrm{L})$, DyLight 488, Fisher Scientific) was added and incubated for 30-60 minutes at $4^{\circ} \mathrm{C}$. Cells were rinsed gently 2 to 3 times to remove excess dye and PBS was added to avoid drying of cells to obtain images of CD31 under Olympus IX81 fluorescence microscope.

\section{Image analysis}

Signal intensity values for CD31 images (sample size, $\mathrm{n}=4$ ) were quantified using the following protocol (ImageJ, NIH; Bethesda, MD). A rectangular region of interest (ROI) with an area of 7840 pixels was defined. Three such different ROIs (replicates, $\mathrm{r}=3$ ) with maximum intensity were selected and measured. Average intensity of the ROIs was recorded in arbitrary units (AU). Care was taken to avoid any false positive signals. 


\section{Statistical Analysis}

Independent t-tests were performed using SPSS (IBM, Armonk, NY) to compare CD31 expression level for NS and OSS group as well as Nicotine and nonNicotine groups ( $\mathrm{n}=4$ samples/group). OSS or Nicotine-treated groups were compared against their respective control groups wherein a significant difference was interpreted to occur at $\mathrm{p}<0.05$.

\subsection{Results}

Cell cytoskeletal and membrane protein changes were assessed after an eight and ten day treatment protocol of shear stress mechanical conditioning and nicotine treatment of BMMSCs respectively. The shear stress protocol included six days of augmenting shear stress, followed by two days of highly oscillatory shear environments (OSI $\sim 0.5)$. Owing to the application of OSS to BMMSCs in our studies, our interest was primarily aimed at identifying the F-actin alterations within the cytoskeleton and the changes in vinculin along the BMMSC membrane. This was because these cellular constituents in addition to talin and certain specific integrins are known to respond to the surrounding mechanical environment, thereby promoting events such as stem cell differentiation and subsequent, gene expression [107]. We restricted our evaluation of changes observed for these proteins to the positive expression of CD31, an endothelial cell surface marker, as an early indicator of mesenchymal to endothelial transformation of BMMSCs under OSS or Nicotine exposure. 


\subsubsection{F-actin staining}

\section{BMMSCs exposed to OSS}

A noticeable axial stretch pattern of actin filaments in BMMSCs exposed to OSS was observed compared to the NS (control) condition. Morphologically, the cells appeared to be elongated whereas cells were randomly oriented and not elongated under the NS condition (Fig.3.2).

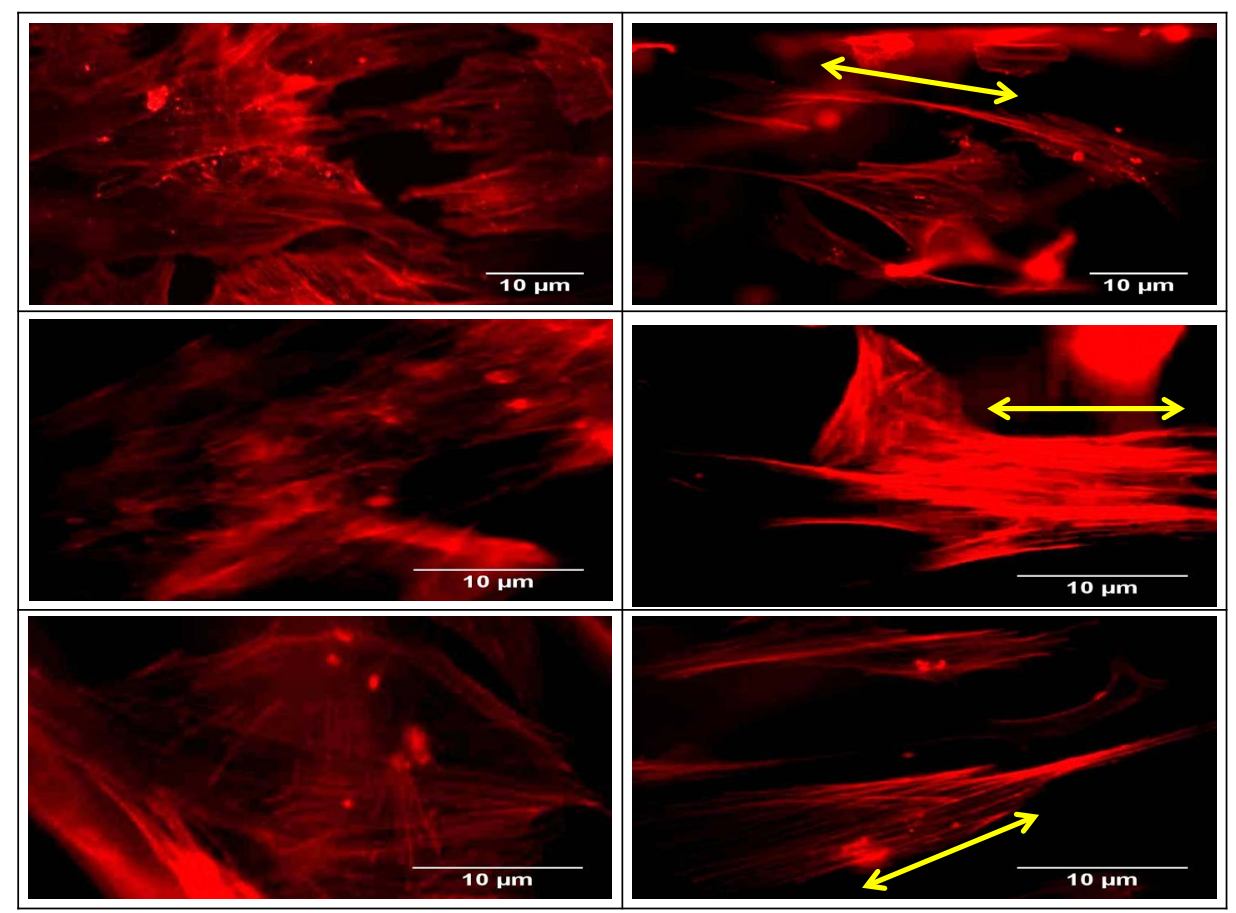

Figure 3.2: Immunofluorescence staining for F-actin (red) of BMMSCs cultured under No Stress (NS) (column1) and OSS (column2) condition for eight days in the microchannels. A distinct stretching pattern of $\mathrm{F}$-actin filaments was observed after exposure to OSS compared to NS counterpart.

\section{BMMSCs exposed to Nicotine}

An increase in the presence of actin filaments were observed in the group consisting of BMMSCs treated with a low-dose of Nicotine $10^{-6} \mathrm{M}$ in comparison to the 
untreated group (Fig.3.3). However, unlike the cells exposed to OSS, a random orientation with no preferred F-actin alignment was observed in the Nictoine-treated samples and its corresponding control group.

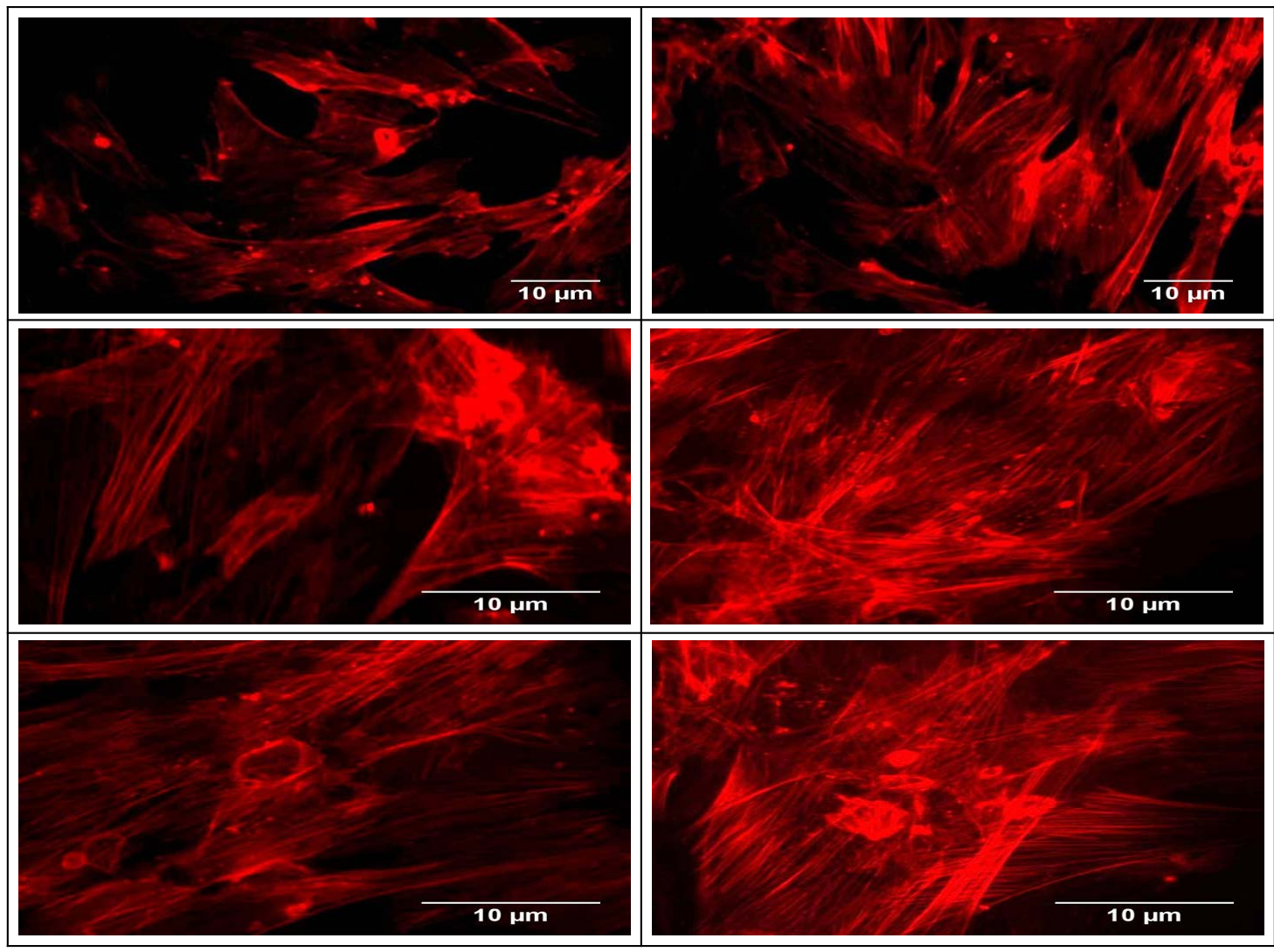

Figure 3.3: Immunofluorescence staining for F-actin (red) in BMMSCs cultured without Nicotine (column1) and with Nicotine $10^{-6} \mathrm{M}$, column 2) in a 24 well plate for 10 days. No visible stretching pattern in F-actin was observed in either of these groups. However, an increase in the number of actin filaments was clearly visible in the Nicotine treated group in comparison to its corresponding control, i.e., untreated group. 


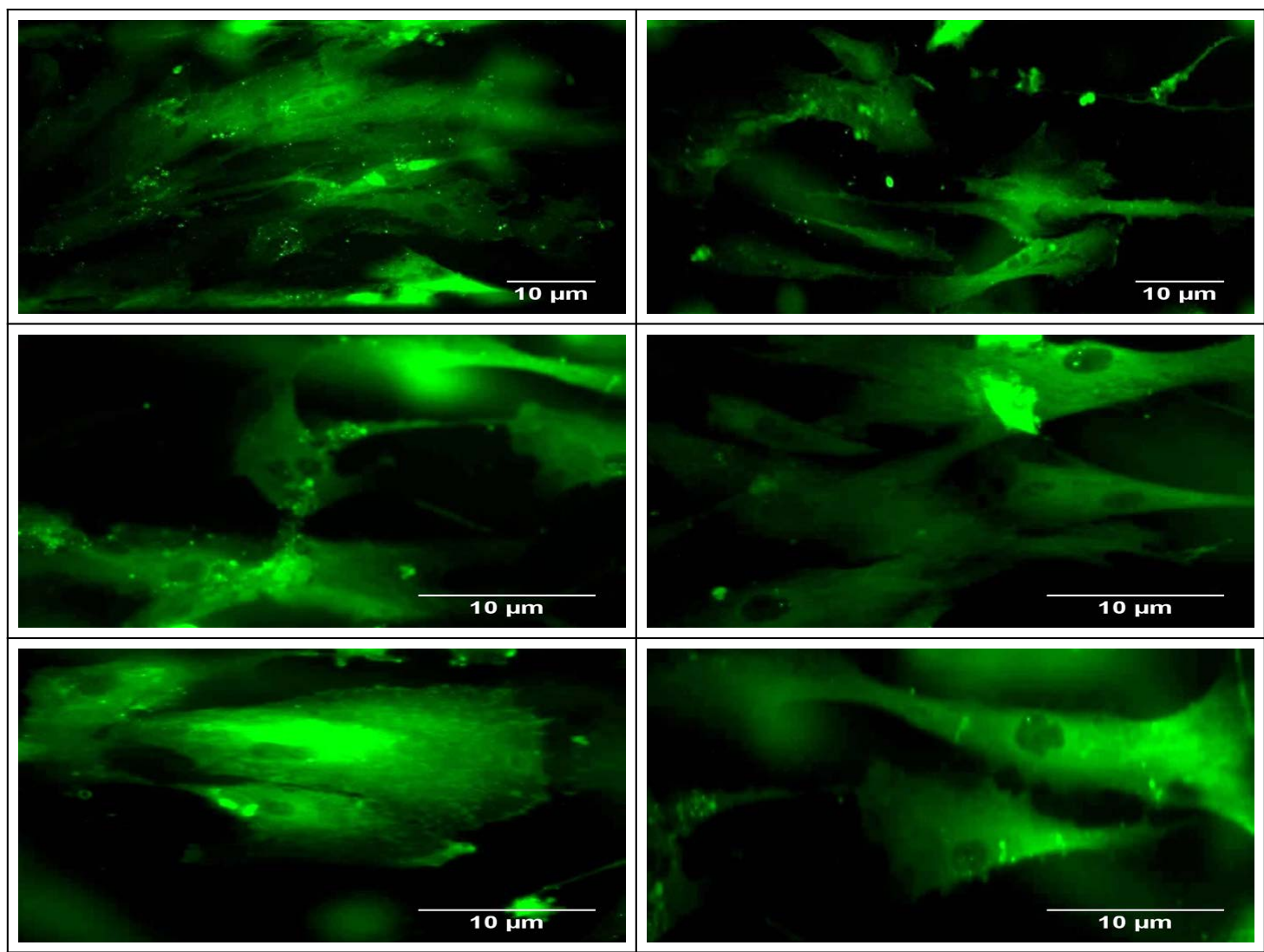

Figure 3.4: Immunofluorescence images of BMMSCs cultured under NS (column1) and OSS (column2) in the microchannels for eight days. An absence is preferential cell membrane distribution in vinculin was observed in both the OSS and corresponding control groups

\section{Vinculin staining}

\section{BMMSCs exposed to OSS}

A higher density of vinculin adhesion molecules along the cell membrane was not observed in NS and OSS samples, nor could distinct focal adhesion points be identified in either group; rather, a random distribution in positive staining (green) was observed throughout the cells (Fig.3.4). 


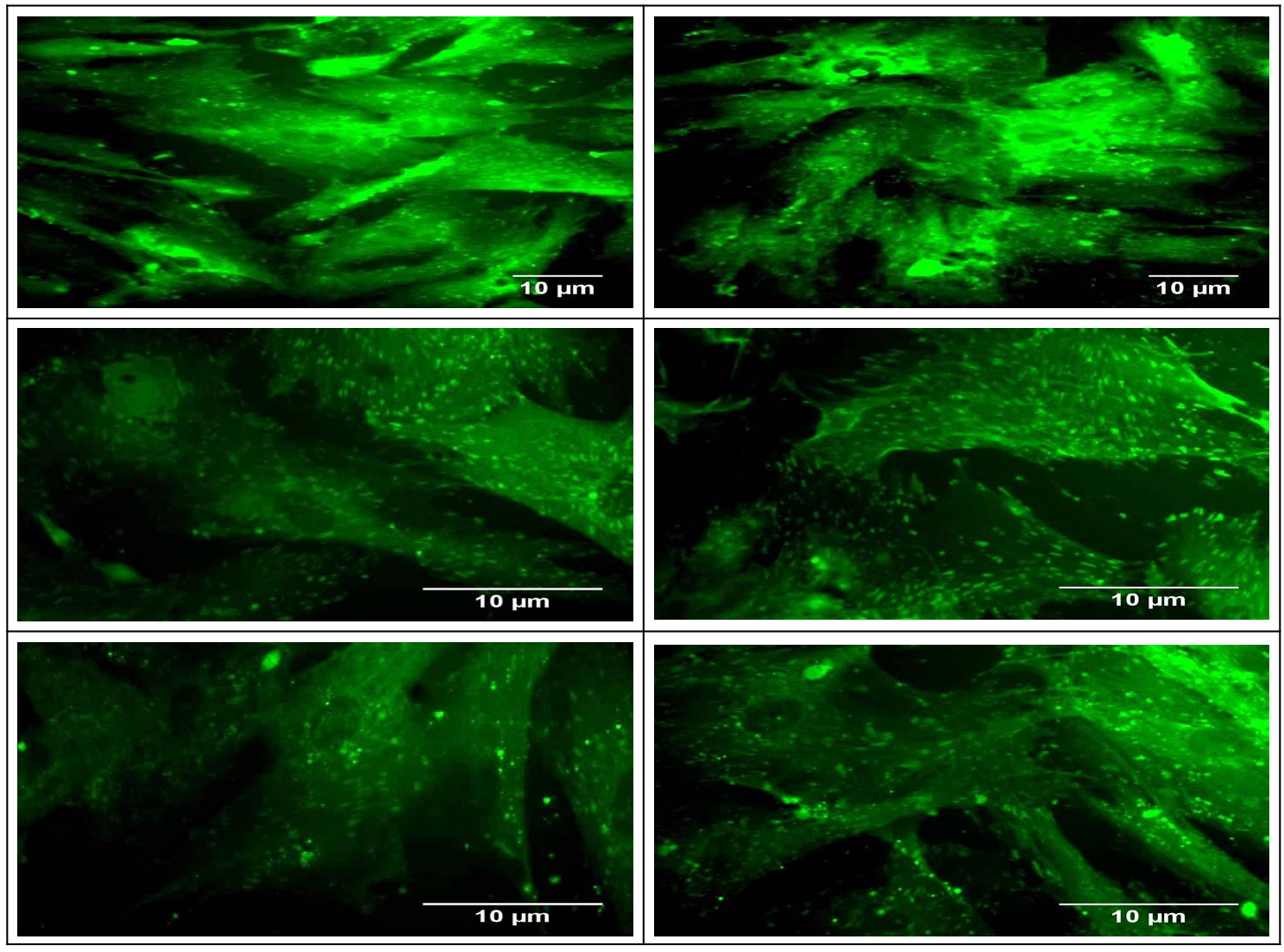

Figure 3.5: Immunofluorescence images of BMMSCs cultured without Nicotine (column1) and with Nicotine $\left(10^{-6} \mathrm{M}\right.$, column 2$)$ for 10 days. An absence is preferential cell membrane distribution in vinculin was observed in both the untreated and Nicotine-treated groups.

\section{BMMSCs exposed to Nicotine}

Preferential vinculin staining was absent along the cell membrane of the Nicotine treated and untreated groups after ten days of culture and was found to occur randomly in both groups. Similar to the results observed for the OSS-treated cells, vinculin was observed to be spread-out throughout the BMMSC cytoplasm in both the nicotine treated and untreated samples (Fig.3.5). 


\section{CD31 staining}

The expression of cluster of differentiation 31 (CD31) (also known as platelet endothelial cell adhesion molecule (PECAM1)) has been previously suggested to demonstrate differentiation of BMMSCs to highly angiogenic and vasculogenic cells for cell-based strategies to treat ischemic cardiovascular diseases [108]. Thus we investigated for positive expression of CD31 in BMMSCs treated with exposure to either OSS or Nicotine and subsequently quantify the level of CD31-derived positive signal intensities by image analysis. BMMSCs exposed to OSS.

\section{BMMSCs exposed to OSS}

An approximate threefold increase in the expression of CD31 was observed in BMMSCs that were exposed to two days of pure OSS environments (OSI $\sim 0.5$ ) following a six-day steady shear stress ramp up protocol. Moreover, the results of the image analysis demonstrated a significant difference $(\mathrm{p}<0.05)$ in CD31 expression between the cells exposed to OSS and its corresponding NS-control group (Fig.3.6).

Table 3.1: Number,Orientation and Length of actin filaments in control, OSS and nicotine groups.

\begin{tabular}{lllll}
\hline Actin filament & & Control & OSS & Nicotine \\
\hline \multirow{3}{*}{ Count (number) } & Average & 8.00 & 2.33 & 15.33 \\
& SDV & 2.41 & 1.08 & 4.75 \\
& SEM & 1.39 & 0.62 & 2.74 \\
Angle (Deg) & Average & 22.12 & 8.98 & 41.66 \\
& SDV & 14.75 & 5.52 & 28.83 \\
& SEM & 8.52 & 3.19 & 16.65 \\
Length (AU) & Average & 259.52 & 479.39 & 228.75 \\
& SDV & 93.35 & 256.16 & 92.79 \\
& SEM & 53.90 & 147.89 & 53.57 \\
\hline
\end{tabular}



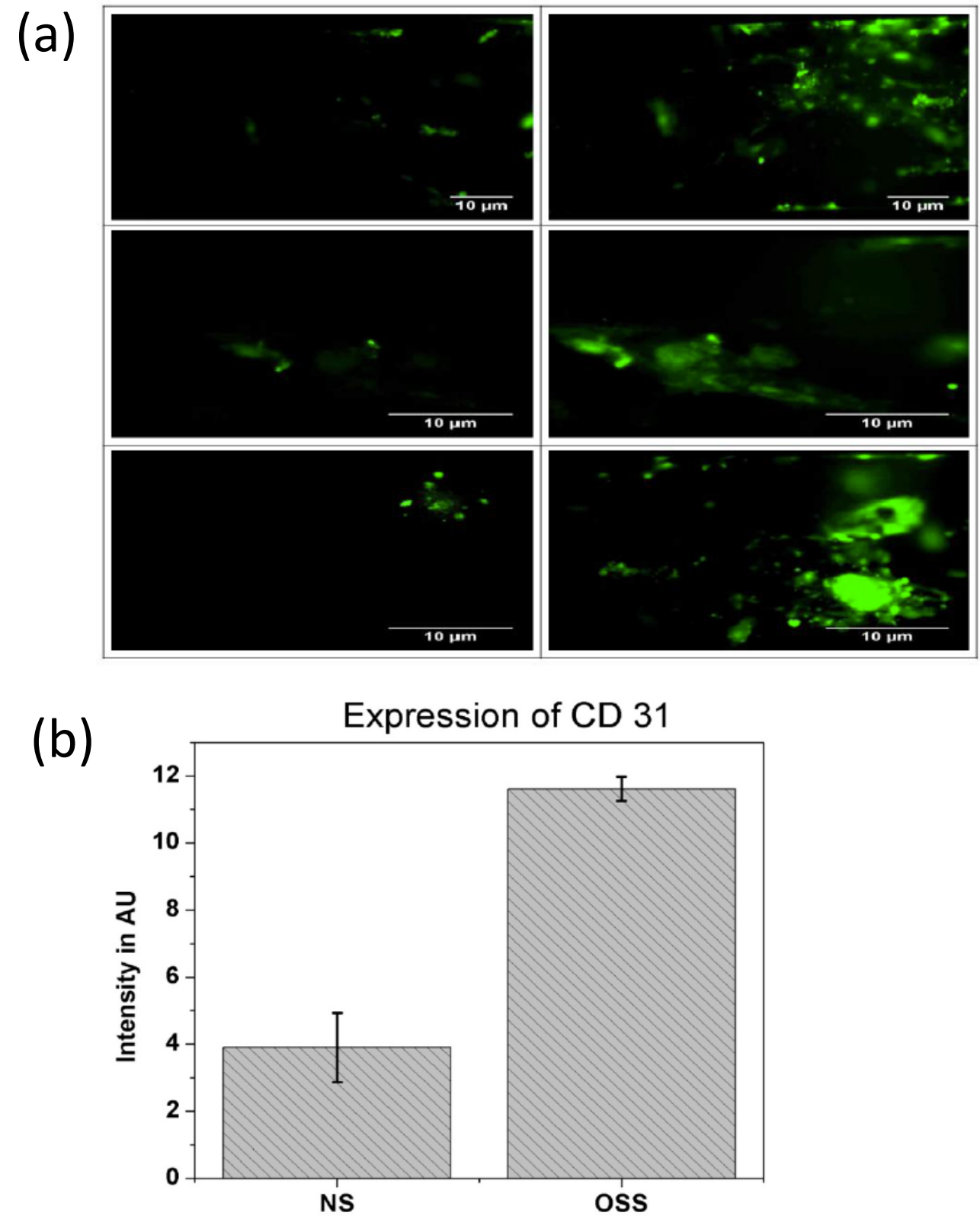

Figure 3.6: a) Immunofluorescence staining for CD31 expression by BMMSCs under NS (column1) and OSS (column2) conditions after 8 days of culture within the microfluidic channel environment. b) Quantification of positive staining (green; from images in part a)) for CD31 signal-intensity in NS and OSS groups; Samples exposed to OSS expressed a significantly higher level of positive CD31 $(\mathrm{p}<0.05)$ in comparison to the control group. 


\section{BMMSCs exposed to Nicotine}

A greater than threefold increase in CD31 positive staining was found in BMMSCs cultured for 10 days in media containing a low dose $\left(10^{-6} \mathrm{M}\right)$ of Nicotine compared to untreated controls (Fig. 7). Moreover, a significant difference $(\mathrm{p}<0.05)$ in CD31 expression was found between the two groups

\subsection{Discussion}

BMMSCs have demonstrated great potential for heart valve tissue engineering [109]. However, the differentiation-specific mechanisms due to optimized biochemical and biomechanical factors are yet to be completely delineated. Therefore, further investigation on the biomechanical and biochemical factors that can enhance functional engineered heart valve tissues originating from BMMSCs is warranted. Previous studies suggested that the fluid-induced shear stresses play a predominant role in eliciting robust tissue formation when compared to solid (flexural and tensile) valve-relevant stresses, since the scaffold used could only allow for modest levels (up to 7\%) of strains [74]. In addition, it was noted that there was a high degree of OSS associated with specimen deformation during the combined steady flow-cyclical flexure event, which was analogous to the closure of valve leaflets . Interestingly, OSS is innately present in native heart valves (particularly on the arterial side of the leaflets), and is presumed to enhance valve coaptation [110]. Thus, from a physiologically relevant cellular mechanics standpoint, the oscillatory nature of shear stresses may play a major role within a regenerative framework, by triggering appropriate BMMSC signaling events that lead to enhanced engineered heart valve tissue formation. Indeed it is likely that the physiological mimicry of the nature of flow oscillations rather than the similitude of the shear stress magnitudes 


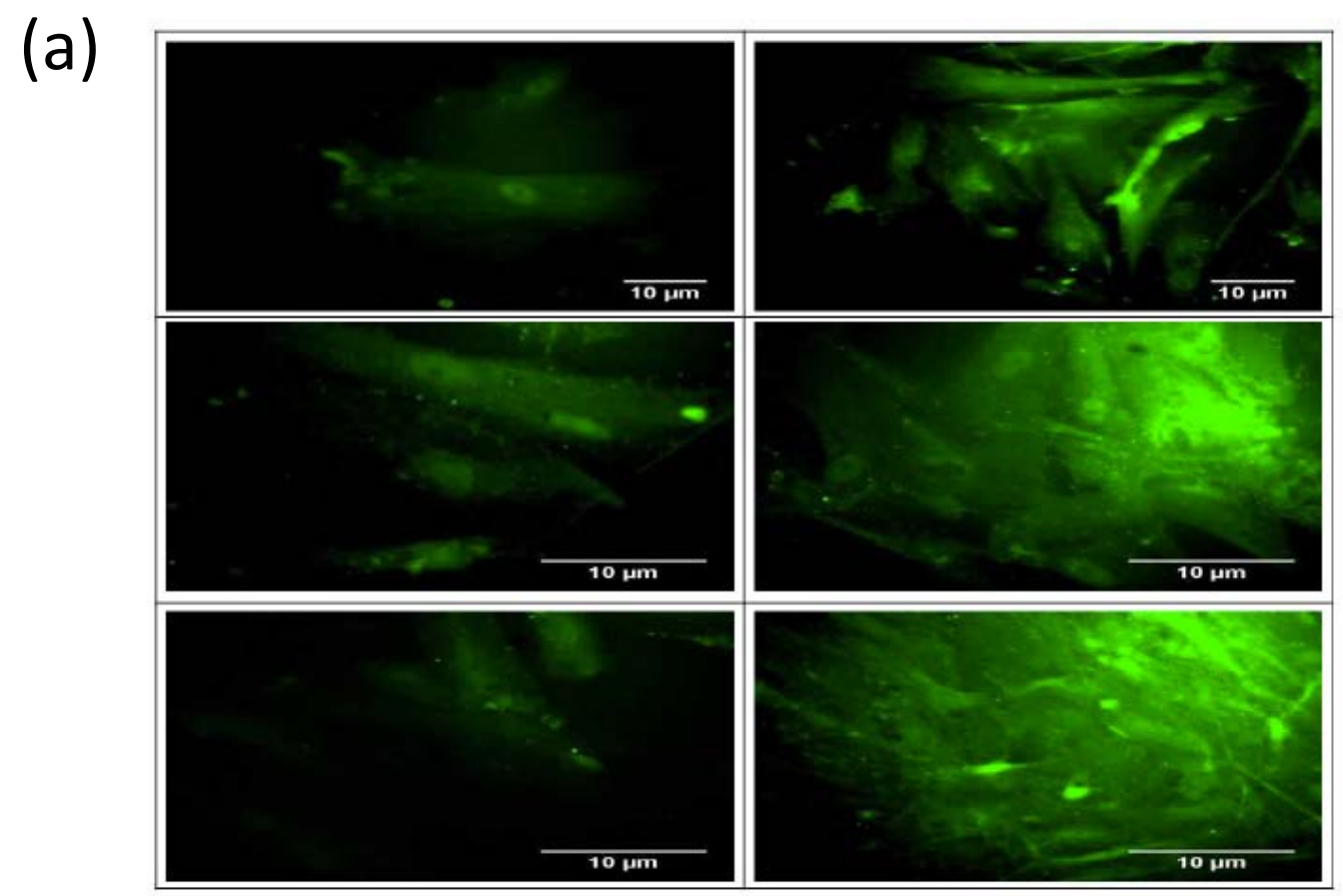

(b)

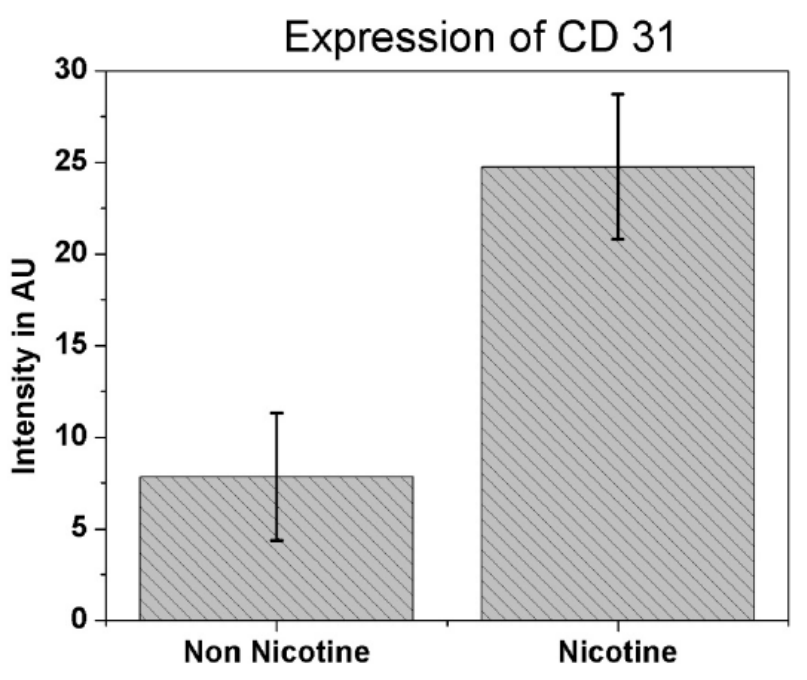

Figure 3.7: Immunofluorescence staining for CD31 expression by BMMSCs under Nicotine-untreated (column1) and Nicotine-treated (column2, 10 $0^{-6} \mathrm{M}$ ) conditions after 10 days of culture within 24-well plates. b) Quantification of positive staining (green; from images in part a)) for CD31 signal-intensity in Nicotine-untreated and Nicotine-treated groups; Samples exposed to low dosage of Nicotine $\left(10^{-6} \mathrm{M}\right)$ expressed a significantly higher level of positive CD31 $(\mathrm{p}<0.05)$ in comparison to the untreated, control group. 
themselves may be more critical for cell and tissue development, since previous findings have demonstrated that robust BMMSC-derived tissue production was achieved even under sub-physiological flow conditions [10].

Elsewhere,studies [111], [112], [113] have already shown that OSS regulates the differentiation capabilities of BMSMCs towards osteogenic, adipogenic and chondrogenic pathways. While flow-stretch-flex stress environments are coupled for the native heart valve, it may not be practically possible for this coupled effect to be routinely applied prior to implantation, nor may all aspects of this environment be necessary to produce an optimal construct. Instead, further understanding of the role of specific biomechanical cues such as OSS on tissue production and cell differentiation from suitable cell sources such as BMMSCs may be more practical.

Meanwhile, endothelial based nicotinic acetylcholine receptors (nACHRs) have been systematically shown to be involved in angiogenesis, and in particular the $\alpha 7$ nACHR homomer [100] , [101], [102] , [114], [115]. Initial activation of an angiogenic pathway can either be endogenous via the agonist acetylcholine or by the external stimulant, Nicotine. Extensive subsequent studies by the Cooke group at Stanford have shown that the fundamental mechanism by which Nicotine in low doses $\left(10^{-8}\right.$ to $\left.10^{-6} \mathrm{M}\right)$ promotes endothelial cell migration, proliferation and tube formation is the augmented permeability of $\mathrm{Ca}^{2+}$ into the cell cytoplasm again via modulation of $\alpha 7 \mathrm{nACHR}([101]$, [114], [115], [116] ). This in turn activates kinases responsible for heightened EC activity. At a different scale, Nicotine also enhances endogenous growth factor production by the cells, such as FGF, NO and endothelin [117] that are involved in angiogenesis. Therefore, while OSS and Nicotine can provoke arterial plaque formation, we hypothesized that the natural occurrence of OSS in native valves and in enhancing engineered tissue formation, as well as the induction of vasculogenesis by Nicotine could contribute beneficially towards struc- 
tural and phenotypic changes of BMMSCs that support the heart valve phenotype. With respect to the phenotypic characteristics, we investigated the potential of BMMSC-based mesenchymal to endothelial transformation rather than mesenchymal to fibroblastic or smooth muscle cell differentiation since the former is likely to be more challenging, while the latter has already been conclusively shown in previous studies [10]. As a first step in this endeavor, an understanding of the cellular structural response to external biomechanical and biochemical factors may correlate to a specific set of desirable cell differentiation events in support of the heart valve phenotype. It has been demonstrated that F-actin as well as vinculin, talin and some other specific integrins may contribute to structural and morphological changes in ECs due to shear [107] , [10] , [118] . In the case of OSS, a highly stretched appearance in the actin filaments was observed. In this regard, we found that OSS conditioning and a low dosage of Nicotine $\left(10^{-6} \mathrm{M}\right)$ exposure to BMMSCs altered the F-actin structure. In the case of OSS, a highly stretched appearance in the actin filaments was observed. This pointed towards direct alterations in the BMMSC cytoskeleton due to OSS, which in turn may lead to unique gene expression activity. Moreover we found that OSS conditioning tended to promote some degree of alignment of actin filaments with respect to each other compared to the no flow (controls) condition (Fig.3.2). The BMMSC response to OSS was strikingly similar to actin filaments in the cytoskeleton of arterial ECs wherein, cell elongation and flow alignment events were also observed [119], [120]. Thus our findings to this point suggested early evidence of BMMSCs responding to OSS in an EC-like manner.

On the other hand, augmentation of actin filaments was clearly observed in low-dose, Nicotine-supplemented samples $\left(10^{-6} \mathrm{M}\right)$ in comparison to untreated controls after 10 days of culture (Fig.3.3). Observed individually but interpreted in 
combination, these microstructural changes in the BMMSC cytoskeleton that were caused independently by OSS and Nicotine external stimuli are likely to modulate (to varying degrees) cellular gene expression and eventual protein synthesis. For example, the increased number of F-actin filaments in Nicotine treated cells may serve to control regulatory pathways of genes which have previously been found to occur via nACHRs in ECs [98], [100].

We decided at this preliminary stage to focus on EC differentiation of BMMSCs by positive detection of CD31, a well-established EC surface marker. Our motivation for selecting this EC marker derived from previous work demonstrating that BMMSCs robustly express CD31 after successfully undergoing mesenchymal to endothelial transformation [108] . Indeed, preliminary structural changes observed in F-actin filaments after OSS exposure seemed to be a precursor for regulating differentiation of BMMSCs to ECs after OSS exposure, as this mechanical stimulant significantly $(\mathrm{p}<0.05)$ increased CD31 positive expression (Fig.3.6). The significant increase $(\mathrm{p}<0.05)$ was also observed independently by the treatment of BMMSCs to a low dose of Nicotine $\left(10^{-6} \mathrm{M}\right)$; however in this event, the mechanism of increased EC differentiation appeared to have been prompted by an increase in the number of F-actin filaments, rather than changes in filament orientation and stretching. Notably the magnitude of CD31 expression after Nicotine treatment was the highest compared to OSS and control groups (Figs.3.6 and 3.7). Thus, even though both OSS and Nicotine independently serve to enhance the differentiation of BMMSCs to ECs, we interpret that Nicotine may serve to robustly augment CD31 expression, while OSS may eventually serve to preferentially align and distribute cells on the surface of TEHV constructs to create a distinct endothelial layer, i.e., a valve endothelium. 
Our study has several limitations: firstly, we conducted our experiments in 2-dimensional cell monolayers. Undoubtedly 3D cell-scaffold interactions will have unique effects on mesenchymal to EC differentiation of BMMSCs. Furthermore, we focused on cell structural changes that elicited BMMSC to EC differentiation, but did not target specific gene expression activity directly regulated by either OSS or Nicotine that led to the phenotypic change. For example, it was shown that OSS directly modulated the normal expression of the gene klf2a during valvulogenesis whereas an absence of klf2a produced defective heart valves [96]. Thus, OSS is essential for normal valve development and is likely to be important in BMMSCderived TEHV development as well. Secondly, we only tested for one EC marker, and perhaps more importantly, did not specifically target the valve EC phenotype. This could be readily achieved for example by determining the positive expression of nucleoside phosphorylase and an absence of Interleukin-1 alpha which are distinct characteristics of valve ECs (as opposed to vascular ECs) [39] . Finally, the combined effects of low dose $\left(10^{-6} \mathrm{M}\right)$ Nicotine and OSS regulation of BMMSCs may have synergistic benefits; however this remains to be determined. These issues are currently being addressed by our on-going research efforts in the area of BMMSC biomechanics, for the purposes of enhancing treatment through cardiovascular regenerative medicine approaches.

In summary, we examined the effects of two unusual suspects in the form of OSS and low dose $\left(10^{-6} \mathrm{M}\right)$ Nicotine for enhancing BMMSC differentiation to ECs. Specifically, we examined the F-actin filaments and vinculin components of BMMSCs after independent exposure to OSS and Nicotine. In both cases, no observable differences were seen in the arrangement of vinculin molecules along the cell membrane in comparison to untreated control counterparts. However, preferential alignment and stretching of F-actin filaments occurred after OSS exposure, whereas 
the number of filaments themselves was clearly augmented when Nicotine was applied. All of these alterations to the filaments within the cytoskeleton resulted in significantly enhanced $(\mathrm{p}<0.05)$ BMMSC differentiation to ECs in comparison to untreated controls. Based on the results obtained in the current study, we speculate that Nicotine may serve the role of heightening the level of EC expression whereas OSS may promote the creation of a TEHV endothelium. We further believe that the regulation of F-actin filaments by OSS and Nicotine to enhance the differentiation of BMMSCs to ECs is a fundamental, yet important finding that can be leveraged to generate necessary cell (e.g. ECs, smooth muscle cells) and tissue (i.e. collagen, glycosaminoglycans, elastin) heterogeneity in TEHVs, and in a broader context, is likely to offer protocol optimization in other areas of cardiovascular medicine as well. 


\section{CHAPTER 4}

\section{Physiologically-relevant flexure and flow induces valvulogenesis in stem cell-seeded scaffolds}

\subsection{Introduction}

Post-fetal heart valve development is intimately connected to local hemodynamic conditions. For treatment of heart valve disease, prosthetic valves perform fairly well in most adults; however, for pediatric patients, there is the added requirement that the replacement valve grows with the child, thus extremely limiting current treatment options. Tissue engineered heart valves (TEHV), such as those derived from autologous bone marrow stem cells (BMSCs), have the potential to recapitulate native valve architecture and accommodate somatic growth. However, a fundamental pre-cursor in promoting directed integration with native tissues rather than random, uncontrolled growth requires an understanding of BMSC mechanobiological responses to valve-relevant mechanical environments. Here, we report on the responses of human BMSC-seeded polymer constructs to the valve-relevant stress states of: (i) steady flow alone, (ii) cyclic flexure alone, and (iii) the combination of cyclic flexure and steady flow (flex-flow). BMSCs were seeded onto a PGA: PLLA polymer scaffold and cultured in static culture for 8 days. Subsequently, the aforementioned mechanical conditions, (groups consisting of steady flow alone $850 \mathrm{ml} / \mathrm{min}$, cyclic flexure alone $-1 \mathrm{~Hz}$, and flex-flow $-850 \mathrm{ml} / \mathrm{min}$ and $1 \mathrm{~Hz}$ ) were

applied for an additional two weeks. We found significant expression $(\mathrm{p}<0.05)$ of the transcription factor klf2a, by the BMSCs under flex-flow conditions, which is known to be critical in valve development. We interpret that this was likely due to the presence of both appreciable fluid-induced shear stress magnitudes and oscillatory shear stresses, which were concomitantly imparted onto the samples. Additionally, under 
flex-flow states, we found significant expression $(\mathrm{p}<0.05)$ of the YARS gene, known to be expressed by valvular but not vascular endothelial cells.Finally, samples from the flex-flow group exhibited a valve-like distribution of cells that expressed endothelial (preference to the surfaces) and myofibroblast (preference to the intermediate region) phenotypes. These results indicate that flex-flow mechanical environments support directed in vitro differentiation of BMSCs uniquely towards the heart valve phenotype as evidenced by cellular distribution and the expression of specific genetic markers. A priori guidance of BMSC-derived, engineered tissue growth using flex-flow states may serve to subsequently promote controlled, engineered to native tissue integration processes in vivo needed for successful long-term valve remodeling.

Heart valves play an important role in controlling unidirectional blood flow. However, birth defects or infections (e.g. rheumatic fever) can cause one or more of the heart valves to malfunction, which may lead to critical valve anomalies in children. Advances in implant design and surgical techniques have substantially augmented the success of prosthetic heart valves in adult patients. However, the efficacy of these implants is severely limited in pediatric patients due to their inability to promote somatic growth and valvular tissue remodeling; as a result, multiple major surgeries and re-operations are commonplace, which places a significant health burden on the growing child.

Similar to native valves, a tissue engineered heart valve (TEHV) has the ability to adapt and evolve with the living host and is conceptually considered a permanent solution to treating heart valve disease [16]. During each cardiac cycle, native valves are continuously subjected to mechanical stresses from the flow of blood; for example, aortic valve leaflets experience peak fluid-induced shear stresses of approximately 5-6 dyne/ $\mathrm{cm}^{2}$ in mid systole [121], [122], [110]. 
Mechanical stimuli, when applied to developing cardiovascular tissues, alter gene expression-promoting tissue remodeling events, which in turn enhances specific mechanical and phenotypic characteristics. Native heart valves are subjected to highly complex cyclic, tensile and fluid-induced stresses [110].In an engineered heart valve tissue context, mechanical stimuli, particularly those that incorporated fluid-induced shear stresses, have enhanced progenitor cell differentiation pathways and construct tissue properties for the valve application [123] , [124] [125], [38]. For example, Hoerstrup et al. performed experiments using a pulsatile flow bioreactor device that enhanced TEHV tri-leaflet structures with $\sim 300 \%$ increase in the collagen extracellular matrix (ECM) content compared to statically cultured counterparts. Elsewhere, bioreactors have been built to couple any combination of flow, cyclic stretch and cyclic flexure (FSF bioreactors), which have also verified that coupled mechanical stimuli significantly promote ECM production, in particular, the combination of steady flow with cyclic flexure [105], [10]. Of particular relevance to heart valves, Vermot et al. showed that blood flow-induced oscillatory shear stresses (OSS) directly modulate the normal expression of a transcription factor from the kruppel-like factor gene family, klf2a in a zebra fish model. The klf2a gene is critically involved in valvulogenesis, whose absence results in defective heart valves [96]. The generation of a functional TEHV has remained elusive in part, due to a lack of information regarding the mechanobiological events necessary to optimize the in vitro culture process. Nonetheless, under mechanical guidance, tissue engineering feasibility studies have thus far demonstrated that native valvular cells can recapitulate valve structure with adequate mechanical strength and morphology [126], [127], [23], [51], [128]. In addition, non-valvular cells, such as bone marrow stem cells (BMSC), saphenous vein endothelial cells (ECs), ascending aorta myofibroblasts and umbilical cord-derived cells, have exhibited increased produc- 
tion of valvular ECM, DNA content and endothelization in vitro under mechanical conditioning states [129], [130], [131], [132], [133], [74] . BMSCs in particular have shown considerable promise for heart valve tissue engineering, as they are multipotent stem cells with a minimal risk of immunogenicity, are void of ethical/legal concerns and can be obtained and culture-expanded easily; typically, BMSCs can be isolated, purified and expanded to a large number in a matter of days [134].BMSCs maintain extensive differentiation, proliferation and clonogenic capacity in vitro. Human BMSCs respond to mechanical conditioning and have been shown to produce heart valve ECM components in vitro, [90], [135]. Engelmayr et al [10], [136], described pioneering work on elucidating the effects of combined cyclic flexure and steady flow states (flex-flow), which served to significantly promote engineered collagen in de novo engineered heart valve tissues derived from BMSCs. However, a fundamental precursor to TEHV studies evaluated at the tissue scale is the need to understand the process by which valve-relevant mechanical stimuli can regulate cell fate, particularly cell differentiation in the context of stem cell sources. Thus, in this study, our primary goal was to determine unique responses of BMSCs to flex-flow conditions in the promotion of valvulogenesis.

\subsection{Methods}

\subsubsection{BMSCs Culture and eExpansion}

BMSCs isolated from human bone marrow, characterized and tested with stromal, stem, and hematopoietic marker, were purchased in frozen vials (Fisher Scientific, Pittsburgh, PA). Cells were recovered from dry ice packaging, and were immediately thawed and diluted with a pre-warmed culture medium to reduce the 
toxic effects of cryopreserve reagents upon arrival. Approximately $5 \times 10^{5}$ cells were transferred to a T75 vented cell culture flask and placed in an incubator supplied with $5 \% \mathrm{CO} 2$ at $37^{\circ} \mathrm{C}$ with $95 \%$ humidity. Flasks were fully confluent at 1 week. An average of 2 x 106 cells were obtained at each passage. Freshly prepared stem cell culture medium with $10 \%$ advanced stem cell undifferentiated growth supplement, $1 \%$ penicillin and streptomycin (Thermo Scientific HyClone, Fisher Scientific)medium was used for cell culture and expansion. An aseptic cell and tissue culture environment was dedicated for the entire duration of the experiment. BMSCs at passages 6 to 8 were utilized for subsequent tissue engineering experiments.

\section{Scaffold Preparation and Cell Seeding}

An equal ratio of poly-glycolic acid (PGA) and poly-L-lactic acid (PLLA), nonwoven polymer felt was utilized as the scaffold material (Biofelt, Biomedical Structures, Warwick, RI) [137], [130], [10]. Specimens measuring 17 mm long, 6 mm wide and $1 \mathrm{~mm}$ thick $(\mathrm{n}=12)$ were cut and two metallic springs were carefully attached to either end of the scaffold. This assembly was required for dynamic tissue culture in our customized U-shaped bioreactor device(Fig.4.1). Prior to cell seeding, scaffolds were gas sterilized with ethylene oxide (EtO; AN 306, Anprolene, Andersen Products Inc, HawRiver, NC) for 12 hours and treated 70\% ethanol. Aeration procedures were performed as per the recommendations described in the manufacturers instruction guide [138] . The following protocol was used to complete the seeding procedure: Approximately 90\% confluent flasks were rinsed with Dulbeccos

Phosphate-Buffered Saline (DPBS, Fisher Scientific) buffer. Next, 0.25\% trypsin and ethylenediaminetetraacetic acid (EDTA) solution were added and incubated at $37^{0} \mathrm{C}$ for 3 minutes. An equal volume of serum was used to neutralize the trypsin solution. Cell suspensions were collected in $15 \mathrm{ml}$ conical tubes and centrifuged at 
$1700 \mathrm{rpm}$ for 5 minutes. A cell pellet was retrieved by removing the supernatant and was suspended with freshly prepared tissue culture media for further usage. A single scaffold was seeded with $2 \times 10^{6}$ BMSCs and suspended in $20 \mathrm{ml}$ of tissue culture media in $50 \mathrm{ml}$ vented conical tubes (Product\#TP87050, TPP, TubeSpin Bioreactor, Zollstrasse 7, CH-8219 Trasadingen, Switzerland). The tissue culture media comprised of Dulbeccos modified Eagles medium (DMEM, Fisher Scientific) supplemented with 10\% fetal bovine serum (Atlanta Biologics, GA, USA), 1\% penicillin and streptomycin (Thermo Scientific HyClone ${ }^{\mathrm{TM}}$; Fisher Scientific), 2ng/ml basic fibroblast growth factor (bFGF, Corning ${ }^{\mathrm{TM}}$; Fisher Scientific) and $82 \mu \mathrm{g} / \mathrm{ml}$ ascorbic acid 2 phosphate (AA2P, Sigma-Aldrich). Subsequently, these tubes were placed in a rotisserie (Labquake ${ }^{\mathrm{TM}}$ Rotisserie Hybridization Rotators, Thermo scientific, USA) at 8 RPM inside a cell and tissue culture incubator. Media was changed every two days and the BMSC-seeded scaffolds were cultured under rotisserie culture for a total timeframe of 8 days.

\subsubsection{Tissue Engineering Experiments}

Beyond the first 8 days of rotisserie culture, samples were randomly assigned to one of four different treatment groups and underwent an additional period of tissue culture for 14 days. These groups were ( $\mathrm{n}=12$ specimens/group): 1) No flow (Static Controls), 2) Steady flow-alone (Flow), 3) Specimen cyclic Flexure-alone (Flex) and 4) combination of steady flow and specimen cyclic flexure (Flex-Flow). For the mechanical conditioned groups, a custom built U-shape bioreactor which been previously described extensively was used [105]. This device is connected to a peristaltic pump and an environmentally sealed linear actuator for experimental purposes. The experimental set-up consisted of four identical conditioning chambers, 
with each chamber containing 3 samples. Specimens were fixed with a pin one end while the other side was to a circular moving post. For Flex and Flex-Flow experiments, the moving post was moved linearly in the axial direction to initiate specimen cyclic flexure using the linear actuator (frequency of $1 \mathrm{~Hz}$ ). For the Flow and Flex-Flow cases, a peristaltic pump (Master flex L/S, model\#7523-80, Cole Parmer, model\#7535-04, East Bunker Court Vernon Hills, IL, USA) was used to maintain a continuous flow rate of $850 \mathrm{ml} / \mathrm{min}$.

a)

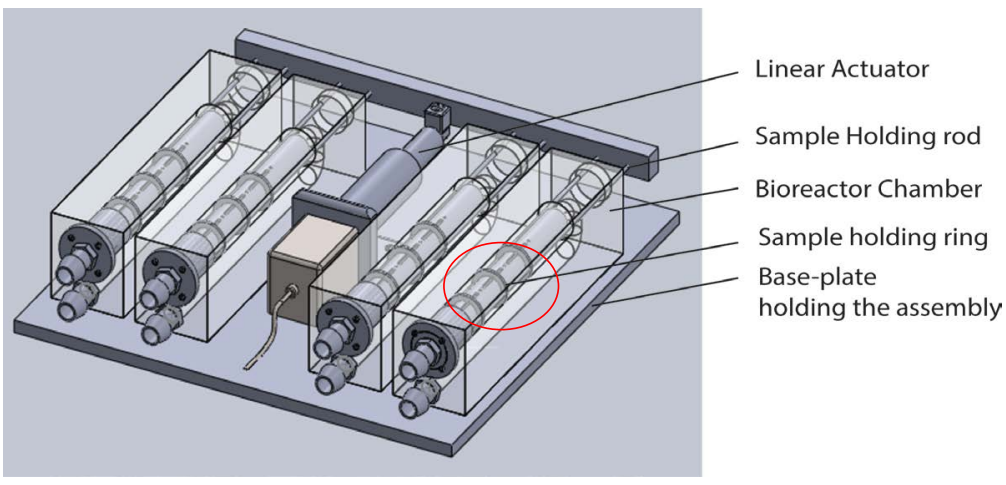

b)

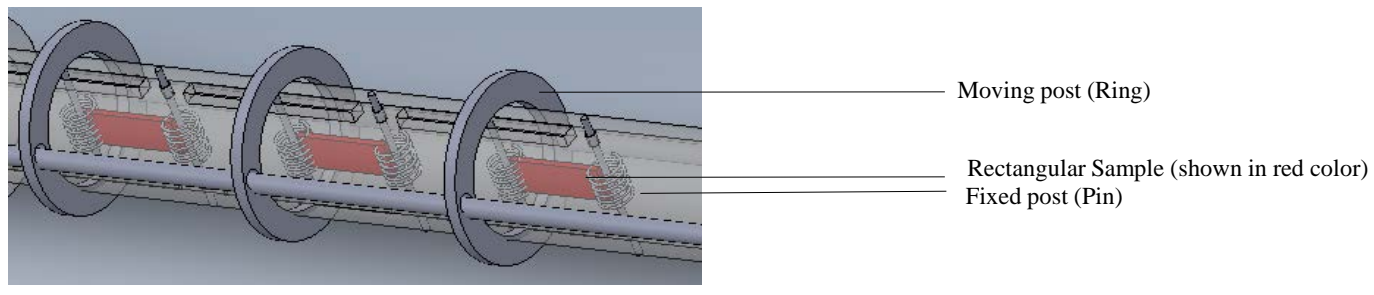

Figure 4.1: a) Schematic diagram of the custom built U-shaped bioreactor connected to a linear actuator which guides the rods that threads through samples, permitting them to bend and straighten. b) Inset: shows three samples inside the conditioning chamber that can be moved one end (ring) and is fixed on the other (pin). In the current study, the actuator was set to a $1 \mathrm{~Hz}$ frequency to permit cyclic flexure while the pump operated at a steady flow rate of $850 \mathrm{ml} / \mathrm{min}$. 


\subsubsection{Collagen Assay}

Specimens from all four groups were removed following 22 days ( $\mathrm{n}=3$ per group) and subjected to collagen biochemical assays (Biocolor life science assays, Carrickfergus, County Antrim, UK). Digested collagen samples were quantified similar to methods described previousl [74]. Samples were digested with a solution of $0.5 \mathrm{M}$ acetic acid (Sigma) and pepsin (1 mg/ml Pepsin (P7000), Sigma). Digestions were carried out for 16 hrs on a rocker (Orbitron Rotator; Boekel Scientific, Feasterville, PA) at $4^{0} \mathrm{C}$. Collagen extracts were then assayed according to the in vitro tissue procedure provided by Sircol soluble collagen assay kit (Biocolor Ltd.). A multimode microplate reader was (Synergy HT, Biotek instrument, Inc,\#7091000) set to an absorbance of $555 \mathrm{~nm}$ to obtain the collagen concentration.

\subsubsection{Quantitative real time polymerase chain reaction}

After 22 days of tissue culture nascent tissues from the four groups were evaluated for gene expression and quantification. Quantitative real time-polymerase chain reaction (QRT-PCR) was performed as previously described [139], [140], [82], [141] . Engineered tissues were washed with DPBS and total RNA was isolated according to manufacturers protocol. Briefly, $1 \mathrm{ml}$ of lysis buffer was added to $30 \mathrm{mg}$ of tissue was flash frozen and homogenized with a homogenizer at high speed till no visible tissue fragments remained in the mixture. A volume of $175 \mu \mathrm{l}$ of tissue lysate was transferred to a $1.5 \mathrm{ml}$ micro-centrifuge tube. The pellet was shifted to a $1.5 \mathrm{ml}$ RNase-free micro-centrifuge tube to perform the RNA isolation. Total RNA was purified with the SV Total RNA Isolation System (Promega). $1 \mu \mathrm{g}$ of total RNA was used for reverse transcription reaction and the cDNA was synthesized using an oligo (dT) 15 primer provided by GoScript TM Reverse tran- 
scription system (Promega). QRT-PCR was performed using GoTaqqPCR Master Mix (Promega). Signal intensities were detected with a Step-One Real-Time PCR System (Applied Biosystems). The PCR mixture contained forward and reverse primers and SYBR green I dye reagent along with the cDNA obtained from reverse transcription. The primers and genes were selected from the referred sources and all primers were purchased (Sigma Aldrich). Primer sequences (Table 1) for YARS, NP, and klf2a genes were obtained from a quantitative real time PCR primer database (http://primerdepot.nci.nih.gov/) to amplify the target sequence. Briefly, the conditions used for the experiment were as follows: PCR tubes (Applied Biosystems, Grand Island, NY) were held at $95^{\circ} \mathrm{C}$ for 2 min before the cycle started to activate the Taq polymerase. The cycling parameters were $95^{0} \mathrm{C}$ for $5 \mathrm{sec} ; 60^{0} \mathrm{C}$ for $45 \mathrm{sec}$; $95^{\circ} \mathrm{C}$ for $15 \mathrm{sec}$. The change in threshold cycle $(\Delta \mathrm{Ct})$ values were averaged and normalized with GAPDH, an endogenous gene using the $\Delta \Delta \mathrm{Ct}$ method described in the reagent guide (Applied Biosystems) [142]. Expression of gene fold changes were calculated as $2^{-\Delta \mathrm{Ct}}$, and gene expression ratio of four groups (Control, Flow, Flex and Flex-Flow)) was compared for further analysis.

\subsection{Immunostaining}

Immunofluorescence (IF) staining of CD31 and $\alpha$-SMA cell surface proteins were performed ( $\mathrm{n}=3$ specimens/group) after 22 days for evidence of endothelial and myofibroblastic phenotypes respectively. This study focused on two valve relevant proteins such as cluster of differentiation 31 (CD 31) and alpha- smooth muscle actin ( $\alpha$-SMA). CD31 is known to be expressed on the surface of EC and $\alpha$-SMA in SMC as well as myofibroblast like cells in valve interstitial cells. Each sample was sectioned along the tissue and three different layers i.e. top surface layer, deep middle 
Table 4.1: Primer sequences utilized for QRT-PCR analyses in this study

\begin{tabular}{lll}
\hline \multirow{2}{*}{ Gene ID } & Gene Name & $\begin{array}{l}\text { F:Forward Primer }\left(5^{\prime}-3^{\prime}\right) \\
\text { R:Reverse Primer }\left(5^{\prime}-3^{\prime}\right)\end{array}$ \\
\hline \multirow{2}{*}{ GAPDH } & Gglyceraldehyde-3 & F:AATGAAGGGGTCATTGATGG \\
& -phosphate dehydrogenase[32] & R:AAGGTGAAGGTCGGAGTCAA \\
YARS & Ttyrosyl-tRNA & F:CCTCCAAATTGGGCATCTAC \\
& synthetase[34] & R: GGAGCTGAGGTGGTAAAGCA \\
FZD2 & Frizzled class & F:CGGCCCCGCAGCGCCCTGCCC \\
& receptor 2 [32,35] & R:ACACGAACCCAGGA \\
& & GGACGCAGGCC \\
MLC1F & Myosin light & F:GAGTTCTCTAAGGAACAGCAGG \\
& & R:CTGCGTGTCTTTGACAA \\
& Kruppel-like & GGAAGGCAATGG \\
klf2a & factor 2a[11] & F:CCGTGTGCTTTCGGTAGTG \\
& & R:AAGAGTTCGCATCTGAAGGC \\
\hline
\end{tabular}

core layer and bottom surface layer were immunostained with anti $\alpha$-SMA and anti CD31 and evaluated for SMC and EC expression. A porcine aortic heart valve was dissected and assigned as positive control. The valve leaflets were immunostained for EC and SMC expression following the same protocol.

Tissue sections at room temperature were washed with DPBS and fixed with $10 \%$ formalin overnight, with a 20:1 volume fraction. After fixation, $2 \mathrm{~mm}$ by $2 \mathrm{~mm}$ tissue sections were cut with the help of a pair of scissors and embedded in the tissue freezing medium (Catalog \# :19636-4, Polysciences, Warrington, PA). To retain structure, tissues were incubated with the liquid freezing medium at room temperature in a petri dish for 2 hrs. Next, the liquid freezing medium was also separately added to plastic molds (Fisher Scientific) and frozen in liquid nitrogen temperature. A white solid bed of the freezing medium was obtained after $\sim 1$ minute. At this point, the prepared tissue section was carefully placed on the frozen solid bed inside the mold and more freezing medium was added to immerse the sample. The mold was subsequently snap-frozen in liquid nitrogen. Finally, serial 
sections (12 m thickness) parallel to the tissue surface were cut using a cryostat microtome (Leica CM3050 S, Buffalo Grove, IL, United States). The following staining procedure was followed: tissue sections mounted on the glass slides were treated with $0.1 \%$ Triton $\mathrm{X}-100$ for 3 to 5 minutes to enhance the permeability of the cell cytoplasm (this step was excluded for CD31 staining). Additional washing steps were performed three times for 5-10 minutes with DPBS. Blocking of nonspecific epitopes was facilitated by adding $1 \%$ goat serum in DPBS for 30 minutes. The primary antibodies used were mouse monoclonal anti-CD31 (ab24590, Abcam, Cambridge, MA, USA) and mouse monoclonal anti $\alpha$-SMA (ab18147, abcam, Cambridge, MA, USA). An overnight incubation at $4^{\circ} \mathrm{C}$ was done. Samples were washed with wash buffer (DPBS+ 0.01\% Triton-X 100) to reduce background. Secondary antibody (Goat polyclonal anti-mouse IgG (H+L) (DyLight 488) (Fisher Scientific) with $1 \%$ goat serum) was added and incubated overnight at $4^{\circ} \mathrm{C}$ for both CD31 and $\alpha$-SMA immunostaining. Glass slides with stained sections were viewed under a fluorescent microscope (Olympus BX51, Center Valley, PA). For CD31, a depth of $92 \pm 10.58 \mathrm{~m}$ from the top of the surface was considered as the top layer, a depth of $76 \pm 4 \mu \mathrm{m}$ from the bottom surface was considered as the bottom layer, and a $264 \pm 18.33 \mu \mathrm{m}$ to $652 \pm 17.43 \mu \mathrm{m}$ depth from the top surface was considered as the deep middle core layer. Similarly, for $\alpha$-SMA, a depth of $140 \pm 17.43 \mu \mathrm{m}$ from the top surface was considered as the top layer, a depth of $\sim 108 \pm 12 \mu \mathrm{m}$ from the bottom surface was considered as the bottom layer, and a depth of $336 \pm 13.85 \mu \mathrm{m}$ to $464 \pm 21.16 \mu \mathrm{m}$ from the top surface was considered as the deep middle core layer. 


\subsubsection{Computational Fluid Dynamics (CFD)}

In order to quantify the fluid-induced stresses imparted on the bioreactor specimens, we conducted CFD simulations. For the cases of flex-flow and cyclic flexure alone, we incorporated moving boundary analyses; specifics on the CFD approaches are described in detail in our previous work [97]. The four cases of flow-alone, cyclic flexure-alone, combined flow and flexure, and no flow were simulated. We used an inlet velocity boundary condition $0.1067 \mathrm{~m} / \mathrm{s}$ for the cases of flex-flow and steady flow-alone, which represented the experimentally prescribed flow rate of 850 $\mathrm{ml} / \mathrm{min}$. No slip conditions were prescribed to the bioreactor walls, while the walls the samples were set equal to the velocity of the grid for the flex-flow and cyclic flexure-alone. The outlet of the bioreactor was set to a zero relative-pressure boundary condition. All simulations were run utilizing a Newtonian, viscous model, with laminar flow conditions, with the following fluid material properties: density = $1.01 \mathrm{~g} / \mathrm{cm}^{3}$ and dynamic viscosity $=1.27 \mathrm{cp}$ (CFx, Ansys Inc., Canonsburg, PA).

The results were analyzed after a convergence criterion of $1 \times 10^{-9}$ set for each of the momentum, continuity, and mesh displacement equations was satisfied. All simulations were conducted in a Hewlett Packard work station with intel(R) Xeon(R) CPU, x5550@ 2.67GHz (2 processors), with 16.0 GB installed memory and 64-bit Windows 7 operating system.

In order to denote the coupled effects of shear stress magnitude and the temporal oscillations in the flow, we utilized an oscillatory shear index (OSI)-scaled shear stress magnitude (OSI- $\mid\{\vec{\tau} \mid)$ which we previously defined as: [97]. OSI- $\mid\{\vec{\tau} \mid=$ $2 \times$ OSI $\times$ TSSM. Where TSSM is the time-averaged shear stress magnitude. The OSI [97] itself is defined by: 


$$
\mathrm{OSI}=\frac{1}{2}\left(1-\frac{\operatorname{abs}\left(\int_{0}^{\mathrm{T}} \tau \mathrm{dt}\right)}{\int_{0}^{\mathrm{T}} \operatorname{abs}(\tau) \mathrm{dt}}\right.
$$

Where, $\mid\{\vec{\tau} \mid$ is the fluid-induced shear stress, $\mathrm{T}$ is the period and $\mathrm{t}$ is time. The OSI ranges from 0 to 0.5 ; an OSI of 0 represents unidirectional flow while an OSI of 0.5 signifies a high degree of temporal oscillations in the flow.

\subsubsection{Statistical Analysis}

One way analysis of variance was conducted to test any significant differences between the four groups investigated for collagen production and gene expression outcomes ( $\mathrm{n}=3$ samples/group/outcome) . A Tukeys post hoc test was subsequently performed to determine significant differences between groups. All statistical analyses were conducted using the statistical package for the social science (SPSS) software (V16, IBM, Armonk, NY). Significant differences between groups were observed to have occurred at a significance level of $\mathrm{p}<0.05$.

\subsection{Results}

\subsubsection{Collagen Production}

The average collagen production in static group was found to be $40.91 \pm 4.23$ (no flow, no flexure), 93.2912.6 (flow-alone), 69.752 .68 (cyclic flexure-alone), 207.38 \pm 36.61 (flex-flow) $\mu \mathrm{g} / \mathrm{g}$ wet weight. (Fig. 2). Collagen content of the flex-flow group was found to be significantly higher $(\mathrm{p}<0.05)$ compared to the other three groups. There was no significant difference found among static, flow only and flex only groups. This observation is in well agreement with previous findings [10]. For comparison, the 
collagen content of porcine aortic valve leaflets were evaluated ( $\mathrm{n}=3$ leaflets) and found to be $2141.17 \pm 491.56 \mu \mathrm{mg} / \mathrm{g}$ wet weight.

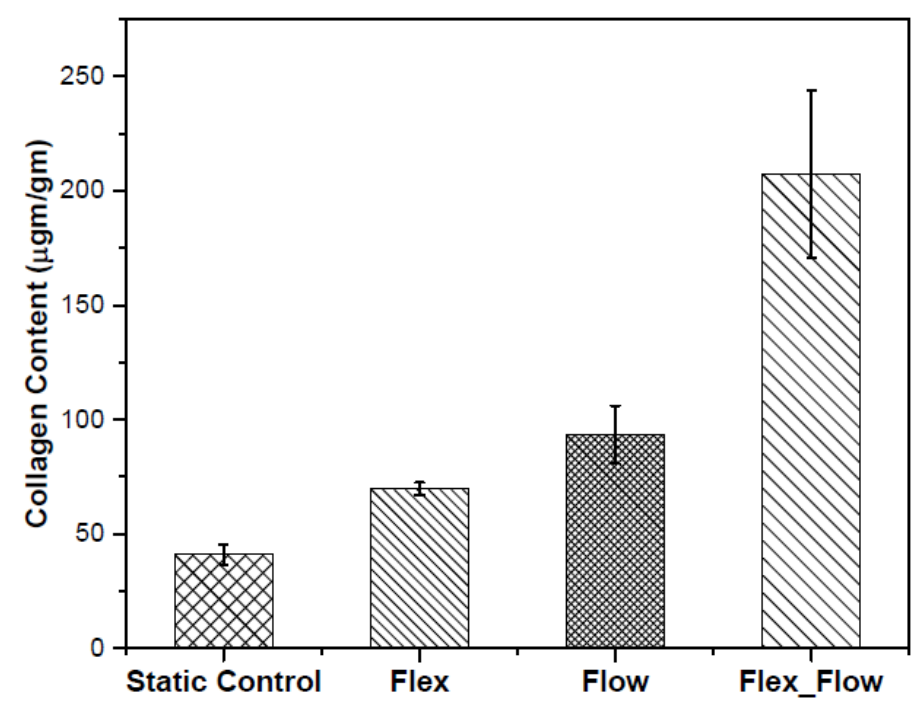

Figure 4.2: Collagen content in specimens derived from each group investigated. The Flex-Flow group produced significantly $(\mathrm{p}<0.05)$ higher collagen compared to all other groups

\subsubsection{Gene expression}

The highest level of expression for both FZD2 and YARS markers, for cardiovascular SMC (when MLC1f is not expressed) and valvular-EC related genes respectively, were observed in RNA extracted from the flex-flow group in which the samples were exposed to combined cyclic flexure $(1 \mathrm{~Hz})$ and flow $(850 \mathrm{ml} / \mathrm{min})$ conditions in the bioreactor (Fig. 3); note that MLC1f was only significantly expressed in the no flow control group $(\mathrm{P}<0.05)$ The Klf2a, transcription factor, critical for valvulogenesis in valve development was also expressed significantly $(\mathrm{p}<0.05)$ in the flex-flow case in comparison to the other groups investigated (no flow control, flow-alone, cyclic flexure-alone). 
1

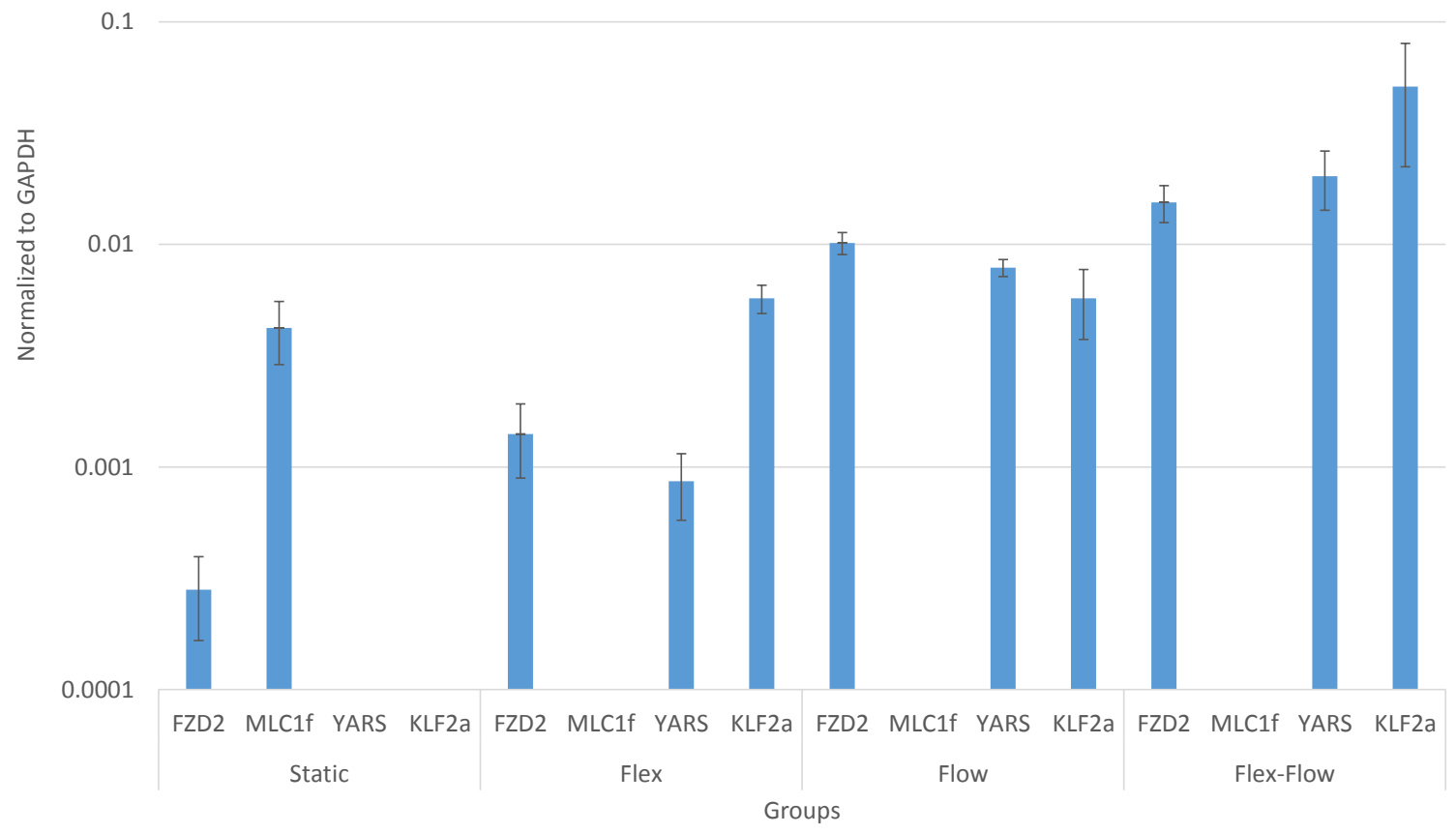

Figure 4.3: Gene expression of BMSC-derived engineered valvular tissues. The four groups investigated were: Static Controls, Flow $(850 \mathrm{ml} / \mathrm{min})$, Flex $(1 \mathrm{~Hz})$ and Flex-Flow (Simultaneous application of $850 \mathrm{ml} / \mathrm{min}$ flow rate and $1 \mathrm{~Hz}$ frequency for cyclic bending of specimens). A flow rate of $850 \mathrm{ml} / \mathrm{min}$ for cell culture media circulating through the bioreactor conditioning chambers permitted physiologicallyrelevant 4 fluid-induced mean shear stresses of 2.91 dyne $/ \mathrm{cm}^{2}$ and $4.73 \mathrm{dynes} / \mathrm{cm}^{2}$ on the inner and outer specimen walls respectively. 


\section{Immunostaining}

It was found that only in the flex-flow group alone, $\alpha$-SMA was significantly expressed in the intermediate core layer compared to surfaces of the valve leaflets (Fig. 5). On the other hand, yet again only in the flex-flow group, the endothelial marker protein CD31 was abundant in the surface layers (both the top and bottom) compared to the intermediate core region of the specimens (Fig. 5). All other groups produced either no expression (Static, Flexure only) or random distribution (Flow only) of CD31 and $\alpha$-SMA.

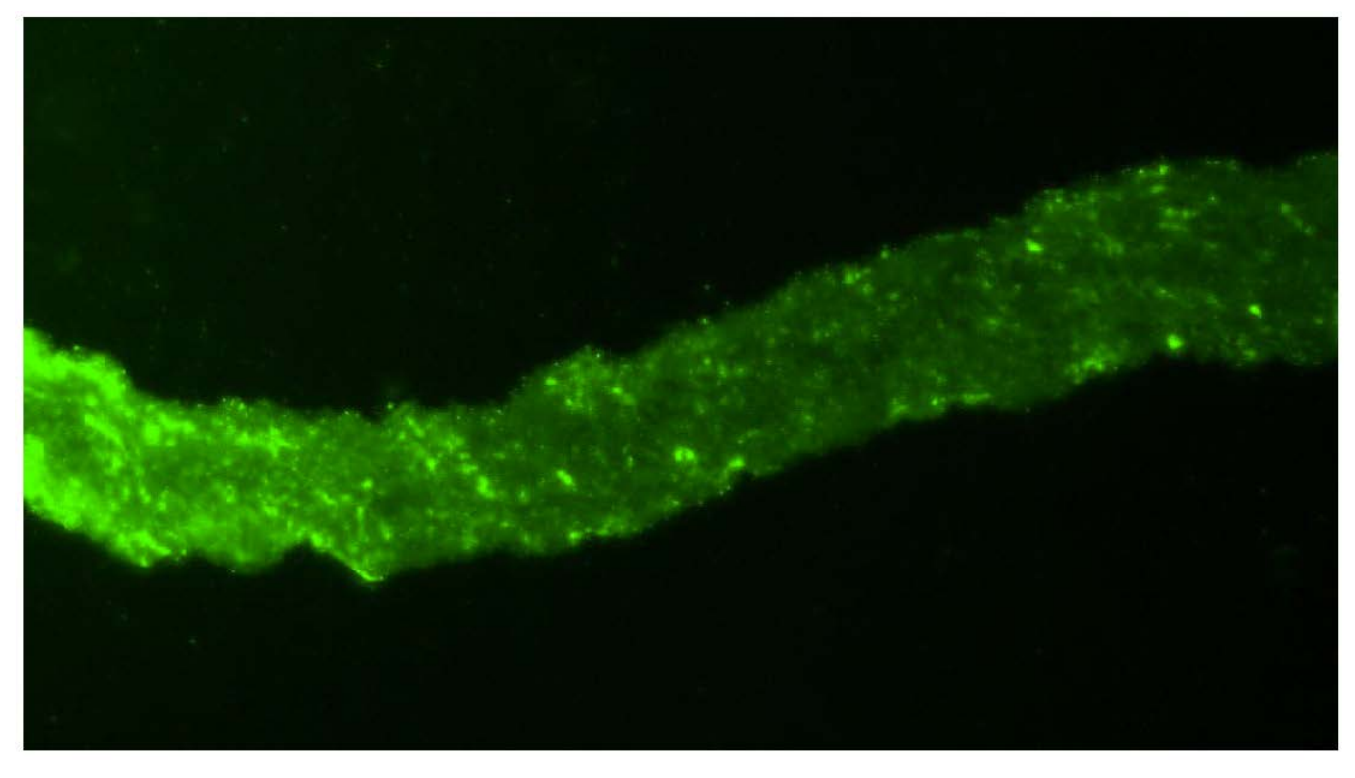

Figure 4.4: Immunofluorescence staining of porcine heart valve shows non-specific binding. Only secondary antibody, no primary antibody, PBS was used as blocking buffer. 


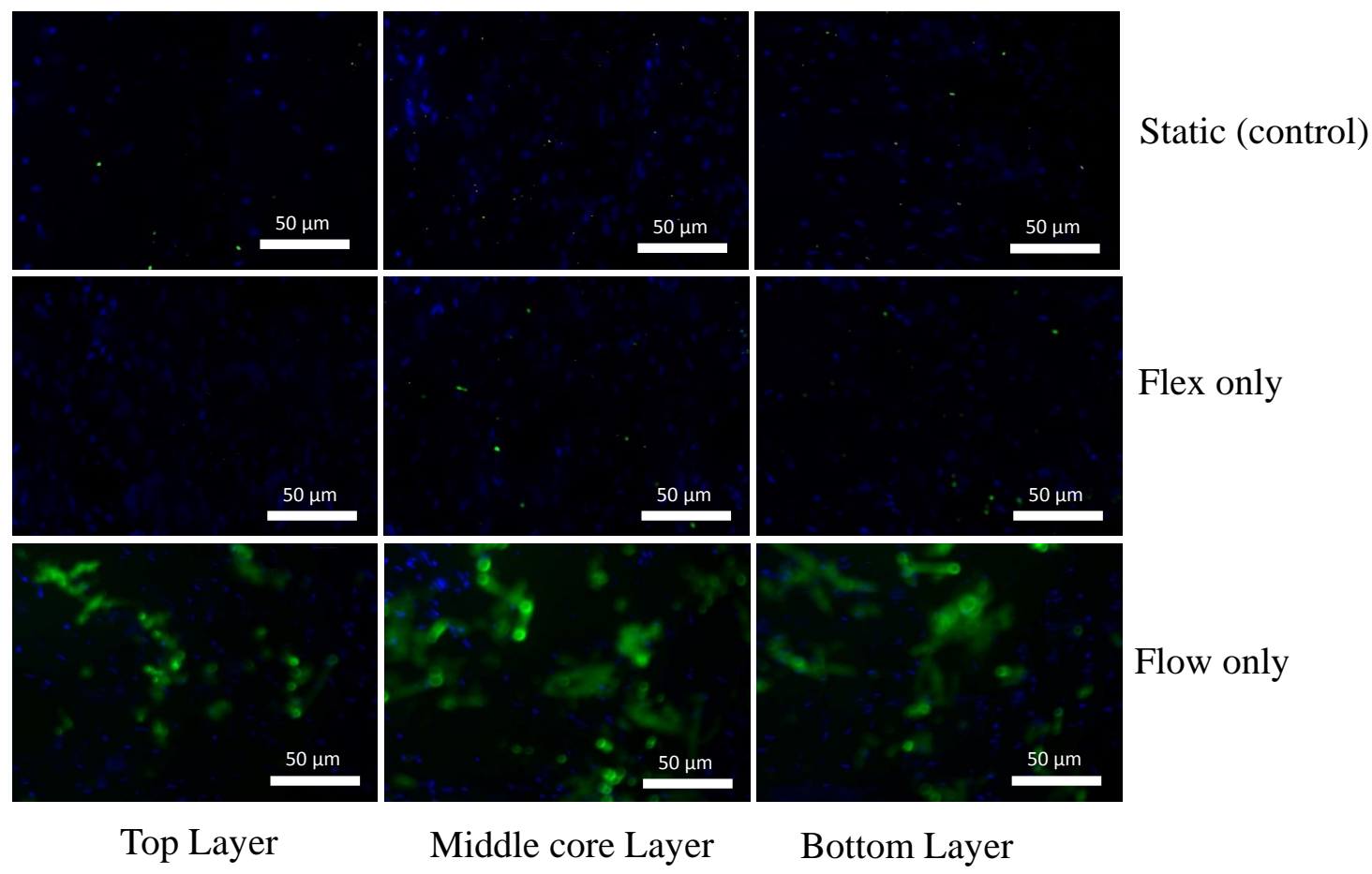

Figure 4.5: Immunofluorescence staining of $\alpha$-SMA protein on both surface layers ( $\sim 90 \mathrm{~m}$ thickness on each side), middle core (interstitial tissue) regions $(\sim 400 \mathrm{~m}$ thickness) of the valve; 1st row: Static Controls; 2nd row: Flex; 3rd row: Flow; 4th row: Flex-Flow conditioning; 5th row: porcine heart valve as Positive control. Among the experimental groups, $\alpha$-SMA-expressing cells were found to be predominant within the interstitial region (middle layer) of the engineered tissues in solely the Flex-Flow group(continue to next page) 

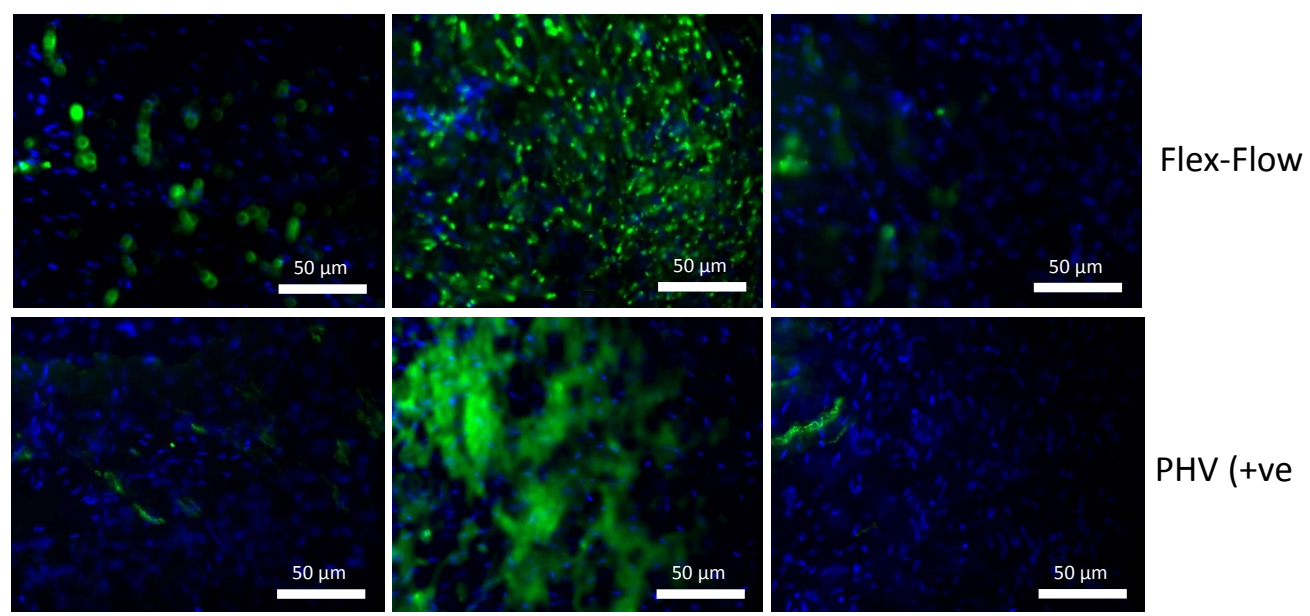

Top Layer

Middle core Layer

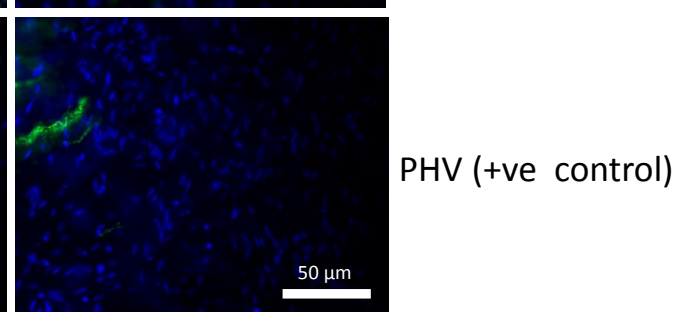

Bottom Layer

Figure 4.6: Immunofluorescence staining of $\alpha$-SMA protein on both surface layers $(\sim 90 \mu \mathrm{m}$ thickness on each side), middle core (interstitial tissue) regions $(\sim 400$ $\mu \mathrm{mm}$ thickness) of the valve; 1st row: Static Controls; 2nd row: Flex; 3rd row: Flow; 4th row: Flex-Flow conditioning; 5th row: porcine heart valve as Positive control. Among the experimental groups, $\alpha$-SMA-expressing cells were found to be predominant within the interstitial region (middle layer) of the engineered tissues in solely the Flex-Flow group(continued from previous page) 

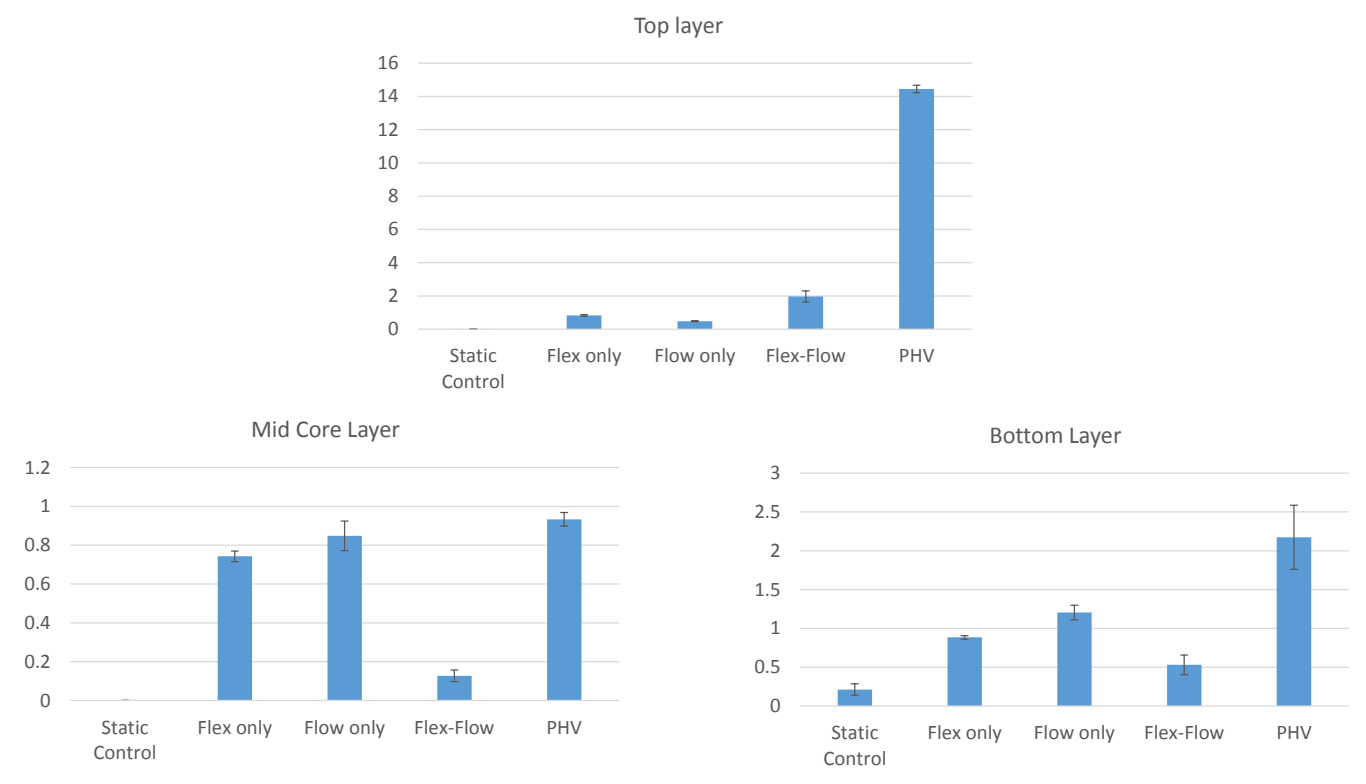

Figure 4.7: $\alpha$-SMA expression in static control, flex only, flow only, flex-flow and PHV (+ve control) in three different layers, such as: top, mid core and bottom of the tissue sample.

\section{Computational Results}

The fluid-induced, time averaged shear stress magnitudes (TSSM) were plotted on the inner and outer surfaces for all the simulation cases (Fig.4.8). The inner wall TSSM values were 0 dyne $/ \mathrm{cm}^{2}, 1.98 \pm 0.37$ dyne $/ \mathrm{cm} 2,0.1 \pm 0.005$ dyne $/ \mathrm{cm}^{2}$, and $2.91 \pm 0.11$ dyne $/ \mathrm{cm}^{2}$ for cases of static control, steady flow-alone, cyclic flexurealone and flex-flow. The outer wall TSSM values were 0 dyne $/ \mathrm{cm}^{2}, 2.43 \pm 0.06$ dyne $/ \mathrm{cm}^{2}, 0.1 \pm 0.003$ dyne $/ \mathrm{cm}^{2}$, and $4.73 \pm 0.09$ dyne $/ \mathrm{cm}^{2}$ for cases of control, steady flow-alone, cyclic flexure-alone and flex-flow.

The OSI distribution was found to be much higher when exposed to cyclic flexure-alone, relative to flex-flow conditions. The area averaged OSI on the specimens inner walls $(\mathrm{n}=3)$ was $0.433 \pm 0.015$ and $0.117 \pm 0.003$ for cyclic flexure-alone and flex-flow cases, respectively, while the corresponding values for the outer wall 


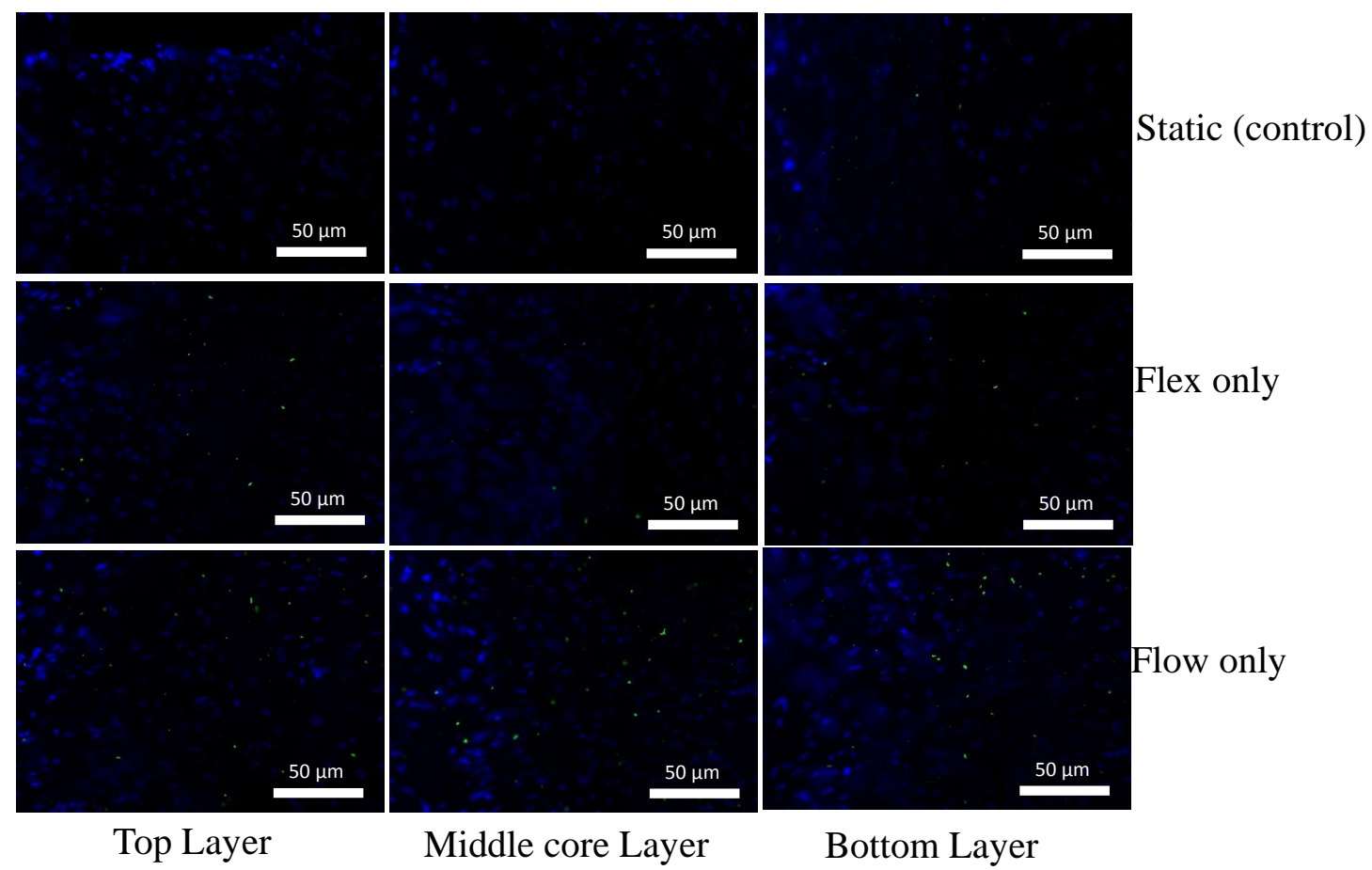

Figure 4.8: Immunofluorescence staining of CD31, an EC marker, on both surface layers $(\sim 90 \mathrm{~mm}$ thickness on each side), middle core sections $(\sim 400 \mathrm{~mm}$ thickness) of the valve tissue; 1st row: Static Controls; 2nd row: Flex; 3rd row: Flow; 4th row: Flex-Flow conditioning; 5th row: porcine heart valve as Positive control. Among the experimental groups, CD31-expressing cells were visible within the superficial layers (top and bottom layers) of the engineered tissues, in solely the flex-flow group.(continue to next page) 

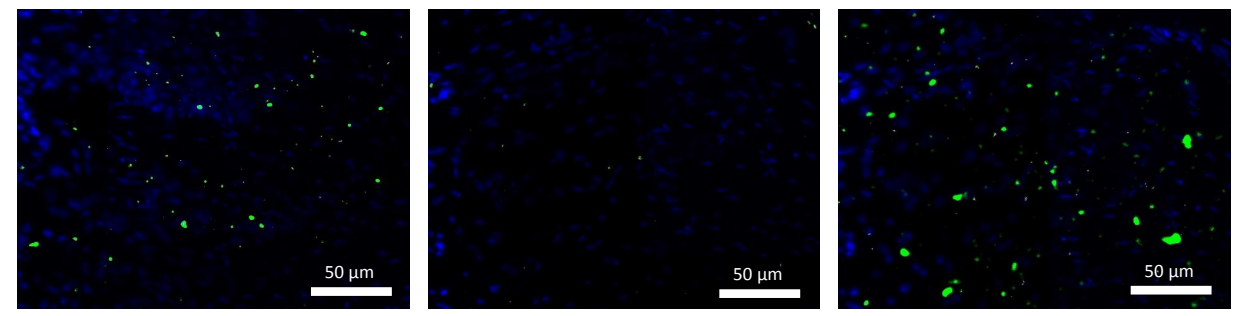

Flex-Flow

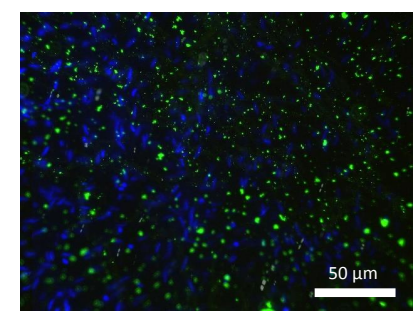

Top Layer

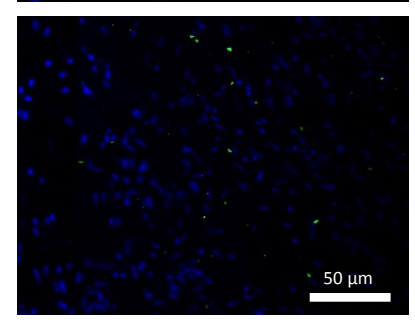

Middle core Layer

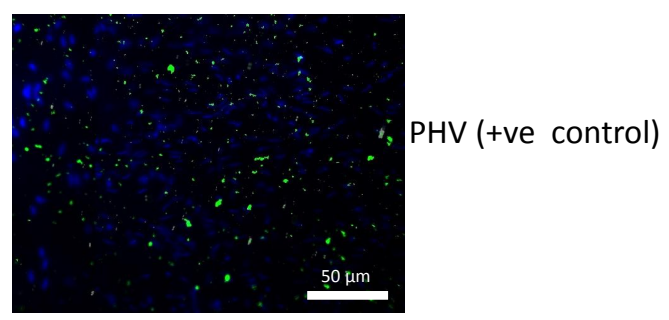

Bottom Layer

Figure 4.9: Immunofluorescence staining of CD31, an EC marker, on both surface layers $(\sim 90 \mathrm{~mm}$ thickness on each side), middle core sections $(\sim 400 \mathrm{~mm}$ thickness) of the valve tissue; 1st row: Static Controls; 2nd row: Flex; 3rd row: Flow; 4th row: Flex-Flow conditioning; 5th row: porcine heart valve as Positive control. Among the experimental groups, CD31-expressing cells were visible within the superficial layers (top and bottom layers) of the engineered tissues, in solely the flex-flow group.(continued from previous page) 

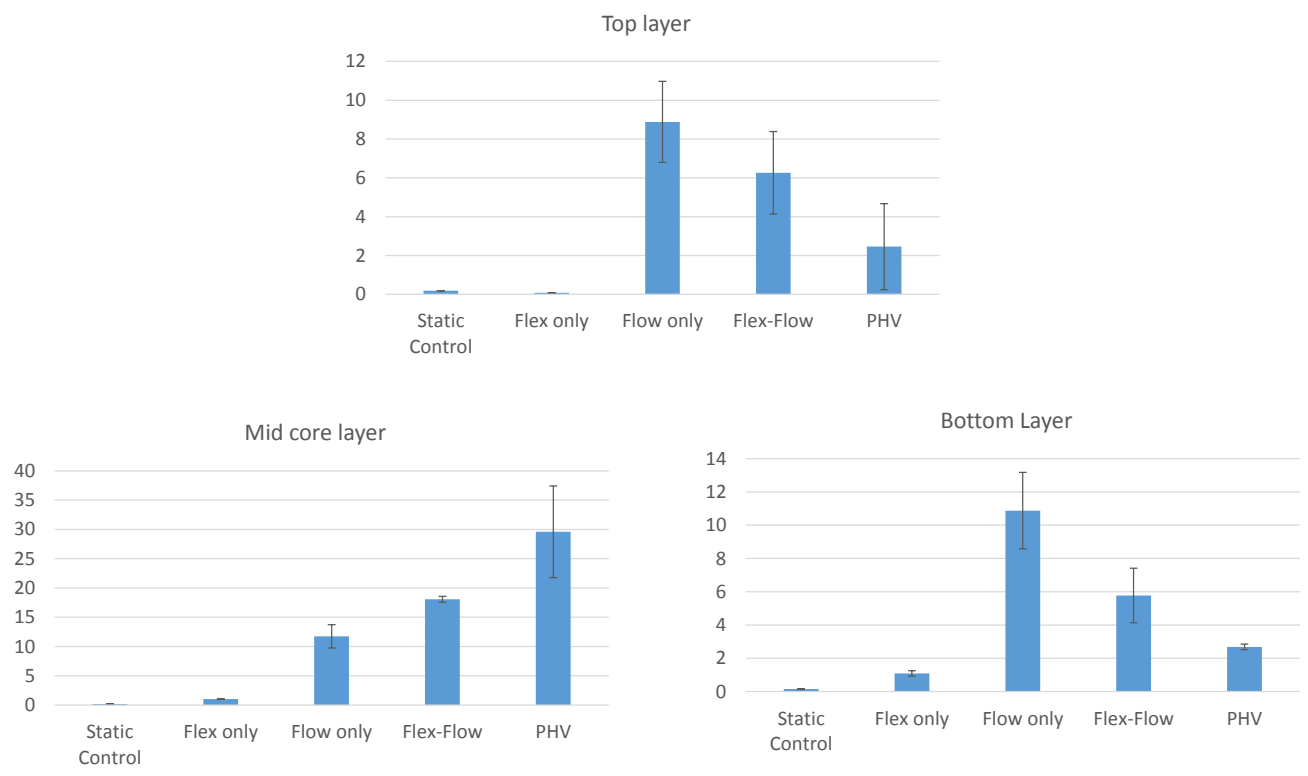

Figure 4.10: CD31 expression in static control, flex only, flow only, flex-flow and PHV (+ve control) in three different layers, such as: top, mid core and bottom of the tissue sample.

$(\mathrm{n}=3)$ were found to be $0.313 \pm 0.011$ and $0.094 \pm 0.10$. The area averaged OSI- $\mid\{\vec{\tau} \mid$ metric was determined to quantify the extent of coupled shear stress magnitude and temporal oscillations in the experiments performed. Over the specimen area (sample size $\mathrm{n}=3$ /group), the area averaged OSI- $\mid\{\vec{\tau} \mid$ for the inner walls were $0.1 \pm$ 0.05 dyne $/ \mathrm{cm}^{2}$ (cyclic flexure-alone) and $0.41 \pm 0.11$ dyne $/ \mathrm{cm}^{2}$ (flex-flow), while for the outer walls, it was $0.16 \pm 0.03 \mathrm{dyne} / \mathrm{cm}^{2}$ (cyclic flexure-alone) and 0.270 .16 dyne $/ \mathrm{cm}^{2}$ (flex-flow) (Fig. 4.9).Note that OSI- $\mid\{\vec{\tau} \mid=0$ in the event that flow is temporally unidirectional or if fluid-induced shear stresses are negligible, which was the case in the steady flow-alone and no flow, respectively. 


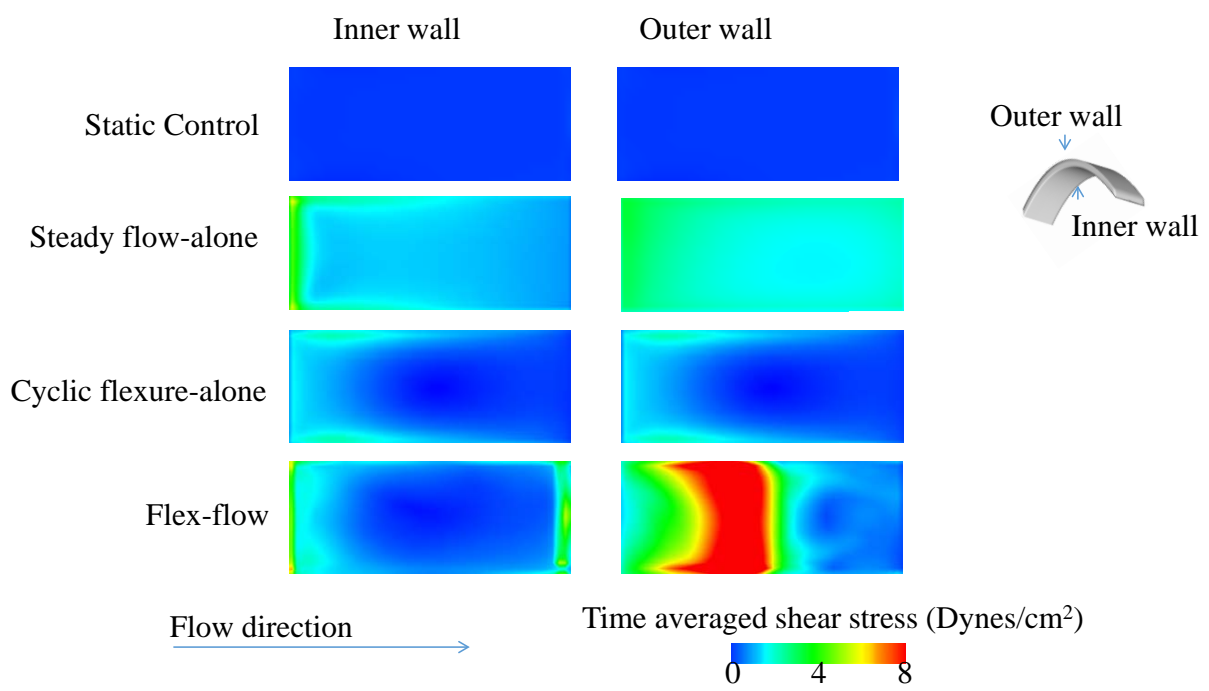

Figure 4.11: Fluid-induced, time-averaged shear stresses over one cycle on specimen inner and outer walls for the following four cases: i) Static Controls, ii) Flow, iii) Flexure iv) Flex-Flow states. In comparing the two dynamic cases (iii) versus (iv), the flex-flow state displayed much higher shear stress values.

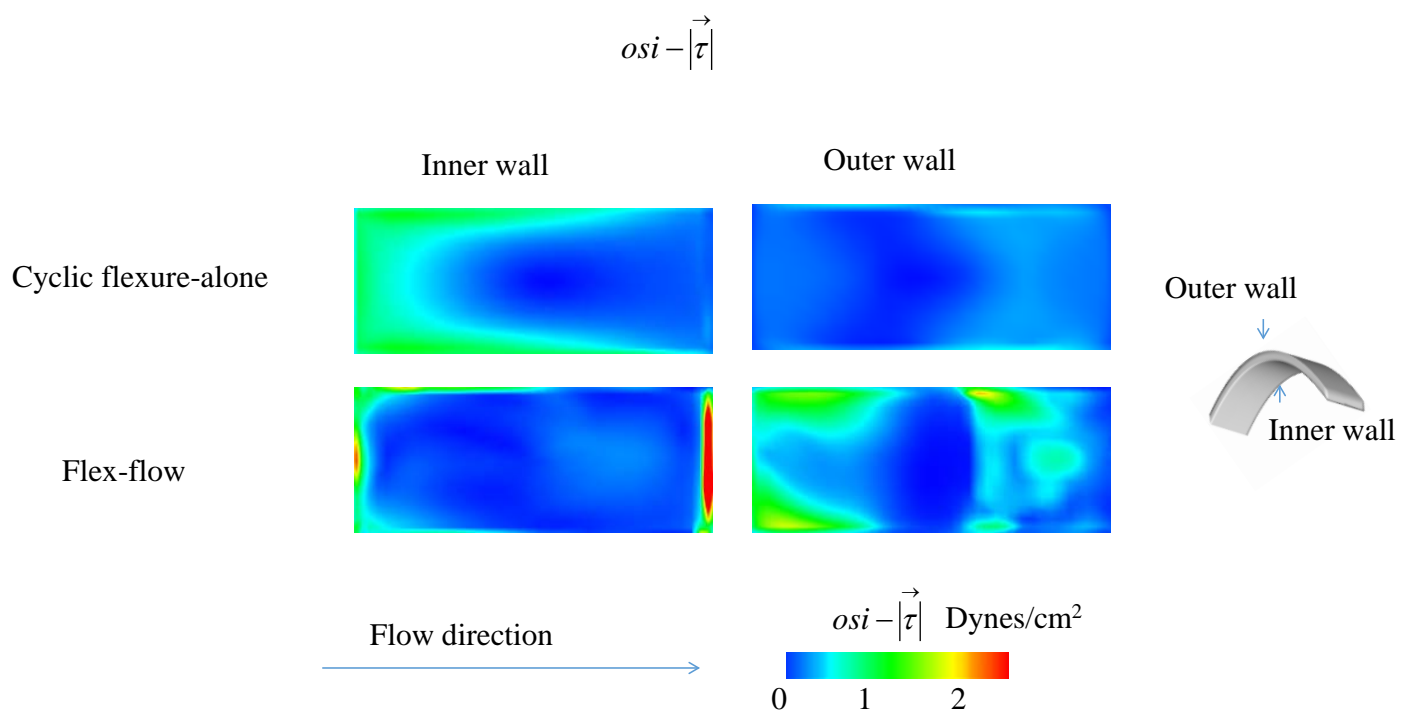

Figure 4.12: OSI-scaled shear stress magnitude (OSI- $\tau)$ on the inner and outer specimen surface for the dynamic Flex and Flex-Flow cases. 


\subsection{Discussion}

Functional replacement of anomalous heart valves, particularly in the case of pediatric critical valve disease, is in dire need of suitable treatment approaches; the primary limitation is that currently available replacement devices do not offer provision for somatic growth. For this reason, the notion of autologous and living biological heart valve substitutes is very appealing. Several studies have demonstrated that the process of developing robust engineered valvular tissues necessitates a dynamic culture process, wherein mechanical stresses, such as flow, flexure and stretch, are imparted onto the growing constructs [10], [136], [69], [127], [74], [143]. These stress states are particularly relevant because valve leaflets experience highly varied and leaflet side-dependent, fluid-induced shear stress distributions, as well as localized cyclic tissue stretching and flexure during the cardiac cycle. In the aortic valve for example, the ventricular-side of the leaflet experiences significantly higher fluidinduced shear stresses compared to the arterial-side. Some in vitro investigations have been able to recapitulate important features of this hemodynamic environment using bioreactors to grow de novo valvular tissues [74], [105], [97]. However, the specific effects of in vitro mechanical conditioning on cell distribution and phenotype within the construct remain unclear. These attributes could support the integration of engineered to native tissues, and thus could play a critical role in guiding subsequent valve remodeling events in vivo. Moreover, the importance of maintaining a physiological range of conditioning parameters (e.g. fluid-induced shear stress) has also not been sufficiently addressed [144], [132]. . On the other hand, the utility of stem cells, such as BMSCs, has been explored in several heart valve tissue engineering approaches to date, which have demonstrated robust tissue growth under mechanical-stimulated environments [10], [69], [74]. Thus, in an attempt to iden- 
tify the effects of valve-relevant stress environments on stem cell phenotype, as well as the implications of physiological scales of mechanical conditioning, here we subjected BMSC-seeded scaffolds to individual and combined modes of fluid shear and flexural stress states, which are both highly relevant to valvular tissues.

We found a significant $(\mathrm{p}<0.05)$ increase in the BMSC-derived collagen content in the flex-flow group relative to the other groups, whereas no significant differences were found among the Static Control, Flex and Flow groups (Fig. 2). Our observation was consistent with previous findings (Engelmayr et al.) [10] who conducted Flex-Flow studies under sub-physiological levels of shear stress (average wall shear stress $\left.=1.15 \mathrm{dynes} / \mathrm{cm}^{2}\right)[?]$ combined with physiological levels of cyclic flexure (1Hz, which corresponds to a heart rate of 60 beats/minute). However, we attempted to recapitulate the regionally varying and side-specific nature of fluid-induced, shear stress distribution of native aortic valves on our engineered tissue specimens. Indeed, previous work [74] has demonstrated that the inner and outer walls of our specimens are analogous to the aortic and ventricular-side of the leaflets. Here, under flex-flow states, the TSSM on the outer wall was 4.73 dynes $/ \mathrm{cm}^{2}$, while along the inner wall, the shear stress was found to be $2.91 \mathrm{dyne} / \mathrm{cm}^{2}$. The ventricular side of the native human aortic valve is exposed to a TSSM in the order of $\sim 3.87$ dynes $/ \mathrm{cm}^{2}[110]$ and thus, the shear stresses determined for the flex-flow specimens in this study are physiologically relevant. In comparing our studies to those conducted at sub-physiologic shear stress levels and thus, the shear stresses determined for the flex-flow specimens in this study are physiologically relevant. In comparing our studies to those conducted at sub-physiologic shear stress levels [10], [?], we found an additional increase in collagen production by $70 \%$, i.e., when the specimen shear stress magnitudes and distribution were regionally similar to native aortic valve leaflets. We note that an earlier study22 demonstrated the importance of physiological scales of conditioning 
by way of mimicking arterial pressure conditions in vitro, which ultimately resulted in $\sim 35 \%$ increase in collagen content compared to sub-physiological flow environments. We speculate that the differences were more pronounced in our case as a direct result of cell regulatory mechanisms that are known to be initiated by fluidinduced shear stresses [145], [118], [146], [147], [148], [149] and which we believe to also be applicable to differentiating BMSCs.

We found that flex-flow conditioning significantly augmented $(\mathrm{p} ; 0.05)$ the klf2a gene compared to all other groups (Fig.4.3). In native valve development, the absence of klf2a leads to substantial valve malformations and is directly modulated by oscillatory fluid-induced shear stresses [96]. Interestingly, we were able to demonstrate that the upregulated expression of Klf2a by stem cells rather than endogenous valvular cells, specifically BMSCs, is also possible when subjected to flex-flow conditions. Our previous work showed that OSS are enhanced under flex-flow conditions and hence are likely to have elicited cellular upregulation of Klf2a.

In investigation of the valvular endothelial cell marker YARS, we found a significantly higher expression $(\mathrm{p}<0.05)$ once again, in only the flex-flow group, compared to the other groups (Fig. 4.3). This result demonstrates the mediation of mesenchymal to endothelial differentiations pathways, primarily via physiological levels of fluid-induced shear stresses, which can be further enhanced by oscillations in the flow field.

When making collective comparisons of Klf2a and YARS markers observed in the flex-flow group relative to corresponding native valve gene expression, we found, not surprisingly, that native valve expression was higher, in the order of $49 \%$ and $70 \%$ respectively. The marked lower density of BMSCs in time-limited, in vitro culture environments is likely to have exhibited truncated gene expression levels compared to gene expression of cells obtained from native valvular tissues. The 
broader argument that needs to be considered however, is that the promotion of the valvular phenotype in vitro, even if it is small, may be critical in the integration of the engineered to native valvular tissues after implantation. From a phenotypic viewpoint, the recognition of the engineered construct by its surrounding in vivo cellular environment is likely to be critical in paracrine cell signaling events, which will serve to ensure guided remodeling of the TEHV and minimize the risk of tissue overgrowth and uncontrolled pannus. Previous studies have already demonstrated the importance of recapitulating the native tri-layer tissue structure in TEHVs in support of robust functionality [31], [9]. Similarly, we speculate that the phenotypic state of BMSC-derived engineered constructs is equally important prior to implantation, which we show here to be directed toward the valvular lineage under flex-flow mechanical conditioning. We note that in addition to the strong expression of the YARS gene, indicative of the valve endothelial cell phenotype, that the specimens in the flex-flow group exhibited robust expression of FZD2 and an absence of MLC1F, suggesting a smooth muscle-like phenotype unique only to the heart valves and the pericardium [150], [140].Thus, we interpret that flex-flow mechanical conditioning during in vitro culture of engineered tissues supports BMSC differentiation in a heterogeneous manner, i.e., by promoting both the valvular endothelial and interstitial cell phenotypes. This finding corroborates our previous computational predictions that associated the simultaneous presence of both OSS and the critical magnitude of shear stress during flex-flow states to synergistically increase collagen content in the engineered [97], which appears to also enhance, as evidenced here, the valve phenotype.

Previous investigations have examined the through-thickness distribution of cells and phenotype in TEHVs [10], [90]. Consistent with flex-flow studies that employed a sub-physiologic range of shear stress conditioning [10] we observed that 
endothelial cellular expression was expressed primarily on the surfaces and was negligible in the interstitial layers (Fig.4.5).We interpret that BMSC to endothelial cell differentiation and intra-scaffold BMSC migration patterns are enhanced under flow states and is not strongly flow magnitude-dependent. Indeed, we previously visualized and monitored the increase in cell scaffold migratory patterns via magnetic resonance imaging, which was found to be augmented under steady flow-alone conditions compared to no flow controls [151]. On the other hand, the link between the mechanical environments and $\alpha$-SMA expressing cells within the de novo valvular tissues is not as straightforward. Engelmayr et al [10] showed robust expression of $\alpha$-SMA-expressing BMSCs preferentially distributed on the surfaces of engineered heart valve tissues, after being subjected to Flex-Flow states with sub-physiological magnitudes of fluid-induced shear stresses. Meanwhile, Hoestrup and colleagues [90] described a consistent distribution of $\alpha$-SMA-expressing BMSCs throughout trileaflet engineered valvular constructs subjected to physiological pressure ranges (30 to $75 \mathrm{mmHg}$ ) in a bioreactor; cell density was in addition the greatest on the surface of the TEHVs, and sparse deep within the tissues. We observed that application of heart valve, physiologically relevant fluid-induced shear stresses (TSSM for, inner wall: 2.91 dyne $/ \mathrm{cm}^{2}$ and outer wall: 4.73 dyne $/ \mathrm{cm}^{2}$ ) served to promote cellularity, particularly, $\alpha$-SMA-expressing BMSCs (Fig. 5). While this occurred under both flow-alone and flex-flow conditions, it was only in the latter group where $\alpha$-SMAexpressing cells were predominant within the interstitial regions of the engineered tissues and were found to be sparse on the superficial layers. On the other hand, as described earlier, CD31-expressing cells indicative of an endothelial phenotype were distributed preferentially on the surfaces of the engineered tissues specimens in only the flex-flow group. Even though the extent of both $\alpha$-SMA and CD31 immunostaining was less pronounced than native valves, as was also evidenced for the valve- 
relevant markers in the gene expression outcomes, it is clear that physiological scales of flex-flow conditioning promote heterogeneous cell distribution in a manner that mimics native valve cellular distribution. We interpret the ability to achieve heterogeneous, valve-relevant, BMSC distribution and differentiation in an in vitro setting to play a critical role in continued tissue remodeling after implantation, including accelerated replication of the native tri-layered valves structure. Such a structure has only been observed in Ovine studies after several weeks (16 32 weeks) [9]following TEHV implantation, and has been limited to solely the replacement of the pulmonary valve rather than the more demanding aortic or mitral positions. Thus, in specific cases of heart valve diseases, such as for example, in the treatment of critical congenital aortic valve stenosis in infants [152], [153], [154], [155], [156], accelerated tissue remodeling may be especially important in order to keep pace with somatic growth.

In summary, physiologically relevant flex-flow states serve to promote cell distribution and phenotype in in vitro grown, BMSC-derived, engineered heart valve tissues.We were able to demonstrate for the first time that the concomitance of OSS and critical levels of shear stress enabled the robust expression of key valvular genes, notably Klf2a and YARs. Note that flex states-alone induce OSS but have negligible shear stress magnitudes and were found to not augment the cellularity and phenotype within the engineered tissues; this is consistent with our previous findings [97]in that both temporal directionality and the magnitude of shear stress is important in eliciting BMSC responses, which we showed here can be achieved experimentally under flex-flow states. In addition, BMSC differentiation and migration within engineered tissues led to surface-lined endothelial-marker expressing cells and interstitium-filled, myofibroblast-marker expressing cells, thereby resembling native valve cellular distribution. We conclude that the in vitro optimization 
of BMSC-derived, engineered heart valve cellular make-up and phenotype is achievable through flex-flow conditions of physiological relevance. This ability to stimulate heterogeneous valvular cellularity and phenotype is likely to be important in guiding subsequent in vivo valve tissue remodeling events and hence, towards ensuring long-term success of the TEHV in pediatric patients. 


\section{CHAPTER 5}

\section{Conclusion,Limitation and Future study}

Tissue engineering is proposed to be the next generation treatment for complex medical conditions. Combination of stem cell therapy, regenerative medicine, 3D printing of living organs are becoming a new generation of treatment approach and gaining success clinically. It is not clear if one single technique or a combination of techniques will dominate the clinical application in next decade; but it is exciting to note that many of the deadly diseases can be probed and treatments can be available for human welfare. In case of heart valve, it is predicted that valve disease will increase three times in next five decades, which pose heavy burden on society, health care and economy [61].

\subsection{Conclusion}

This study presents a novel approach for tissue engineering of heart valve utilizing bone marrow stem cells, polymer scaffolds in vitro. Specifically a guided strategy for stem cell differentiation into valvular cell lineages with an optimal biomechanical and/or biochemical signal were developed. In this study, we focused out investigation on gene expression and protein distribution while being subjected to physio-

logically relevant mechanical conditioning. The physiological parameters were: 4.73 dynes $/ \mathrm{cm}^{2}$ of mean fluid-induced shear stress and $1 \mathrm{~Hz}$ of cyclic flexure. In the 1 st chapter of this dissertation, the motivation behind this study is presented. Current treatments for HV diseases, treatment options and related challenges are mentioned. The unanimous need for an alternate approach was discussed; ultimately, to date, however obtaining a functional TEHV remains a challenge. The following hypothesis was proposed in vitro oscillatory shear stress via flex-flow states regulates human 
bone marrow mesenchymal stem cells to differentiate to heart valve phenotypes. Three specific aims were defined and investigated; I) Apply oscillatory shear stress (OSS) to a two dimensional (2D) bone marrow mesenchymal stem cell (BMSCs) mono-layer to observe the changes in cell entities, such as f- actin and vinculin. F-actin is a cytoskeletal protein, vinculin is a focal adhesion protein and both are known to respond to shear stresses. After a duration of 8 days OSS application, cells will be evaluated for endothelial cell expression by immunofluorescence technique to detect CD31 which is a marker for EC and expressed on EC surface. This investigation demonstrated that OSS can differentiate BMSCs to endothelial cell (EC). II) Apply physiologically relevant heart valve shear stress conditions such as flow and/or flexure to three dimensional (3D) BMSC-seeded polymer scaffolds to study the effects of mechanical regulation on tissue regeneration and associated ECM components such as collagen production. III) Apply heart valve relevant shear stress conditions as in specific aim 2 to 3D BMSC-seeded scaffold to investigate gene and protein expression in engineered tissue.

In the 2nd chapter a critical review of previous studies was presented. Reviews were discussed to understand different viewpoints and proposed methods and developments in a chronological manner. Brief descriptions of current available treatments in the form of mechanical and bioprosthetic heart valves were tabulated. The requirement of TEHV was discussed. Currents status, challenges and future objectives were mentioned in an extensive manner. The possibilities of a new generation treatments were detailed. It is very clear that with the availability of stem cell therapy, synthetic and natural scaffolds and advanced surgical expertise, TEHV is a potential treatment of the future; however caution should be made selecting cell source, scaffold material and implantation techniques. There has been tremendous efforts and improvements made to obtain a suitable functional TEHV; it will 
still take extensive research and developments to accomplish the goal. Various expertise in the field of science, engineering and medicine need to be combined to identify important elements in heart valve developmental biology, chemical requirements, engineered design and ease of implantation to eventually optimize construct functionality.

In the 3rd chapter a study of biochemical and mechanical components were presented. In this study a group of bone marrow mesenchymal stem cells were treated with a low dose nicotine, a chemical component known to induce endothelial differentiation; whereas other group was exposed to oscillatory shear stress, a mechanical stimulant to induce endothelial cell differentiation. The objective of the study was to evaluate if BMSCs were responsive to mechanical stimulation and whether OSS induce endothelial differentiation. This study proposed that, while Nicotine may stimulate an increase in the differentiation of BMSCs to endothelial cells, OSS may play a greater role in cellular distribution, and the eventual creation of a tissue engineered heart valves (TEHV) endothelium [157].

In 4 th chapter, experimental details of a 3D in vitro study for heart valve tissue engineering was discussed. Briefly, BMSCs seeded polymer constructs were recruited in physiological flow, flexure conditions. A custom made FSF bioreactor was deployed to produce physiological flow of $850 \mathrm{ml} / \mathrm{min}$, flexure of $1 \mathrm{~Hz}$ and a combination of both flow and flexure on the tissue samples. After 22 days of conditioning neo tissue was formed and evaluated for heart valve characteristics such as gene expression, protein expression, collagen production and tissue layer formation. Significant collagen was produced in flex-flow group, which is well in agreement with previous pioneer study performed by Engelmayr group [10]. Previous studies have presented encouraging results in direct implantation of natural or synthetic scaffolds with or without cell seeded constructs in vivo; however, these 
valve constructs failed within few years of implant [20], [21]. Compromised mechanical properties, calcification or fibrosis were the cause of failure. In order to create a long term viable construct, biological properties such as gene regulation, protein expression during various stages of valve implant should be addressed. Therefore, our study focused on the effects of various mechanical signaling on tissue regeneration and gene and protein expression. Some promising results obtained from the experiments were presented. It is concluded that an appreciable amount of shear stress magnitude combined with oscillatory shear stress in the physiological range regulates heart valve relevant gene expression and protein organization. Specifically, the mechanical combination of 4.73 dynes $/ \mathrm{cm}^{2}$ steady flow with $1 \mathrm{~Hz}$ cyclic flexure, both within physiological magnitudes promoted heterogeneous BMSC differentiation to valve endothelial and myofibroblast phenotypes. In addition differentiated cells were preferentially distributed spatially, with endothelial cells on the surface while $\alpha$-SMA positive expressing cells were found predominantly deep within the engineered valvular tissues.

\subsection{Limitations}

This study was focused primarily on evaluating physiologic mechanical conditioning parameters for generating valve tissue with characteristic expressions of valve relevant phenotypes. Even though we found some exciting results that provided insight into valvulogenesis of BMSCs in physiological flexure and flow condition, however this study has some limitations.

1) The total sample size for the experiment is 48. Each group has 12 samples. Four diff t outcomes, such as collagen assay to measure ECM production (2), QRT PCR to quantify gene expression [39], [96], [137], immunostaining to locate protein 
distribution [29], [36] and histology to observe the valve tri layer ECM structure [9] were evaluated. Each outcome has a sample size of 3, which limit the power analysis of the experiment. A one way analysis of variance (one way ANOVA) test was performed to find out significant difference in the collagen production and gene expression. A Tukeys post hoc analysis suggests flex-flow group has significant collagen production and two critical valve relevant gene such as klf2a and YARS expression compared to all other groups. In order to get more conclusive results; greater sample size should be considered.

\section{Report}

Collagen
\begin{tabular}{|l|r|r|r|r|}
\hline & Mean & $\mathrm{N}$ & Std. Deviation & $\begin{array}{c}\text { Std. Error of } \\
\text { Mean }\end{array}$ \\
\hline Static & 40.9110 & 3 & 7.33481 & 4.23476 \\
Flex & 69.7493 & 3 & 4.65711 & 2.68879 \\
Flow & 93.2977 & 3 & 21.82732 & 12.60201 \\
FlexFlow & 207.3800 & 3 & 63.42543 & 36.61869 \\
Total & 102.8345 & 12 & 71.98421 & 20.78005 \\
\hline
\end{tabular}

Figure 5.1: A one way analysis of variance (one way ANOVA) test showing significant difference in the collagen production

2) This experiment used a polyglycolic acid (PGA) and poly L lactic acid (PLLA) equal ratio matrix as the base to regenerate the valve tissue. Even if this polymer is widely used in tissue engineering experiments, it is not suitable for valve regeneration. The valve mechanical properties are not compatible with this polymers strength and flexibility. Therefore, a suitable biodegradable scaffold should be identified. In order to mimic the physiological condition, the engineered valve tissue should ideally be oriented perpendicular to the flow direction. In this study 
ANOVA

Collagen

\begin{tabular}{|l|r|r|r|r|r|}
\hline & $\begin{array}{c}\text { Sum of } \\
\text { Squares }\end{array}$ & df & Mean Square & F & Sig. \\
\hline Between Groups & 47849.583 & 3 & 15949.861 & 13.946 & .002 \\
Within Groups & 9149.410 & 8 & 1143.676 & & \\
Total & 56998.993 & 11 & & & \\
\hline
\end{tabular}

Figure 5.2: Result of Anova analysis

\section{Post Hoc Tests}

\section{Multiple Comparisons}

Dependent Variable: Collagen

Tukey HSD

\begin{tabular}{|ll|c|c|r|r|r|}
\hline & & \multicolumn{2}{|c|}{$\begin{array}{c}\text { Mean } \\
\text { Difference }(\mathrm{I}-\end{array}$} & & & \multicolumn{2}{|c|}{$95 \%$ Confidence Interval } \\
\cline { 6 - 7 } (I) Groups & (J) Groups & J) & Std. Error & Sig. & Lower Bound & Upper Bound \\
\hline Static & Flex & -28.83833 & 27.61251 & .730 & -117.2633 & 59.5867 \\
& Flow & -52.38667 & 27.61251 & .301 & -140.8117 & 36.0383 \\
& FlexFlow & $-166.46900^{*}$ & 27.61251 & .001 & -254.8940 & -78.0440 \\
\hline Flex & Static & 28.83833 & 27.61251 & .730 & -59.5867 & 117.2633 \\
& Flow & -23.54833 & 27.61251 & .828 & -111.9733 & 64.8767 \\
& FlexFlow & $-137.63067^{*}$ & 27.61251 & .005 & -226.0557 & -49.2057 \\
\hline Flow & Static & 52.38667 & 27.61251 & .301 & -36.0383 & 140.8117 \\
& Flex & 23.54833 & 27.61251 & .828 & -64.8767 & 111.9733 \\
& FlexFlow & $-114.08233^{*}$ & 27.61251 & .014 & -202.5073 & -25.6573 \\
\hline FlexFlow & Static & $166.46900^{*}$ & 27.61251 & .001 & 78.0440 & 254.8940 \\
& Flex & $137.63067^{*}$ & 27.61251 & .005 & 49.2057 & 226.0557 \\
& Flow & $114.08233^{*}$ & 27.61251 & .014 & 25.6573 & 202.5073 \\
\hline
\end{tabular}

*. The mean difference is significant at the 0.05 level.

Figure 5.3: Analysis of variance 
all our samples were positioned parallel to the flow direction, which was intrinsic to bioreactor design.

3) Most of the valve regeneration study fails after few years of implantation due to compromised biological or mechanical properties. So animal model for in vivo studies should be performed as the next step in this research, wherein the engineered tissues grown in this study be investigated for valve repair or replacement purposes.

\section{$5.3 \quad$ Future Study}

More in vitro study is required to obtain statistical significance of the presented results. In vivo animal study in Ovine or Sheep model should be performed. Currently, we have obtained some natural tissue matrix derived from porcine small intestine submucosa (SIS), which shows promising results in vascular graft, pericardium repair; however, valve application of this material is not yet evaluated. Therefore, a similar in vitro study using SIS should be designed to evaluate the gene expression and protein distribution in detail. 


\section{BIBLIOGRAPHY}

[1] Lloyd-Jones D, Adams RJ, Brown TM, Carnethon M, Dai S, De Simone G, et al. Heart disease and stroke statistics-2010 update: a report from the American Heart Association [Journal Article]. Circulation. 2010;121(7):e46$\mathrm{e} 215$.

[2] Nkomo VT, Gardin JM, Skelton TN, Gottdiener JS, Scott CG, EnriquezSarano M. Burden of valvular heart diseases: a population-based study [Journal Article]. The Lancet. 2006;368(9540):1005-1011.

[3] Pibarot P, Dumesnil JG. Prosthetic heart valves selection of the optimal prosthesis and long-term management [Journal Article]. Circulation. 2009;119(7):1034-1048.

[4] Minino AM, Murphy SL, Xu J, Kochanek KD. Deaths: final data for 2008 [Journal Article]. National vital statistics reports: from the Centers for Disease Control and Prevention, National Center for Health Statistics, National Vital Statistics System. 2011;59(10):1-126.

[5] Cannegieter SC, Rosendaal FR, Briet E. Thromboembolic and bleeding complications in patients with mechanical heart valve prostheses [Journal Article]. Circulation. 1994;89(2):635-41. Cannegieter, S C Rosendaal, F R Briet, E Journal Article Review United states Circulation. 1994 Feb;89(2):635-41.

[6] Schoen FJ, Levy RJ. Tissue heart valves: current challenges and future research perspectives [Journal Article]. Journal of biomedical materials research. 1999;47(4):439-465.

[7] Bettinger CJ, Weinberg EJ, Kulig KM, Vacanti JP, Wang Y, Borenstein JT, et al. Three dimensional Microfluidic TissueEngineering Scaffolds Using a Flexible Biodegradable Polymer [Journal Article]. Advanced Materials. 2006;18(2):165-169.

[8] Barrett DG, Yousaf MN. Thermosets synthesized by thermal polyesterification for tissue engineering applications [Journal Article]. Soft Matter. 2010;6(20):5026-5036.

[9] Sutherland FW, Perry TE, Yu Y, Sherwood MC, Rabkin E, Masuda Y, et al. From stem cells to viable autologous semilunar heart valve [Journal Article]. Circulation. 2005;111(21):2783-2791. 
[10] Engelmayr J G C, Sales VL, Mayer J J E, Sacks MS. Cyclic flexure and laminar flow synergistically accelerate mesenchymal stem cell-mediated engineered tissue formation: Implications for engineered heart valve tissues [Journal Article]. Biomaterials. 2006;27(36):6083-95.

[11] Chester AH, Taylor PM. Molecular and functional characteristics of heartvalve interstitial cells [Journal Article]. Philosophical Transactions of the Royal Society B: Biological Sciences. 2007;362(1484):1437-1443.

[12] Iaizzo PA. Handbook of cardiac anatomy, physiology, and devices. Springer; 2009.

[13] Robb JS, Robb RC. The normal heart: anatomy and physiology of the structural units [Journal Article]. American Heart Journal. 1942;23(4):455-467.

[14] Fox SI. Human physiology. McGraw-Hill Higher Education; 2008.

[15] Sacks MS, David Merryman W, Schmidt DE. On the biomechanics of heart valve function [Journal Article]. Journal of Biomechanics. 2009;42(12):18041824.

[16] Vesely I. Heart valve tissue engineering [Journal Article]. Circ Res. $2005 ; 97(8): 743-55$.

[17] Marchand MA, Aupart MR, Norton R, Goldsmith IR, Pelletier LC, Pellerin $\mathrm{M}$, et al. Fifteen-year experience with the mitral Carpentier-Edwards PERIMOUNT pericardial bioprosthesis [Journal Article]. The Annals of thoracic surgery. 2001;71(5):S236-S239.

[18] Biglioli P, Spampinato N, Cannata A, Musumeci A, Parolari A, Gagliardi $\mathrm{C}$, et al. Long-term outcomes of the Carpentier-Edwards pericardial valve prosthesis in the aortic position: effect of patient age [Journal Article]. Journal of heart valve disease. 2004;13:S49-S51.

[19] Melina G, De Robertis F, Amrani M, Khaghani A, Yacoub M. Mid-term pattern of survival, hemodynamic performance and rate of complications after medtronic freestyle versus homograft full aortic root replacement: results from a prospective randomized trial [Journal Article]. Journal of Heart Valve Disease. 2004;13(6):972-976.

[20] Hammermeister K, Sethi GK, Henderson WG, Grover FL, Oprian C, Rahimtoola SH. Outcomes 15 years after valve replacement with a mechanical 
versus a bioprosthetic valve: final report of the Veterans Affairs randomized trial [Journal Article]. Journal of the American College of Cardiology. 2000;36(4):1152-1158.

[21] Jamieson W, Von Lipinski O, Miyagishima R, Burr L, Janusz M, Ling H, et al. Performance of bioprostheses and mechanical prostheses assessed by composites of valve-related complications to 15 years after mitral valve replacement [Journal Article]. The Journal of thoracic and cardiovascular surgery. 2005;129(6):1301-1308.

[22] Schoen FJ, Levy RJ. Pathology of substitute heart valves: new concepts and developments [Journal Article]. Journal of cardiac surgery. 1994;9(s2):222-227.

[23] Shinoka T, Breuer CK, Tanel RE, Zund G, Miura T, Ma PX, et al. Tissue engineering heart valves: valve leaflet replacement study in a lamb model [Journal Article]. Ann Thorac Surg. 1995;60(6 Suppl):S513-6.

[24] Lloyd-Jones D, Adams R, Carnethon M, De Simone G, Ferguson TB, Flegal $\mathrm{K}$, et al. Heart disease and stroke statistics update a report from the American Heart Association Statistics Committee and Stroke Statistics Subcommittee [Journal Article]. Circulation. 2009;119(3):e21-e181.

[25] Fiane A, Lindberg H, Saatvedt K, Svennevig J. Mechanical valve replacement in congenital heart disease [Journal Article]. The Journal of heart valve disease. 1996;5(3):337-342.

[26] Kirklin J, Smith D, Novick W, Naftel D, Kirklin J, Pacifico A, et al. Longterm function of cryopreserved aortic homografts. A ten-year study [Journal Article]. The Journal of thoracic and cardiovascular surgery. 1993;106(1):15465; discussion165-6.

[27] McIntire LV. World technology panel report on tissue engineering [Journal Article]. Annals of biomedical engineering. 2002;30(10):1216-1220.

[28] Srivastava D, Olson EN. A genetic blueprint for cardiac development [Journal Article]. Nature. 2000;407(6801):221-226.

[29] Armstrong EJ, Bischoff J. Heart valve development endothelial cell signaling and differentiation [Journal Article]. Circulation research. 2004;95(5):459-470. 
[30] Mendelson K, Schoen FJ. Heart valve tissue engineering: concepts, approaches, progress, and challenges [Journal Article]. Annals of biomedical engineering. 2006;34(12):1799-1819.

[31] Aikawa E, Whittaker P, Farber M, Mendelson K, Padera RF, Aikawa M, et al. Human Semilunar Cardiac Valve Remodeling by Activated Cells From Fetus to Adult Implications for Postnatal Adaptation, Pathology, and Tissue Engineering [Journal Article]. Circulation. 2006;113(10):1344-1352.

[32] Rabkin E, Aikawa M, Stone JR, Fukumoto Y, Libby P, Schoen FJ. Activated interstitial myofibroblasts express catabolic enzymes and mediate matrix remodeling in myxomatous heart valves [Journal Article]. Circulation. 2001;104(21):2525-2532.

[33] Rabkin E, Hoerstrup S, Aikawa M, Mayer Jr J, Schoen F. Evolution of cell phenotype and extracellular matrix in tissue-engineered heart valves during in-vitro maturation and in-vivo remodeling [Journal Article]. The Journal of heart valve disease. 2002;11(3):308-14; discussion 314.

[34] Rabkin-Aikawa E, Farber M, Aikawa M, Schoen FJ. Dynamic and reversible changes of interstitial cell phenotype during remodeling of cardiac valves [Journal Article]. The Journal of heart valve disease. 2004;(13):841-7.

[35] Yacoub MH, Cohn LH. Novel approaches to cardiac valve repair from structure to function: Part I [Journal Article]. Circulation. 2004;109(8):942-950.

[36] Merryman WD, Engelmayr Jr GC, Liao J, Sacks MS. Defining biomechanical endpoints for tissue engineered heart valve leaflets from native leaflet properties [Journal Article]. Progress in Pediatric cardiology. 2006;21(2):153-160.

[37] Davies PF, Passerini AG, Simmons CA. Aortic Valve Turning Over a New Leaf (let) in Endothelial Phenotypic Heterogeneity [Journal Article]. Arteriosclerosis, thrombosis, and vascular biology. 2004;24(8):1331-1333.

[38] Butcher JT, Penrod AM, GarcÃa AJ, Nerem RM. Unique morphology and focal adhesion development of valvular endothelial cells in static and fluid flow environments [Journal Article]. Arteriosclerosis, thrombosis, and vascular biology. 2004;24(8):1429-1434.

[39] Butcher JT, Tressel S, Johnson T, Turner D, Sorescu G, Jo H, et al. Transcriptional profiles of valvular and vascular endothelial cells reveal phenotypic 
differences: influence of shear stress [Journal Article]. Arterioscler Thromb Vasc Biol. 2006;26(1):69-77.

[40] Simmons CA, Grant GR, Manduchi E, Davies PF. Spatial heterogeneity of endothelial phenotypes correlates with side-specific vulnerability to calcification in normal porcine aortic valves [Journal Article]. Circulation research. 2005;96(7):792-799.

[41] Taylor PM, Batten P, Brand NJ, Thomas PS, Yacoub MH. The cardiac valve interstitial cell [Journal Article]. The international journal of biochemistry \& cell biology. 2003;35(2):113-118.

[42] Merryman WD, Liao J, Parekh A, Candiello JE, Lin H, Sacks MS. Differences in tissue-remodeling potential of aortic and pulmonary heart valve interstitial cells [Journal Article]. Tissue engineering. 2007;13(9):2281-2289.

[43] Merryman WD, Lukoff HD, Long RA, Engelmayr Jr GC, Hopkins RA, Sacks MS. Synergistic effects of cyclic tension and transforming growth factor- $\hat{I}^{2} 1$ on the aortic valve myofibroblast [Journal Article]. Cardiovascular Pathology. 2007;16(5):268-276.

[44] Shelton JC, Bader DL, Lee DA. Mechanical conditioning influences the metabolic response of cell-seeded constructs [Journal Article]. Cells Tissues Organs. 2003;175(3):140-150.

[45] van der Meulen MC, Huiskes R. Why mechanobiology?: A survey article [Journal Article]. Journal of Biomechanics. 2002;35(4):401-414.

[46] Sarkadi B, Parker JC. Activation of ion transport pathways by changes in cell volume [Journal Article]. Biochimica et Biophysica Acta (BBA)-Reviews on Biomembranes. 1991;1071(4):407-427.

[47] Fu J, Wang YK, Yang MT, Desai RA, Yu X, Liu Z, et al. Mechanical regulation of cell function with geometrically modulated elastomeric substrates [Journal Article]. Nature methods. 2010;7(9):733-736.

[48] Mol A, Bouten C, Baaijens F, Znd G, Turina MI, Hoerstrup SP. Tissue engineering of semilunar heart valves: current status and future developments [Journal Article]. J Heart Valve Dis. 2004;13(2):272-80.

[49] Leyh RG, Wilhelmi M, Walles T, Kallenbach K, Rebe P, Oberbeck A, et al. Acellularized porcine heart valve scaffolds for heart valve tissue engineer- 
ing and the risk of cross-species transmission of porcine endogenous retrovirus [Journal Article]. The Journal of thoracic and cardiovascular surgery. 2003;126(4):1000-1004.

[50] Lichtenberg A, Cebotari S, Tudorache I, Hilfiker A, Haverich A. In: Biological scaffolds for heart valve tissue engineering. Springer; 2007. p. 309-317.

[51] Steinhoff G, Stock U, Karim N, Mertsching H, Timke A, Meliss RR, et al. Tissue engineering of pulmonary heart valves on allogenic acellular matrix conduits: in vivo restoration of valve tissue [Journal Article]. Circulation. 2000;102(19 Suppl 3):Iii50-5.

[52] Kim SS, Lim SH, Hong YS, Cho SW, Ryu JH, Chang BC, et al. Tissue Engineering of Heart Valves In Vivo Using Bone Marrow derived Cells [Journal Article]. Artificial organs. 2006;30(7):554-557.

[53] Simon P, Kasimir MT, Seebacher G, Weigel G, Ullrich R, Salzer-Muhar U, et al. Early failure of the tissue engineered porcine heart valve SYNERGRAFT in pediatric patients [Journal Article]. European Journal of Cardio-Thoracic Surgery. 2003;23(6):1002-1006.

[54] Erdbragger W, Konertz W, Dohmen PM, Posner S, Ellerbrok H, Brodde OE, et al. Decellularized xenogenic heart valves reveal remodeling and growth potential in vivo [Journal Article]. Tissue engineering. 2006;12(8):2059-2068.

[55] Goldstein S, Clarke DR, Walsh SP, Black KS, O Brien MF. Transpecies heart valve transplant: advanced studies of a bioengineered xeno-autograft [Journal Article]. The Annals of thoracic surgery. 2000;70(6):1962-1969.

[56] Elkins RC, Goldstein S, Hewitt CW, Walsh SP, Dawson P, Ollerenshaw J, et al. Recellularization of heart valve grafts by a process of adaptive remodeling. In: Seminars in thoracic and cardiovascular surgery. vol. 13. WB SAUNDERS CO;. p. 87-92.

[57] Leyh RG, Wilhelmi M, Rebe P, Fischer S, Kofidis T, Haverich A, et al. In vivo repopulation of xenogeneic and allogeneic acellular valve matrix conduits in the pulmonary circulation [Journal Article]. The Annals of thoracic surgery. 2003;75(5):1457-1463.

[58] Takagi K, Fukunaga S, Nishi A, Shojima T, Yoshikawa K, Hori H, et al. In vivo recellularization of plain decellularized xenografts with specific cell char- 
acterization in the systemic circulation: histological and immunohistochemical study [Journal Article]. Artificial organs. 2006;30(4):233-241.

[59] Kim WG, Huh JH. Time related histopathologic changes of acellularized xenogenic pulmonary valved conduits [Journal Article]. ASAIO journal. 2004;50(6):601-605.

[60] Posnerb LRRVS, Konertza W. Is there a possibility for a glutaraldehyde-free porcine heart valve to grow? [Journal Article]. Eur Surg Res. 2006;38:54-61.

[61] Mol A, Smits AI, Bouten CV, Baaijens FP. Tissue engineering of heart valves: advances and current challenges [Journal Article]. 2009;.

[62] Dohmen PM, Hauptmann S, Terytze A, Konertz WF. In-vivo repopularization of a tissue-engineered heart valve in a human subject [Journal Article]. JOURNAL OF HEART VALVE DISEASE. 2007;16(4):447.

[63] Zilla P, Bezuidenhout D, Human P. Prosthetic vascular grafts: wrong models, wrong questions and no healing [Journal Article]. Biomaterials. 2007;28(34):5009-5027.

[64] Miller DV, Edwards WD, Zehr KJ. Endothelial and smooth muscle cell populations in a decellularized cryopreserved aortic homograft (SynerGraft) 2 years after implantation [Journal Article]. The Journal of thoracic and cardiovascular surgery. 2006;132(1):175-176. e1.

[65] Niklason L, Gao J, Abbott W, Hirschi K, Houser S, Marini R, et al. Functional arteries grown in vitro [Journal Article]. Science. 1999;284(5413):489-493.

[66] Seliktar D, Black RA, Vito RP, Nerem RM. Dynamic mechanical conditioning of collagen-gel blood vessel constructs induces remodeling in vitro [Journal Article]. Annals of biomedical engineering. 2000;28(4):351-362.

[67] Sodian R, Lemke T, Loebe M, Hoerstrup SP, Potapov EV, Hausmann H, et al. New pulsatile bioreactor for fabrication of tissue engineered patches [Journal Article]. Journal of biomedical materials research. 2001;58(4):401-405.

[68] Zeltinger J, Landeen LK, Alexander HG, Kidd ID, Sibanda B. Development and characterization of tissue-engineered aortic valves [Journal Article]. Tissue engineering. 2001;7(1):9-22. 
[69] Hoerstrup SP, Sodian R, Daebritz S, Wang J, Bacha EA, Martin DP, et al. Functional living trileaflet heart valves grown in vitro [Journal Article]. Circulation. 2000;102(suppl 3):Iii-44-Iii-49.

[70] Jockenhoevel S, Zund G, Hoerstrup SP, Schnell A, Turina M. Cardiovascular tissue engineering: a new laminar flow chamber for in vitro improvement of mechanical tissue properties [Journal Article]. ASAIO journal. 2002;48(1):811.

[71] Engelmayr Jr GC, Rabkin E, Sutherland FW, Schoen FJ, Mayer Jr JE, Sacks MS. The independent role of cyclic flexure in the early in vitro development of an engineered heart valve tissue [Journal Article]. Biomaterials. 2005;26(2):175-187.

[72] Engelmayr Jr GC, Hildebrand DK, Sutherland FW, Mayer Jr JE, Sacks MS. A novel bioreactor for the dynamic flexural stimulation of tissue engineered heart valve biomaterials [Journal Article]. Biomaterials. 2003;24(14):2523-2532.

[73] Balguid A, Rubbens MP, Mol A, Bank RA, Bogers AJ, Van Kats JP, et al. The role of collagen cross-links in biomechanical behavior of human aortic heart valve leaflets-relevance for tissue engineering [Journal Article]. Tissue engineering. 2007;13(7):1501-1511.

[74] Ramaswamy S, Gottlieb D, Engelmayr J G C, Aikawa E, Schmidt DE, GaitanLeon DM, et al. The role of organ level conditioning on the promotion of engineered heart valve tissue development in-vitro using mesenchymal stem cells [Journal Article]. Biomaterials. 2010;31(6):1114-1125.

[75] Rippel RA, Ghanbari H, Seifalian AM. Tissue-engineered heart valve: future of cardiac surgery [Journal Article]. World journal of surgery. 2012;36(7):15811591.

[76] Hoffman JI, Kaplan S. The incidence of congenital heart disease [Journal Article]. J Am Coll Cardiol. 2002;39(12):1890-900.

[77] Ferencz C, Rubin JD, McCarter RJ, Brenner JI, Neill CA, Perry LW, et al. Congenital heart disease: prevalence at livebirth. The BaltimoreWashington Infant Study [Journal Article]. American Journal of Epidemiology. 1985;121(1):31-36.

[78] Mitchell SC, Korones SB, Berendes HW. Congenital heart disease in 56,109 births. Incidence and natural history [Journal Article]. Circulation. 
1971;43(3):323-32. Mitchell, S C Korones, S B Berendes, H W Journal Article United states Circulation. 1971 Mar;43(3):323-32.

[79] Elizabeth M HL Rickner B, RA L. Congenital heart disease in adults. [Journal Article]. The New England Journal of Medicine. 2000;342(4):(256-263).

[80] Deverall PB, Campalani G, Anderson DR. Heart valve replacement [Journal Article]. Arch Dis Child. 1985;60(12):1111-2. 1468-2044 Deverall, P B Campalani, G Anderson, D R Editorial England Arch Dis Child. 1985 Dec;60(12):1111-2.

[81] Iung B, Baron G, Butchart EG, Delahaye F, Gohlke-Barwolf C, Levang OW, et al. A prospective survey of patients with valvular heart disease in Europe: The Euro Heart Survey on Valvular Heart Disease [Journal Article]. Eur Heart J. 2003;24(13):1231-43. Iung, Bernard Baron, Gabriel Butchart, Eric G Delahaye, Francois Gohlke-Barwolf, Christa Levang, Olaf W Tornos, Pilar Vanoverschelde, Jean-Louis Vermeer, Frank Boersma, Eric Ravaud, Philippe Vahanian, Alec Journal Article Multicenter Study England Eur Heart J. 2003 Jul;24(13):1231-43.

[82] Simon P. Q-Gene: processing quantitative real-time RTPCR data [Journal Article]. Bioinformatics. 2003;19(11):1439-1440.

[83] Thomson JA, Itskovitz-Eldor J, Shapiro SS, Waknitz MA, Swiergiel JJ, Marshall VS, et al. Embryonic stem cell lines derived from human blastocysts [Journal Article]. Science (New York, NY). 1998;282(5391):1145-1147.

[84] Takahashi K, Tanabe K, Ohnuki M, Narita M, Ichisaka T, Tomoda K, et al. Induction of pluripotent stem cells from adult human fibroblasts by defined factors [Journal Article]. Cell. 2007;131(5):861-72.

[85] Lin T, Ambasudhan R, Yuan X, Li W, Hilcove S, Abujarour R, et al. A chemical platform for improved induction of human iPSCs [Journal Article]. Nat Methods. 2009;6(11):805-8.

[86] Gnecchi M, Zhang Z, Ni A, Dzau VJ. Paracrine mechanisms in adult stem cell signaling and therapy [Journal Article]. Circulation research. 2008;103(11):1204-1219.

[87] Dimarino AM, Caplan AI, Bonfield TL. Mesenchymal Stem Cells in Tissue Repair [Journal Article]. Frontiers in immunology. 2013;4:201. 
[88] Perry TE, Kaushal S, Sutherland FW, Guleserian KJ, Bischoff J, Sacks M, et al. Bone marrow as a cell source for tissue engineering heart valves [Journal Article]. The Annals of thoracic surgery. 2003;75(3):761-767.

[89] Hoerstrup SP, Cummings Mrcs I, Lachat M, Schoen FJ, Jenni R, Leschka S, et al. Functional growth in tissue-engineered living, vascular grafts: follow-up at 100 weeks in a large animal model [Journal Article]. Circulation. 2006;114(1 Suppl):I159-66.

[90] Hoerstrup SP, Kadner A, Melnitchouk S, Trojan A, Eid K, Tracy J, et al. Tissue engineering of functional trileaflet heart valves from human marrow stromal cells [Journal Article]. Circulation. 2002;106(12 Suppl 1):I143-50. LR: 20041117; JID: 0147763; ppublish.

[91] Sacks MS, Schoen FJ, Mayer Jr JE. Bioengineering challenges for heart valve tissue engineering [Journal Article]. Annual review of biomedical engineering. 2009;11:289-313.

[92] Hove JD, Gambhir SS, Kofoed KF, Freiberg J, Kelbaek H. Quantitation of the regional blood flow in the interventricular septum using positron emission tomography and nitrogen-13 ammonia [Journal Article]. European journal of nuclear medicine and molecular imaging. 2003;30(1):109-116.

[93] Wang Y, Johnsen HE, Mortensen S, Bindslev L, Ripa RS, Haack-Sorensen M, et al. Changes in circulating mesenchymal stem cells, stem cell homing factor, and vascular growth factors in patients with acute ST elevation myocardial infarction treated with primary percutaneous coronary intervention [Journal Article]. Heart (British Cardiac Society). 2006;92(6):768-774.

[94] Yamamoto M, Sato S, Hemmi H, Uematsu S, Hoshino K, Kaisho T, et al. TRAM is specifically involved in the Toll-like receptor 4-mediated MyD88-independent signaling pathway [Journal Article]. Nature immunology. 2003;4(11):1144-1150.

[95] Illi B, Scopece A, Nanni S, Farsetti A, Morgante L, Biglioli P, et al. Epigenetic histone modification and cardiovascular lineage programming in mouse embryonic stem cells exposed to laminar shear stress [Journal Article]. Circulation research. 2005;96(5):501-508.

[96] Vermot J, Forouhar AS, Liebling M, Wu D, Plummer D, Gharib M, et al. Reversing blood flows act through klf2a to ensure normal valvulogenesis in the developing heart [Journal Article]. PLoS biology. 2009;7(11):e1000246. 
[97] Salinas M, Ramaswamy S. Computational simulations predict a key role for oscillatory fluid shear stress in de novo valvular tissue formation [Journal Article]. Journal of biomechanics. 2014;47(14):3517-3523.

[98] Cooke JP, Ghebremariam YT. Endothelial nicotinic acetylcholine receptors and angiogenesis [Journal Article]. Trends in cardiovascular medicine. 2008;18(7):247-253.

[99] Hou HY, Wang YS, Xu JF, Wang BR. Nicotine promotes contribution of bone marrow-derived cells to experimental choroidal neovascularization in mice [Journal Article]. Experimental eye research. 2008;86(6):983-990.

[100] Cooke JP. Angiogenesis and the role of the endothelial nicotinic acetylcholine receptor [Journal Article]. Life sciences. 2007;80(24):2347-2351.

[101] Wu JC, Chruscinski A, De Jesus Perez VA, Singh H, Pitsiouni M, Rabinovitch $\mathrm{M}$, et al. Cholinergic modulation of angiogenesis: role of the 7 nicotinic acetylcholine receptor [Journal Article]. Journal of cellular biochemistry. 2009;108(2):433-446.

[102] Yu J, Huang NF, Wilson KD, Velotta JB, Huang M, Li Z, et al. nAChRs mediate human embryonic stem cell-derived endothelial cells: proliferation, apoptosis, and angiogenesis [Journal Article]. PloS one. 2009;4(9):e7040.

[103] Mimura K, Tomimatsu T, Sharentuya N, Tskitishvili E, Kinugasa-Taniguchi Y, Kanagawa T, et al. Nicotine restores endothelial dysfunction caused by excess sFlt1 and sEng in an in vitro model of preeclamptic vascular endothelium: a possible therapeutic role of nicotinic acetylcholine receptor (nAChR) agonists for preeclampsia [Journal Article]. American Journal of Obstetrics and Gynecology. 2010;202(5):464.e1-464.e6.

[104] Lotz J, Meier C, Leppert A, Galanski M. Cardiovascular Flow Measurement with Phase-Contrast MR Imaging: Basic Facts and Implementation 1 [Journal Article]. Radiographics. 2002;22(3):651-671.

[105] Ramaswamy S SDHCHASM Boronyak S. A novel bioreactor for the study of physiological fluid induced stresses for heart valve tissue engineering;; 2014.

[106] He X, Ku DN. Pulsatile flow in the human left coronary artery bifurcation: average conditions [Journal Article]. Journal of biomechanical engineering. 1996;118(1):74-82. 
[107] Nelson CM, Pirone DM, Tan JL, Chen CS. Vascular endothelial-cadherin regulates cytoskeletal tension, cell spreading, and focal adhesions by stimulating RhoA [Journal Article]. Molecular biology of the cell. 2004;15(6):2943-2953.

[108] Kim SW, Kim H, Cho HJ, Lee JU, Levit R, Yoon YS. Human peripheral bloodderived CD31+ cells have robust angiogenic and vasculogenic properties and are effective for treating ischemic vascular disease [Journal Article]. Journal of the American College of Cardiology. 2010;56(7):593-607.

[109] Barry FP, Murphy JM. Mesenchymal stem cells: clinical applications and biological characterization [Journal Article]. The international journal of biochemistry \& cell biology. 2004;36(4):568-584.

[110] Sacks MS, Yoganathan AP. Heart valve function: a biomechanical perspective [Journal Article]. Philos Trans R Soc Lond B Biol Sci. 2007;362(1484):136991.

[111] Arnsdorf EJ, Tummala P, Kwon RY, Jacobs CR. Mechanically induced osteogenic differentiation-the role of RhoA, ROCKII and cytoskeletal dynamics [Journal Article]. J Cell Sci. 2009;122(Pt 4):546-53.

[112] Arnsdorf EJ, Tummala P, Jacobs CR. Non-canonical Wnt signaling and Ncadherin related beta-catenin signaling play a role in mechanically induced osteogenic cell fate [Journal Article]. PLoS One. 2009;4(4):e5388.

[113] Li YJ, Batra NN, You L, Meier SC, Coe IA, Yellowley CE, et al. Oscillatory fluid flow affects human marrow stromal cell proliferation and differentiation [Journal Article]. Journal of Orthopaedic Research. 2004;22(6):1283-1289.

[114] Cooke JP, Bitterman H. Nicotine and angiogenesis: a new paradigm for tobacco-related diseases [Journal Article]. Annals of medicine. 2004;36(1):3340 .

[115] Villablanca AC. Nicotine stimulates DNA synthesis and proliferation in vascular endothelial cells in vitro [Journal Article]. Journal of Applied Physiology. 1998;84(6):2089-2098.

[116] Serobyan N, Schraufstatter IU, Strongin A, Khaldoyanidi SK. Nicotinic acetylcholine receptor-mediated stimulation of endothelial cells results in the arrest of haematopoietic progenitor cells on endothelium [Journal Article]. British Journal of Haematology. 2005;129(2):257-265. 
[117] Lee J, Cooke JP. Nicotine and pathological angiogenesis [Journal Article]. Life Sci. 2012;91(21-22):1058-64.

[118] Girard PR, Nerem RM. Shear stress modulates endothelial cell morphology and F-actin organization through the regulation of focal adhesion associated proteins [Journal Article]. Journal of cellular physiology. 1995;163(1):179-193.

[119] Eskin SG, McIntire LV. Hemodynamic effects on atherosclerosis and thrombosis [Journal Article]. Semin Thromb Hemost. 1988;14(2):170-4.

[120] Orr AW, Helmke BP, Blackman BR, Schwartz MA. Mechanisms of mechanotransduction [Journal Article]. Dev Cell. 2006;10(1):11-20.

[121] Yap CH, Saikrishnan N, Tamilselvan G, Yoganathan AP. Experimental measurement of dynamic fluid shear stress on the aortic surface of the aortic valve leaflet [Journal Article]. Biomech Model Mechanobiol. 2012;11(1-2):171-82.

[122] Yoganathan AP, He Z, Casey Jones S. Fluid mechanics of heart valves [Journal Article]. Annu Rev Biomed Eng. 2004;6:331-362.

[123] Schmidt D, Achermann J, Odermatt B, Breymann C, Mol A, Genoni M, et al. Prenatally Fabricated Autologous Human Living Heart Valves Based on Amniotic Fluid Derived Progenitor Cells as Single Cell Source [Journal Article]. Circulation. 2007;116(11 suppl):I-64-I-70.

[124] Schmidt D, Mol A, Breymann C, Achermann J, Odermatt B, GÃ $\llbracket$ ssi M, et al. Living autologous heart valves engineered from human prenatally harvested progenitors [Journal Article]. Circulation. 2006;114(1 suppl):I-125-I-131.

[125] Wang H, Riha GM, Yan S, Li M, Chai H, Yang H, et al. Shear stress induces endothelial differentiation from a murine embryonic mesenchymal progenitor cell line [Journal Article]. Arteriosclerosis, thrombosis, and vascular biology. 2005;25(9):1817-1823.

[126] Hoerstrup SP, Sodian R, Daebritz S, Wang J, Bacha EA, Martin DP, et al. Functional living trileaflet heart valves grown in vitro [Journal Article]. Circulation. 2000;102(suppl 3):Iii-44-Iii-49.

[127] Mol A, Driessen NJ, Rutten MC, Hoerstrup SP, Bouten CV, Baaijens FP. Tissue engineering of human heart valve leaflets: a novel bioreactor for a 
strain-based conditioning approach [Journal Article]. Annals of biomedical engineering. 2005;33(12):1778-1788.

[128] Stock UA, Vacanti JP. Tissue engineering: current state and prospects [Journal Article]. Annual review of medicine. 2001;52(1):443-451.

[129] Bancroft GN, Sikavitsas VI, Mikos AG. Technical note: Design of a flow perfusion bioreactor system for bone tissue-engineering applications [Journal Article]. Tissue Engineering. 2003;9(3):549-554.

[130] Bilodeau K, Mantovani D. Bioreactors for tissue engineering: focus on mechanical constraints. A comparative review [Journal Article]. Tissue Engineering. 2006;12(8):2367-2383.

[131] Dumont K, Yperman J, Verbeken E, Segers P, Meuris B, Vandenberghe S, et al. Design of a new pulsatile bioreactor for tissue engineered aortic heart valve formation [Journal Article]. Artificial organs. 2002;26(8):710-714.

[132] Freed LE, Guilak F, Guo XE, Gray ML, Tranquillo R, Holmes JW, et al. Advanced tools for tissue engineering: scaffolds, bioreactors, and signaling [Journal Article]. Tissue engineering. 2006;12(12):3285-3305.

[133] Hildebrand DK, Wu ZJ, Mayer Jr JE, Sacks MS. Design and hydrodynamic evaluation of a novel pulsatile bioreactor for biologically active heart valves [Journal Article]. Annals of biomedical engineering. 2004;32(8):1039-1049.

[134] Flanagan TC, Pandit A. Living artificial heart valve alternatives: a review [Journal Article]. Eur Cell Mater. 2003;6(1):28-45.

[135] Kadner A, Hoerstrup SP, Tracy J, Breymann C, Melnitchouk S, Kadner G, et al. Human umbilical cord cells: a new cell source for cardiovascular tissue engineering [Journal Article]. The Annals of thoracic surgery. 2002;74(4):14221428.

[136] Engelmayr Jr GC, Soletti L, Vigmostad SC, Budilarto SG, Federspiel WJ, Chandran KB, et al. A novel flex-stretch-flow bioreactor for the study of engineered heart valve tissue mechanobiology [Journal Article]. Annals of biomedical engineering. 2008;36(5):700-712.

[137] Alfonso AR, Rath S, Rafiee P, Hernandez-Espino M, Din M, George F, et al. Glycosaminoglycan entrapment by fibrin in engineered heart valve tissues [Journal Article]. Acta biomaterialia. 2013;9(9):8149-8157. 
[138] Andersen Products I. Anproline Gas Sterilization: Key Operator Training Kit The power of knowledge, Study Guide [Web Page]. www.anpro.com;.

[139] Freeman WM, Walker SJ, Vrana KE. Quantitative RT-PCR: pitfalls and potential [Journal Article]. Biotechniques. 1999;26:112-125.

[140] Martinez C, Rath S, Van Gulden S, Pelaez D, Alfonso A, Fernandez N, et al. Periodontal ligament cells cultured under steady-flow environments demonstrate potential for use in heart valve tissue engineering [Journal Article]. Tissue Engineering Part A. 2012;19(3-4):458-466.

[141] Zhang J, Niu C, Ye L, Huang H, He X, Tong WG, et al. Identification of the haematopoietic stem cell niche and control of the niche size [Journal Article]. Nature. 2003;425(6960):836-841.

[142] Biosystem A. Guide to Performing Relative Quantitation of Gene Expression Using Real-Time Quantitative PCR; Part Number 4371095 Rev B [Web Page]. www.docs.appliedbiosystems.com;.

[143] Schenke-Layland K, Opitz F, Gross M, DÃ ฯring C, Halbhuber K, Schirrmeister $\mathrm{F}$, et al. Complete dynamic repopulation of decellularized heart valves by application of defined physical signals an in vitro study [Journal Article]. Cardiovascular research. 2003;60(3):497-509.

[144] Barron V, Lyons E, Stenson-Cox C, McHugh P, Pandit A. Bioreactors for cardiovascular cell and tissue growth: a review [Journal Article]. Annals of biomedical engineering. 2003;31(9):1017-1030.

[145] Fisher AB, Chien S, Barakat AI, Nerem RM. Endothelial cellular response to altered shear stress [Journal Article]. American Journal of Physiology-Lung Cellular and Molecular Physiology. 2001;281(3):L529-L533.

[146] Li YSJ, Haga JH, Chien S. Molecular basis of the effects of shear stress on vascular endothelial cells [Journal Article]. Journal of biomechanics. 2005;38(10):1949-1971.

[147] Malek AM, Alper SL, Izumo S. Hemodynamic shear stress and its role in atherosclerosis [Journal Article]. Jama. 1999;282(21):2035-2042.

[148] Nagel T, Resnick N, Atkinson WJ, Dewey Jr CF, Gimbrone Jr MA. Shear stress selectively upregulates intercellular adhesion molecule-1 expression in 
cultured human vascular endothelial cells [Journal Article]. Journal of Clinical Investigation. 1994;94(2):885.

[149] Topper JN, Gimbrone Jr MA. Blood flow and vascular gene expression: fluid shear stress as a modulator of endothelial phenotype [Journal Article]. Molecular medicine today. 1999;5(1):40-46.

[150] Brand NJ, Roy A, Hoare G, Chester A, Yacoub MH. Cultured interstitial cells from human heart valves express both specific skeletal muscle and non-muscle markers [Journal Article]. The international journal of biochemistry \& cell biology. 2006;38(1):30-42.

[151] Martinez C, Henao A, Rodriguez JE, Padgett KR, Ramaswamy S. Monitoring Steady Flow Effects on Cell Distribution in Engineered Valve Tissues by Magnetic Resonance Imaging [Journal Article]. Molecular imaging. 2013;12(7).

[152] Horstkotte D, Loogen F. The natural history of aortic valve stenosis [Journal Article]. European heart journal. 1988;9(suppl E):57-64.

[153] Justo RN, McCrindle BW, Benson LN, Williams WG, Freedom RM, Smallhorn JF. Aortic valve regurgitation after surgical versus percutaneous balloon valvotomy for congenital aortic valve stenosis [Journal Article]. The American journal of cardiology. 1996;77(15):1332-1338.

[154] Konno S, Imai Y, Iida Y, Nakajima M, Tatsuno K. A new method for prosthetic valve replacement in congenital aortic stenosis associated with hypoplasia of the aortic valve ring [Journal Article]. The Journal of thoracic and cardiovascular surgery. 1975;70(5):909-917.

[155] Lindroos M, Kupari M, Heikkil J, Tilvis R. Prevalence of aortic valve abnormalities in the elderly: an echocardiographic study of a random population sample [Journal Article]. Journal of the American College of Cardiology. 1993;21(5):1220-1225.

[156] Reynolds JL, Nadas AS, Rudolph AM, Gross RE. Critical congenital aortic stenosis with minimal electrocardiographic changes: A report on two siblings [Journal Article]. New England Journal of Medicine. 1960;262(6):276-282.

[157] Rath S, Bhatacharjee S, Salinas M, Ramaswamy S. Marrow Stem Cell Differentiation for Valvulogenesis via Oscillatory Flow and Nicotine Agonists: Unusual Suspects [Journal Article]. Journal of Long-Term Effects of Medical Implants. 2015;25(1-2). 
VITA

\section{SASMITA RATH}

$2009-2015$

$\mathrm{PhD}$, Biomedical Engineering

Florida International University

Miami, FL

Major Field: Tissue Engineering

Selected Publications and Presentations

1. S. Rath,M. Salinas, A. Villegas, S. Ramaswamy; Physiologically-Relevant Flexure and Flow Induces Valvulogenesis in Stem Cell-Seeded Scaffolds ; (submitted)

2. S. Rath, M. Salinas, S. Bhatacharjee, S. Ramaswamy; Marrow Stem Cell differentiation for Valvulogenesis via Oscillatory Flow and Nicotine Agonists: Unusual Suspects; (Accepted for Publication in Journal of Long Term Effects of Medical Implants, 2014)

3. A.R. Alfonso, S. Rath, P. Rafiee, M. Hernandez-Espino, M. Din, S. Ramaswamy; Glycosaminoglycan Entrapment by Fibrin in Engineered Heart Valve Tissues; Acta Biomaterialia, Volume 9, Issue 9, 81498157 (2013)

4. C. Martinez, S. Rath, S. Van Guldena, D. Pelaez, A. Alfonso, N. Fernandez, L. Kos, H. Cheung, S. Ramaswamy, Periodontal Ligament Cells Cultured under Steady Flow Environments Demonstrate Potential for Use in Heart Valve Tissue Engineering; Tissue Engineering Part A,19(3-4):458-66 (2013) 5.S.Rath, A.Villegas, M. Salinas, S. Ramaswamy; Physiological relevant shear stress and flexure in developing valvular tissues;(Oral presentation, BMES,2014)

6. S.Rath, S. Ramaswamy, Distribution of Actin Filaments and Focal Adhesions in 
Marrow Stem Cells under Various Flow-Based Culture Conditions (Oral Presentation, SBEC-2013)

7. S. Rath, S. Van Gulden, S. Ramaswamy; Mechanotransduction events in bone marrow mesenchymal stem cells after fluid flow exposure; (7th World Congress of Biomechanics,2014)

8. S. Behdad, S. Rath, B. Boesl, S. Ramaswamy; Investigation of the Effect of Biomechanical Stresses on Human Bone Marrow Stem Cell Differentiation by In Situ Fluorescent Microscopy; (Abstract accepted, 7th World Congress of Biomechanics, 2014)

9. S.Rath, S.Ramaswamy, Mechanically-regulated gene expression in heart valve targeted tissue engineering studies; (UF, Society for Biomaterial, 2014) 